\title{
Guidelines for the Clinical Application of Bypass Grafts and the Surgical Techniques (JCS 2011) Published in 2012
}

\author{
- Digest Version -
}

JCS Joint Working Group

\begin{tabular}{|c|c|}
\hline . opreviations.... & 2. Non-Left Anterior Descen \\
\hline duction of the Revised Guidelines ..................... 1609 & V Issues After CABG …………………..... \\
\hline $\begin{array}{l}\text { Coronary Revascularization (PCI/CABG) for Stable } \\
\text { Coronary Artery Disease: Statements and Indications }\end{array}$ & $\begin{array}{l}\text { 1. Antiplatelet Therapy to Prolong the Patency of the } \\
\text { Saphenous Vein Grafts }\end{array}$ \\
\hline Proposed by the Coronary Revascularization Coul & 2. Treatment With Calcium Channel Blockers After \\
\hline I Statements .......................................... & $\begin{array}{l}\text { CABG Using Radial Artery Grafts . } \\
\text { 3. PCI to Treat Graft Lesions............. }\end{array}$ \\
\hline $\begin{array}{l}\text { 1.Purpose of } \\
\text { 2.Collaboratic }\end{array}$ & 4. Drug Treatment for Hyperlipidemia. \\
\hline $\begin{array}{l}\text { 2. Condiabore } \\
\text { Cardiac }\end{array}$ & ive Treatment After CABG. \\
\hline 1610 & 6. Hormone Therapy................. \\
\hline $\begin{array}{l}\text { 3. Treatment Outcome } \\
\text { 4. Treatment Outcome }\end{array}$ & 8. Cardiac Rehabilitation $\cdots . .$. \\
\hline 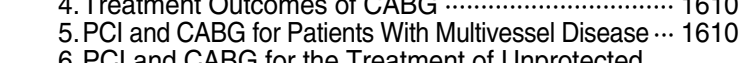 & VI Selection of CABG Procedures and Grafts \\
\hline 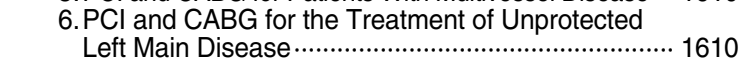 & $\cdots 1619$ \\
\hline (n) & E Elderly Patients $\geq 8$ \\
\hline 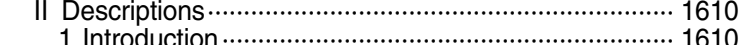 & $\cdot 1610$ \\
\hline ection of Evidence, Levels of & 3. Diabetes ……....................... \\
\hline $\begin{array}{l}\text { 2.Criteria for Selection of Evidence, Levels of } \\
\text { Evidence, Interpretation of Study Results, and }\end{array}$ & 4. Respiratory Dysfunction …... \\
\hline & scular Disorders... \\
\hline ent $\# 1 \ldots 1611$ & th....................... \\
\hline 4. The Imp & It Surgery in Patients With Cirrhosis \\
\hline $\begin{array}{l}\text { Cardic } \\
\text { Proce }\end{array}$ & 9. Valvular Disease ............................................ \\
\hline $\operatorname{Pr}$ & 11. Aortic Aneurysm …………..... \\
\hline $\begin{array}{l}\text { 5. Treatment Outcomes of PCl: Statement \#3 …......... } 1611 \\
6 . \text { Treatment Outcomes of CABG: Statement \#4….... } 1612\end{array}$ & .... 1621 \\
\hline 7. Impc & Vascular D \\
\hline $\begin{array}{l}\text { Int } \\
\mathrm{Cli}\end{array}$ & Dysfunctio \\
\hline & … 1621 \\
\hline 3.PCl & 16. Acute Coronary S \\
\hline Patients With Lef & 17. Fatal Ventricular Ar \\
\hline Patients With Lef & ....... 1622 \\
\hline $\begin{array}{l}\text { Disease: Statement \#6. } \\
\text { dications for Coronary Re }\end{array}$ & \\
\hline odications for Coronan Rev & 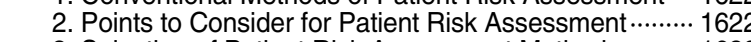 \\
\hline & ... 1622 \\
\hline$\cdot 1615$ & …. 1622 \\
\hline ר-Pump and Off- & Ğuideline Document .. 1622 \\
\hline || Graft Vessels .............. & III Economic Efficienc \\
\hline 1. Left Internal Thoracic Artery ........... & idelines Regarding \\
\hline 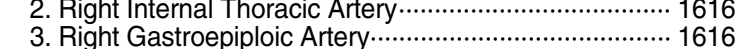 & $\begin{array}{l}\text { the Economic Efficiency of CABG ................................ } 16 \\
\text { 2. Health Economic Analysis of CABG in Japan: }\end{array}$ \\
\hline Inferior Epigastric Artery.. & 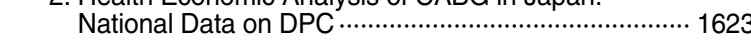 \\
\hline Rodial arter & Technical Innovations .... \\
\hline Vein Grafts ....... & motic Devices.... \\
\hline III Graft Arrangement ....................... & ery ………........ \\
\hline ... 1617 & ke Off-Pump CABG …………………....... \\
\hline 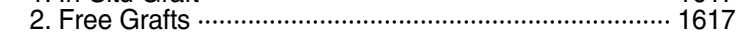 & 4. Transmyocardial Las \\
\hline iv selection & \\
\hline
\end{tabular}

(Circ J 2013; 77: 1608-1641)

Released online May 14, 2013

Mailing address: Scientific Committee of the Japanese Circulation Society, 8th Floor CUBE OIKE Bldg., 599 Bano-cho, Karasuma Aneyakoji, Nakagyo-ku, Kyoto 604-8172, Japan. E-mail: meeting@j-circ.or.jp

This English language document is a revised digest version of Guidelines for the Clinical Application of Bypass Grafts and the Surgical Techniques reported at the Japanese Circulation Society Joint Working Groups performed in 2010 (Website: http://www.j-circ.or.jp/ guideline/pdf/JCS2011_ochi_d.pdf).

Joint Working Groups: The Japanese Circulation Society, The Japanese Coronary Association, Japanese Association for Coronary Artery Surgery, The Japanese Association for Thoracic Surgery, The Japanese Society for Cardiovascular Surgery, The Japanese College of Cardiology

ISSN-1346-9843 doi:10.1253/circj.CJ-66-0066

All rights are reserved to the Japanese Circulation Society. For permissions, please e-mail: cj@j-circ.or.jp 


\section{Abbreviations}

AATS: American Association for Thoracic Surgery

A-C: aortocoronary

$\mathrm{ACC}(\mathrm{F})$ : American College of Cardiology (Foundation)

ACE: angiotensin converting enzyme

ACS: acute coronary syndrome

AHA: American Heart Association

ARB: angiotensin II receptor blocker

ASNC: American Society of Nuclear Cardiology

BARI 2D: Bypass Angioplasty Revascularization Investigation 2 Diabetes

BITA: bilateral internal thoracic artery

BMI: body mass index

BMS: bare metal stent

CABG: coronary artery bypass grafting

CAD: coronary artery disease

CAS: carotid artery stenting

CEA: carotid endarterectomy

$\mathrm{CCAB}$ : conventional coronary artery bypass grafting

COPD: chronic obstructive pulmonary disease

COURAGE: Clinical Outcomes Utilizing Revascularization and Aggressive Drug Evaluation

CREDO-Kyoto: Coronary REvascularization Demonstrating Outcome Study in Kyoto

Cx: circumflex

DES: drug eluting stent

DPC: diagnosis procedure combination

DSWI: deep sternal wound infection

Dx: diagonal

EACTS: European Association for Cardiothoracic Surgery

ESC: European Society of Cardiology

EuroSCORE: European System for Cardiac Operative Risk Evaluation

FITA: free internal thoracic artery

GEA: gastroepiploic artery

$\mathrm{Hb}$ : hemoglobin
HDL: high density lipoprotein

Ho: Holmium

ICU: intensive care unit

IEA: inferior epigastric artery

ITA: internal thoracic artery

JACVSD: Japan Adult Cardiovascular Surgery Database

JDS: Japan Diabetes Society

JSAP: Japanese Stable Angina Pectoris

LAD: left anterior descending

LDL: low density lipoprotein

LITA: left internal thoracic artery

LMT: left main trunk

MASS II: Medicine, Angioplasty, or Surgery Study

MIDCAB: minimally invasive direct coronary artery bypass

NGSP: National Glycohemoglobin Standardization Program

NHI: National Health Insurance

OPCAB: off-pump coronary artery bypass grafting

OPR: Ontario Province Risk

PCI: percutaneous coronary intervention

POBA: percutaneous old balloon angioplasty

PTCA: percutaneous transluminal coronary angioplasty

QOL: quality of life

RA: radial artery

RCA: right coronary artery

RITA: right internal thoracic artery

SCAI: Society for Cardiovascular Angiography and Interventions

SITA: single internal thoracic artery

STS: Society of Thoracic Surgeons

SVG: saphenous vein graft

SYNTAX: SYNergy between percutaneous coronary intervention with TAXus and cardiac surgery

TEA: thoracic epidural anesthesia

TMLR: transmyocardial laser revascularization

\section{Introduction of the Revised Guidelines}

Coronary artery bypass grafting (CABG), a procedure started in the 1960s using saphenous vein graft (SVG), has been established as one of the most commonly performed surgical revascularization for the treatment of ischemic heart disease. Since then there have been two major improvements in this procedure.

The first change is the development of arterial graft. After the use of the SVG was found to be associated with a low long-term patency rate due to the rapid progression of atherosclerotic lesions, the use of internal thoracic artery (ITA) grafts became prevalent. Especially, it has been demonstrated that anastomosis of the ITA to the left anterior descending (LAD) artery improves long-term prognosis after CABG. Following the ITA, the clinical use of the right gastroepiploic artery (GEA) and radial artery (RA) as coronary bypass grafts has become common. Total arterial revascularization, a CABG procedure using only arterial grafts, was established.

The second change is the introduction and rapid adoption of off-pump CABG (OPCAB), a form of CABG performed without cardiopulmonary bypass and cardioplegic arrest as an alternative to conventional CABG (CCAB) using cardiopulmonary bypass and cardioplegic arrest.
On the basis of ITA-LAD anastomosis, combining these two improvements resulted in a variety of grafting procedures including composite graft such as T- and Y-graft using the right and left ITA (RITA, LITA), GEA and RA grafts, and sequential graft, a technique to revascularize more than one coronary branch with the same graft, using off-pump techniques.

OPCAB has quickly become prevalent in Japan as it accounted for more than $60 \%$ of all CABG cases in an annual survey conducted by the Japanese Association for Thoracic Surgery in 2010. This survey also revealed that CABG using only arterial grafts accounted for 50 to $60 \%$ of all CABG cases. These results contrast sharply with the findings in Western countries in which OPCAB is used in about $15 \%$ of all CABG cases and the use of LITA-LAD anastomosis and SVG is prevalent.

On the other hand, arterial grafts are known to show typical biological responses that are not observed in vein grafts. When arterial grafts are anastomosed to coronary arteries with lowgrade stenosis, the string phenomenon due to competitive flow from the native coronary arteries may develop and result in graft occlusion. The string phenomenon associated with the use of pedunculated ITA or GEA grafts is believed to be due 
to insufficient flow capacities of grafts.

The use of RA grafts in CABG had been abandoned due to the frequent occurrence of spasm, but has resumed when calcium channel blockers can effectively prevent spasms of RA grafts.

It also has been known empirically that RA grafts used in aortocoronary (A-C) bypass grafting are often associated with graft occlusion when competitive flow from the native coro- nary arteries with low-grade stenosis is present, and there is continuing debate on the use of RA grafts in this procedure.

The present guideline document is a partly revision of the "Guidelines for the Clinical Application of Bypass Grafts and the Surgical Techniques (JCS 2006)" prepared as a 2004-2005 JCS Joint Working Groups Report ${ }^{1}$ after discussion of the evidence obtained in and outside Japan about patients "who receive which grafts using what procedures".

\section{Coronary Revascularization (PCI/CABG) for Stable Coronary Artery Disease: Statements and Indications Proposed by the Coronary Revascularization Council}

\section{Statements}

\section{Purpose of Coronary Revascularization}

In patients with stable coronary artery disease (CAD), coronary revascularization is performed to improve long-term prognosis, prevent myocardial infarction and unstable angina, and improve the quality of life (QOL) by reducing anginal symptoms.

\section{Collaboration of Interventional Cardiologists and Cardiac Surgeons in Decision-Making Process for Coronary Rrevascularization}

It is desirable that interventional cardiologists and cardiac surgeons discuss to decide how to perform coronary revascularization in patients with severe stable CAD (i.e., patients with left main disease, patients with multivessel disease involving the proximal LAD artery, especially patients with multivessel disease associated with cardiac dysfunction, and diabetic patients with multivessel disease) before proposing treatment options to the patients, and that the patients should decide their treatment options by themselves.

\section{Treatment Outcomes of $\mathrm{PCI}$}

As compared with recent initial intensive medical therapy alone, percutaneous coronary intervention (PCI) plus medical therapy is effective in reducing anginal symptoms, but does not improve long-term prognosis or prevent myocardial infarction [Level of Evidence: A].

PCI plus medical therapy is not superior to recent initial intensive medical therapy in the prevention of unstable angina [Level of Evidence: B]. On the other hand, data available in Japan indicate the preventive effects of PCI plus medical therapy [Level of Evidence: B].

The incidence of repeat revascularization is lower in patients receiving drug eluting stent (DES) than those receiving percutaneous old balloon angioplasty (POBA) or bare metal stent (BMS) [Level of Evidence: A] . However, there is no conclusive evidence indicating that DES improves long-term prognosis and decreases the incidence of myocardial infarction.

\section{Treatment Outcomes of CABG}

CABG is effective in reducing anginal symptoms, prevents myocardial infarction, and improves long-term prognosis [Level of Evidence: A]. The use of ITA grafts increases and prolongs the beneficial effects of CABG on long-term prognosis [Level of Evidence: B].

5. PCI and CABG for Patients With Multivessel Disease

In randomized clinical studies in patients with multivessel dis- ease without left main involvement before the DES era, the incidence of repeat revascularization was higher in patients receiving PCI than those receiving $\mathrm{CABG}$, but these methods did not differ in terms of long-term prognosis and incidence of myocardial infarction [Level of Evidence: A].

In recent comparative studies in the DES era, the long-term prognosis of patients with three-vessel disease without left main involvement is poorer in patients receiving PCI than in those undergoing $\mathrm{CABG}$, and the incidences of myocardial infarction and repeat revascularization are also high in patients receiving PCI [Level of Evidence: B].

\section{PCI and CABG for the Treatment of Unprotected Left Main Disease}

Basically, patients with unprotected left main disease should be treated with CABG. However, no high-level evidence is available regarding comparisons between CABG and PCI in this patient population. In recent comparative studies in the DES era, the incidence of repeat revascularization was higher in patients receiving PCI than CABG for the treatment of left main disease, but no differences were observed in long-term prognosis and the incidence of myocardial infarction.

\section{Descriptions}

\section{Introduction}

In 2000, the first guidelines for interventional therapy of CAD in Japan were published. ${ }^{2}$ The interventional therapy described in the guideline included $\mathrm{CABG}$, and recommended indications of elective interventions were described. In 2006, the Guidelines for the Clinical Application of Bypass Grafts and the Surgical Techniques (JCS 2006) were published, ${ }^{1}$ and many other guideline documents were published to promote comprehensive treatment of ischemic heart disease, including primary prevention, diagnosis and understanding pathophysiology, treatment strategies, and secondary prevention.

During the ten years since the publication of the "Guidelines on Indications of Elective Intervention (including CABG) in the Treatment of Coronary Artery Disease 2 ", techniques for coronary revascularization such as PCI and CABG have improved significantly. The Japanese Circulation Society started to revise the guideline documents to reflect the advancement of interventional techniques. During the revision process, a development of restructured guideline documents that systematically describe coronary revascularization and includes the "Guidelines for the Clinical Application of Bypass Grafts and the Surgical Techniques (JCS 2006)" was proposed. ${ }^{1}$ A consensus was achieved that the new comprehensive guideline documents will consist of general statements including basic 
principles of coronary revascularization such as the merits and demerits of different techniques, a multifaceted comparison between PCI and CABG, and the criteria for selecting between $\mathrm{PCI}$ and $\mathrm{CABG}$, and specific guideline documents describing practical matters. The general statements will be consistent with the "Guidelines for Elective Percutaneous Coronary Intervention in Patients with Stable Coronary Disease (JCS 2011)", which is a revision of the PCI guidelines published in $2000,{ }^{2}$ and the "Guidelines for the Clinical Application of Bypass Grafts and the Surgical Techniques (JCS 2011)", which is a revision of the CABG guidelines published in $2006 .^{1}$ The present guideline documents discuss stable CAD, and do not include acute-phase CAD.

The joint guidelines on coronary revascularization prepared by the European Society of Cardiology (ESC) and the European Association for Cardiothoracic Surgery (EACTS) in 2010 emphasize the importance of the heart team including general practitioners, interventional cardiologists and cardiac surgeons in the treatment of CAD. ${ }^{3}$ It is expected that the heart team will play a central role in the treatment of CAD in Japan. To better describe the roles of the heart team, the statements, descriptions, and indications for coronary revascularization in the general statements chapter of the revised PCI and CABG guideline documents were prepared through extensive discussion by the "Coronary Revascularization Council" consisting of interventional cardiologists, cardiac surgeons and diabetes specialists who represent the Japanese Circulation Society, the Japanese College of Cardiology, the Japanese Coronary Association, the Japanese Association of Cardiovascular Intervention and Therapeutics, the Japanese Society for Cardiovascular Surgery, the Japanese Association for Thoracic Surgery, the Japanese Association for Coronary Artery Surgery, and the Japan Diabetes Society.

\section{Criteria for Selection of Evidence, Levels of Evidence, Interpretation of Study Results, and Classification of Recommendations}

Because these statements represent the basis of guidelines, the statements and descriptions were prepared on the basis only of high-level evidence (Level A, evidence demonstrated with more than one randomized clinical studies or meta-analyses, and Level B, demonstrated with a randomized clinical study or multicenter, large-scale registry studies). However, as the SYNTAX (SYNergy between percutaneous coronary intervention with TAXus and cardiac surgery) study (www.syntaxscore. com) is the only randomized clinical study that directly compared CABG vs. PCI using DES, the results of sub-analyses, which were Level $\mathbf{C}$ evidence, were also used. Level $\mathbf{C}$ evidence represents consensus opinion of experts, small-scale clinical studies, results of sub-analysis, and others.

\section{Classification of Recommendations}

Class I: There is evidence and/or general agreement that a given procedure/treatment is useful/effective.

Class II: There is conflicting evidence and/or a divergence of opinion about the usefulness/efficacy of a given procedure/treatment.

Class IIa: Weight of evidence/opinion is in favor of usefulness/efficacy.

Class IIb: Usefulness/efficacy is less well established by evidence/opinion.

Class III: There is evidence and/or general agreement that the procedure/treatment is not useful/effective, and in some cases may be harmful.
Although the true treatment outcome can be assessed in randomized clinical studies, it is difficult to assess the validity of indications and treatment outcomes of PCI and CABG in the actual clinical practice by using the results of randomized clinical studies and meta-analyses only. We thus placed emphasis on the results of multicenter, large-scale registry studies. It has been widely known that the clinical characteristics, treatment strategies and outcomes of patients with stable CAD in Japan differ from those in Western countries, but much of high-level evidence available is on the Western patient populations. We should create patient database of PCI and CABG and assess the data to establish evidence in patients in Japan.

\section{Purpose of Coronary Revascularization: Statement \#1}

The most important purpose of coronary revascularization for stable CAD is to improve long-term prognosis by preventing the incidence of myocardial infarction and unstable angina. Because stable CAD may often manifest as angina, management of angina to improve QOL is also an important purpose.

\section{The Importance of Collaboration Between Interventional Cardiologists and Cardiac Surgeons in Decision-Making Process for Coronary Revascularization: Statement \#2} PCI and CABG, two different approaches sharing a common goal of ensuring successful coronary revascularization, have different risks and benefits. When physicians consider whether PCI or CABG is better for a given patient, they should assess the expected outcomes of each technique on the patient as well as the risk of complications (e.g., stroke, infections, contrast-induced nephropathy, and radiation exposure), the safety and invasiveness of the technique used, expected duration of hospitalization, medical cost, and underlying diseases to determine the optimal treatment strategy for the patients.

Especially in patients of severe stable CAD (i.e., patients with left main disease, patients with multivessel disease involving the proximal LAD artery, especially patients with multivessel disease associated with cardiac dysfunction, and diabetic patients with multivessel disease), interventional cardiologists and cardiac surgeons should discuss to determine treatment options, and should fully inform patients about the expected short- and long-term treatment outcomes of PCI and CABG, the safety and invasiveness of these techniques, and the possibility of requiring further treatment before obtaining informed consent. When the heart team, a multidisciplinary team of healthcare professionals including interventional cardiologists and cardiac surgeons, is difficult to establish in the hospital due to the unavailability of cardiac surgeons, it is desirable to collaborate with nearby hospitals providing cardiac surgery services to ensure the safe treatment. Because the treatment outcomes of PCI and CABG may largely depend on the skill and expertise of interventionists/surgeons and medical team members, physicians should consider these factors carefully to determine what is the optimal treatment strategy for each patient. Data on the results in individual institutions such as the number of patients treated, severity of CAD, and shortand long-term outcomes should be accumulated and analyzed in a formal framework.

\section{Treatment Outcomes of PCI: Statement \#3}

A meta-analysis of 11 randomized clinical studies of PCI in a total of 2,950 patients with stable CAD revealed that PCI does not improve long-term prognosis or prevent myocardial infarction as compared with patients receiving initial medical therapy. ${ }^{4}$ In the COURAGE (Clinical Outcomes Utilizing Revascularization and Aggressive Drug Evaluation), a randomized 
clinical study in 2,287 patients with stable angina (excluding patients with left main disease; proximal LAD disease was present in $31 \%$, one-vessel disease in $31 \%$, two-vessel disease in $39 \%$, three-vessel disease in $30 \%$, and diabetes in $32 \%$ ), patients were randomized to receive PCI with optimal medical therapy (PCI plus medical therapy group) or to start optimal medical therapy and receive PCI whenever necessary (initial intensive medical therapy group). ${ }^{5}$ All patients received optimal medical therapy during the study (treatment targets were (1) smoking cessation, (2) low density lipoprotein [LDL] levels of 60 to $85 \mathrm{mg} / \mathrm{dL}$, (3) high density lipoprotein [HDL] level of $\geq 40 \mathrm{mg} / \mathrm{dL}$, (4) triglyceride of $<150 \mathrm{mg} / \mathrm{dL}, 30$ to $45 \mathrm{~min}$ utes of moderate exercise 5 times per week, body mass index [BMI] of $<25 \mathrm{~kg} / \mathrm{m}^{2}$, blood pressure of $<130 / 85 \mathrm{mmHg}$, and hemoglobin A1c [HbA1c][National Glycohemoglobin Standardization Program; NGSP value $]^{*}$ of $<7.0 \%$ ). During the follow-up period for 4.6 years, there were no differences between the two groups in the incidences of death, myocardial infarction and unstable angina. In the BARI 2D (Bypass Angioplasty Revascularization Investigation 2 Diabetes), a randomized clinical study in 1,605 patients with type 2 diabetes (excluding patients with left main disease; proximal LAD disease was present in $10.3 \%$, and three-vessel disease in $20.3 \%$; the prevalences of one- and two-vessel disease were not reported), there were no significant differences in the incidences of death and myocardial infarction during the 5.3-year followup period between patients receiving PCI plus medical therapy and patients receiving initial intensive medical therapy and undergoing PCI whenever necessary ${ }^{6,7}$ All patients received initial intensive medical therapy during the study (treatment targets were HbA1c [NGSP value] of $<7.0 \%$, LDL level of $<100 \mathrm{mg} / \mathrm{dL}$, and blood pressure of $<130 / 80 \mathrm{mmHg}$ ). The reasons why PCI plus medical therapy did not improve the incidences of death and myocardial infarction may include the following: (1) Because unstable plaques, a major cause of acute coronary syndrome (ACS), are often present in nonsignificant stenotic lesions, while significant stenoses causing anginal symptoms are often related to stable plaques, treatment of significant stenoses by PCI did not affect the incidences of myocardial infarction and death; (2) The incidence of cardiac accidents in patients receiving initial intensive medical therapy was lower than expected in both the COURAGE and BARI $2 \mathrm{D}$ studies, and these results are considered to reflect favorable efficacy of systemic treatment with aggressive risk management strategies. (3) Among patients receiving initial intensive medical therapy, patients with severe myocardial ischemia not responding to medical therapy, which accounted for 30 to $40 \%$, underwent PCI for culprit lesions and showed an improvement in myocardial ischemia. As mentioned in the item (3) above, about one in three patients receiving initial intensive medical therapy underwent PCI. This means that these studies compared a group of patients undergoing PCI at the initiation of the study and a group of patients among whom PCI was conducted for selected patients whenever necessary. The absence of differences between the PCI plus medical therapy group and the initial intensive medical therapy group does not lead the conclusion that PCI does not improve long-term prognosis or prevent myocardial infarction. In order to demonstrate the effects of PCI on the incidences of death and myocardial infarction in clinical studies, patients not responding to medical therapy should be followed up for a long period of time without conducting PCI, but such studies are not allowed for ethical reasons.

*In Japan, HbA1c has been encouraged to report as the NGSP value rather than the conventional JDS (Japan Diabetes Society) value from April 1, 2012, onward. The relationship between the NGSP and the conventional JDS is as follows: NGSP value $(\%)=1.02 \times \mathrm{JDS}$ value $(\%)+0.25 \%$. Within the clinically relevant range between 5.0 to $9.9 \%$ (JDS), the relationship may be expressed as follows: HbA1c $(\mathrm{NGSP})=\mathrm{HbA} 1 \mathrm{c}(\mathrm{JDS})+$ $0.4 \%$.

In the COURAGE study, patients in the PCI plus medical therapy group showed less anginal symptoms and better QOL as compared with those in the initial intensive medical therapy group, but these differences disappeared in the second to third year of the study. ${ }^{8}$ These findings may be explained by the study design where in the initial intensive medical therapy group patients not responding to medical therapy underwent PCI.

In the JSAP (Japanese Stable Angina Pectoris), a randomized clinical study in 384 low-risk patients with stable angina (one-vessel disease was present in 67.5\%, two-vessel disease in $38.5 \%$, and diabetes in $39.6 \%$; patients with left main disease, those with three-vessel diseases, and those with proximal LAD disease were excluded), patients undergoing PCI plus medical therapy did not appear to be superior to patients with initial medical therapy (at the discretion of the treating physicians) in terms of the incidences of death and myocardial infarction during the 3.2-year follow-up period. ${ }^{9}$ In contrast to the COURAGE study, the JSAP study demonstrated that PCI plus medical therapy prevented the development of unstable angina and reduced anginal symptoms, and the differences were observed even in the third year of the study. Although the two studies cannot be compared directly as they are substantially different in terms of patient characteristics and drug treatment, the difference between the results of the COURAGE and JSAP studies may be explained with the following two facts. (1) While an aggressive intervention for multiple risk factors was made in the COURAGE study, in the JSAP study drug treatment such as statin therapy during the follow-up period was performed at the discretion of treating physians. (2) The incidence of ACS developing as an acute complication of PCI may be lower among patients in Japan than among Western patients.

The results of meta-analyses revealed that the incidence of revascularization was significantly lower in patients receiving DES than BMS, indicating that DES is effective in the prevention of restenosis. ${ }^{10,11}$ However, although the restenosis rate has been decreasing as PCI devices become more advanced from POBA, BMS to DES, the incidences of death and myocardial infarction among patients receiving coronary revascularization have not improved. ${ }^{10,11}$ The absence of improvement is thought to be a result of the following facts: (1) Because repeat PCI for restenosis is easily and frequently performed, the advancement of stents used in PCI has little influence on the severity of myocardial ischemia after repeat PCI; and (2) PCI has been indicated for severer CAD as PCI devices become more advanced.

\section{Treatment Outcomes of CABG: Statement \#4}

In a systematic overview using individual patient data from 7 randomized clinical studies in a total of 2,649 patients with stable CAD (among whom left main disease was present in $6.6 \%$, proximal LAD disease in $59.4 \%$, one-vessel disease in $10.2 \%$, two-vessel disease in $32.4 \%$, and three-vessel disease in 50.6\%, and diabetes in 9.6\%), Yusuf et al. reported in 1994 that the initial CABG group had significantly lower risk of death than the initial medical treatment group $(37.4 \%$ of patients underwent $\mathrm{CABG}$ during the study period), and demon- 
strated that $\mathrm{CABG}$ is effective in improving long-term prognosis. ${ }^{12}$ The improvement in long-term prognosis became apparent at 5 years, and also observed at 10 years. A subanalysis revealed that the risk reduction was greater in patients with proximal LAD disease, those with three-vessel disease, those with left main disease, and those with cardiac dysfunction, and the risk reduction was highest in patients with left main disease. Initial CABG was not effective in this regard for patients with one- or two-vessel diseases.

The ITAs are considered "the gold standard" of CABG grafts because of the favorable long-term graft patency. In a large multicenter registry in the United States, ITA grafts conferred a survival advantage as compared with vein grafts. ${ }^{13}$ The survival curves of the two groups showed separation over the years of follow-up, with a more marked downsloping after 8 years and thereafter during the follow-up period (mean, 16.8 years). In a meta-analysis of observational studies, Taggart et al. reported that bilateral ITA (BITA) grafts give better survival rates than single ITA grafts. ${ }^{14}$

Yusuf et al. analyzed the results of randomized clinical studies conducted in 1972 and 1984, which do not reflect the current surgical procedures and drug regimens. ${ }^{12}$ The readers should be aware that (1) the 30-day mortality of patients undergoing $\mathrm{CABG}$ was $3.2 \%$, which was higher than those in recent studies; (2) the use of ITA grafts, which are known to improve long-term prognosis, was limited to $<10 \%$ of patients; and (3) patients did not receive statins, calcium channel blockers, angiotensin converting enzyme (ACE) inhibitors and angiotensin II receptor blockers (ARBs) that are commonly administered to patients undergoing $\mathrm{CABG}$.

In the BARI 2D study recently conducted in 763 patients with type 2 diabetes (proximal LAD disease was present in $19.4 \%$, and three-vessel disease in $52.4 \%$; the prevalences of one- and two-vessel diseases were not reported), at 5-year follow-up, incidence of death did not differ significantly between the CABG and the initial intensive medical therapy group $(39.7 \%$ of the patients underwent coronary revascularization during the study). ${ }^{6}$ In the MASS II (Medicine, Angioplasty, or Surgery Study), a randomized clinical study in 611 patients with multivessel disease (not including patients with left main disease and patients with cardiac dysfunction), the overall mortality and incidence of cardiac death at the 5-year follow-up did not differ significantly between the CABG group and the medical therapy group $(39.4 \%$ of the patients underwent coronary revascularization during the study). ${ }^{15}$ However, the incidence of cardiac death at the 10-year follow-up was significantly lower in the CABG group than the medical therapy group, although the overall mortality did not differ between the two groups. ${ }^{16}$ At the present time when intensive medical therapy is available, the beneficial effect of CABG on long-term prognosis may have become smaller than before, or longer follow-up is required to demonstrate a significant difference between CABG and intensive medical therapy. Randomized clinical studies for at least 10 years should be performed to determine the true beneficial effects of CABG on long-term prognosis and how long such effect will continue.

The results of the BARI 2D study indicated that CABG was superior to initial intensive medical therapy in terms of the prevention of myocardial infarction ${ }^{7}$ and QOL including activity status. ${ }^{17}$ In the MASS II, the incidence of myocardial infarction at 10-year follow-up was lower in the CABG group than in the medical therapy group. ${ }^{16}$ The mechanism of the prevention of acute myocardial infarction in patients receiving CABG is thought to be "distal protection" in which bypass grafts may protect myocardium distal to a ruptured plaque when a graft is connected to the distal part of the clogged artery. ${ }^{18}$ During the 10- year follow-up in the MASS II, patients in the CABG group showed a greater improvement in anginal symptoms than the initial medical therapy group. ${ }^{16}$

\section{Important Points to Be Considered When Interpreting the Results of Randomized Clinical Studies Comparing $\mathrm{PCI}$ and $\mathrm{CABG}$}

A large number of randomized clinical studies have been conducted to compare PCI and CABG. Physicians should consider the following three points when interpreting the results of such studies. First, because patients with left main disease or three-vessel disease have been historically considered to require $\mathrm{CABG}$, patients with left main disease have been excluded in the majority of randomized clinical studies, and the percentage of patients with three-vessel disease has been small. These studies have been conducted in patients with coronary stenosis treatable with PCI, and patients with complex lesions that require $\mathrm{CABG}$ rather than $\mathrm{PCI}$ have not been enrolled in these studies. Second, it is believed that 5 to 10 years of follow-up is required to confirm the treatment outcomes of CABG over PCI, but the observation period is often too short in many studies. Third, the importance of intensive medical therapy is widely acknowledged, but drug regimens during the follow-up period differ between the PCI and CABG groups.

The SYNTAX, the only randomized clinical study to date that directly compared between CABG and PCI with DES, was intended to show non-inferiority of PCI compared with CABG in 1,800 patients with left main disease or three-vessel disease (left main disease was present in 39\%, three-vessel disease in $61 \%$, and diabetes in $25 \%$ ). For the primary endpoint, the $12-$ month rate of major adverse cardiac or cerebrovascular events (i.e., death, stroke, myocardial infarction, or repeat revascularization), were significantly higher in the PCI group, so the noninferiority of PCI as compared with CABG was not demonstrated. ${ }^{19}$ At 3-year follow-up, the incidences of death (CABG $6.7 \%$ vs. PCI $8.6 \%$ ) and stroke (CABG $3.4 \%$ vs. PCI $2.0 \%$ ) were not significantly different between the treatment groups. However, the incidences of myocardial infarction (CABG 3.6\% vs. PCI $7.1 \%$ ) and repeat revascularization (CABG $10.7 \%$ vs. PCI 19.7\%) were higher in PCI-treated patients. ${ }^{20}$ It should be noted that among 3,075 patients registered in the SYNTAX study, 1,800 patients (59\%) were considered to be indicated for both PCI and CABG and were randomly assigned to undergo CABG or PCI with DES, while the remaining 1,275 patients were enrolled in the registry study because $84 \%$ of them $(1,077$ patients) were indicated only for CABG, and $16 \%$ of them (198 patients) were indicated only for PCI. The most common reasons for the enrollment in the $\mathrm{CABG}$ registry were complex lesions inaccessible to PCI $(70.9 \%)$ and chronic total occlusion $(22.0 \%)$, while those in the PCI registry were underlying diseases $(70.7 \%)$ and unavailability of suitable grafts $(9.1 \%)$. Patients in the randomized cohort will continue to be followed for 5 years. Patients in the CABG cohort were less likely to receive antiplatelet drugs, statins, $\beta$-blockers, ARBs, and calcium channel blockers than those in PCI cohort.

\section{8. $\mathrm{PCI}$ and $\mathrm{CABG}$ for Patients With Multivessel Disease: Statement \#5}

Hlatky et al. conducted a collaborative analysis of data from 10 randomized trials comparing between CABG and PCI not using DES which provided data on 7,812 patients (proximal LAD disease was present in 51\%, two-vessel disease in $63 \%$, three-vessel disease in $37 \%$, and diabetes in $16 \%$ ), and reported that the incidence of repeat revascularization during the 6-year 
follow-up period was higher in patients receiving PCI than CABG, but the incidences of death and myocardial infarction did not differ significantly between the two groups. ${ }^{21}$ However, a sub-analysis of the SYNTAX study revealed incidences of death, myocardial infarction and repeat revascularization in patients with three-vessel disease were lower in patients undergoing CABG than those receiving PCI with DES. When patients with three-vessel disease were further classified into those with higher and lower SYNTAX scores, those with lower SYNTAX scores showed no significant differences in incidences of death, myocardial infarction and stroke between PCI and CABG, while those with higher SYNTAX scores showed superiority of CABG in these measures. According to these data, the ESC/EACTS Guidelines on Myocardial Revascularization published in August $2010,{ }^{3}$ CABG is a Class I recommendation with Level of Evidence: A for patients with threevessel disease, and PCI is a Class IIa recommendation for patients with three-vessel disease and a SYNTAX score of $\leq 22$, and a Class III recommendation for patients with complex three-vessel disease and a SYNTX score of $\geq 23$.

Observational studies such as the CREDO-Kyoto (Coronary REvascularization Demonstrating Outcome Study in Kyoto) PCI/CABG registry in Japan ${ }^{22}$ and a registry study in New York State ${ }^{23}$ have compared PCI and CABG in the treatment of multivessel disease without left main involvement in the clinical setting. In the CREDO-Kyoto registry in 5,420 patients (proximal LAD disease was present in $80 \%$, twovessel disease in $49 \%$, three-vessel disease in $51 \%$, diabetes in $46 \%$, and total occlusion in $40 \%$ ), the risk-adjusted mortality tended to be higher in PCI without DES than CABG, and significantly higher in PCI than CABG in diabetic patients and patients with cardiac dysfunction. However, there were no differences between PCI and CABG when compared in patients $<75$ years of age. In the New York State registry study in 17,400 patients (proximal LAD disease was present in $52 \%$, two-vessel disease in $56 \%$, three-vessel disease in $41 \%$, and diabetes in $38 \%$ ), the incidence of repeat revascularization, risk-adjusted incidence of myocardial infarction, and mortality were lower in CABG than PCI with DES. The incidences of death and myocardial infarction were lower in CABG than PCI in patients with two- or three-vessel disease group, elderly patients $\geq 80$ years of age, and patients with cardiac dysfunction. In an analysis of 6,327 patients with multivessel and/ or left main disease in the CREDO-Kyoto registry, the riskadjusted mortality and incidences of myocardial infarction and repeat revascularization during the 3.5-year follow-up period were higher in patients after PCI than those after CABG. ${ }^{24}$ Mortality was also higher in PCI than CABG in patients with diabetes, patients with cardiac dysfunction, patients with proximal LAD disease, and elderly patients $\geq 75$ years of age. The incidence of stroke was lower in PCI than CABG, but did not differ between PCI and OPCAB.

\section{PCI and CABG for Patients With Left Main Disease: Statement \#6}

In a systemic overview of individual patient data from 7 randomized clinical studies, Yusuf et al. reported that the reduction in risk of death by $\mathrm{CABG}$ as compared with medical therapy was greatest in patients with left main disease..$^{12} \mathrm{Re}$ cent studies of stents vs. CABG for left main disease suggested that PCI might be an acceptable treatment option for patients with left main disease. ${ }^{25}$ However, these studies included patients with stable CAD and patients with ACS. To date, there have been no well-conducted observational studies or randomized clinical studies that compared between PCI and
CABG for the treatment of unprotected left main lesions in patients with stable CAD. Accordingly, CABG rather than PCI has been selected in coronary revascularization for patients with left main disease.

In the ACCF/SCAI/STS/AATS/AHA/ASNC (American College of Cardiology Foundation/Society for Cardiovascular Angiography and Interventions/Society of Thoracic Surgeons/ American Association for Thoracic Surgery/American Heart Association/ American Society of Nuclear Cardiology) 2009 Appropriateness Criteria for Coronary Revascularization, CABG is considered as an appropriate procedure for unprotected left main disease, while PCI is considered inappropriate even for isolated left main lesions. ${ }^{26}$ The 2009 Focused Updates of the ACC/AHA Guidelines for the Management of Patients With ST-Elevation Myocardial Infarction and ACC/ AHA/SCAI Guidelines on Percutaneous Coronary Intervention describe recommendations for PCI for unprotected left main disease as follows: ${ }^{27} \mathrm{PCI}$ of the left main coronary artery with stents as an alternative to CABG may be considered in patients with anatomic conditions that are associated with a low risk of PCI procedural complications (i.e., isolated left main lesions or left main plus one-vessel disease) and risk factors such as severe lung disease, prior thoracic surgery, or poor bypass graft targets that would make $\mathrm{CABG}$ a high-risk procedure or unlikely to be successful. Conversely, CABG for unprotected left main disease may be relatively more favorable for patients with left main plus multivessel disease, distal/ bifurcation left main lesions, or low surgical risk with a good chance of technical success. ${ }^{27}$ In the j-Cypher registry, a multicenter large-scale registry of patients undergoing sirolimuseluting stent implantation in Japan, among patients with bifurcation lesions who underwent PCI for unprotected left main disease, patients with stenting of both the main and side branches using two-stent strategy had significantly higher incidences of cardiac death and revascularization than those with mainbranch stenting alone using one-stent strategy. ${ }^{28}$

The results of a sub-analysis of SYNTAX study after 3-year follow-up, the incidence of repeat revascularization was lower in patients undergoing CABG than those receiving PCI with DES, although the incidences of death and myocardial infarction did not differ between the two groups. ${ }^{20}$ Among patients with left main disease and lower SYNTAX scores, there were no differences in incidences of death, myocardial infarction and stroke between the PCI with DES and CABG groups, while among those with higher SYNTAX scores, incidences of death and myocardial infarction tended to be lower in CABG than PCI with DES groups. However, we should be aware of the limitations of randomized clinical studies. In the SYNTAX study, 312 (29\%) of the 1,085 patients with left main disease who were enrolled in the study were considered to be indicated only for CABG, and were enrolled in the registry study. In August 2010, the ESC and the EACTS published joint guidelines on myocardial revascularization. In the ESC/EACTS joint guidelines, CABG is a Class I recommendation with Level of Evidence: A for patients with left main disease on the basis of the results of the SYNTAX study. ${ }^{3}$ PCI is a Class IIa or IIb recommendation with Level of Evidence: B for patients with isolated ostial or shaft lesions of the left main coronary artery or patients with left main plus one-vessel disease, and is a Class IIb or III recommendation for the treatment of bifurcation lesions in patients with isolated left main coronary artery/ left main plus one-vessel disease or the treatment of left main plus multivessel disease. 


\begin{tabular}{|c|c|c|}
\hline Anatomical conditions & $\mathbf{P C l}$ & CABG \\
\hline \multicolumn{3}{|l|}{ 1- or 2-vessel disease } \\
\hline No proximal LAD lesions & I A & $\mathrm{Ilb} \mathrm{C}$ \\
\hline Proximal LAD lesions (without ostial LAD lesions) & IC & I A \\
\hline Ostial LAD lesions & $\mathrm{Ilb} \mathrm{C}$ & I A \\
\hline \multicolumn{3}{|l|}{ 3-vessel disease } \\
\hline No proximal LAD lesions & Illb B & I A \\
\hline Proximal LAD lesions & III B & I A \\
\hline \multicolumn{3}{|l|}{ Unprotected left main disease } \\
\hline Isolated ostial or shaft lesions plus 1-vessel disease & $\mathrm{Ilb} \mathrm{C}$ & I A \\
\hline Isolated bifurcation lesions or bifurcation lesions plus 1-vessel disease & $\mathrm{III} \mathrm{C} / \mathrm{IIb} \mathrm{C}^{*}$ & I A \\
\hline Multivessel disease & III C & I A \\
\hline
\end{tabular}

* $\mathrm{llb}$ recommendation for patients with no lesions involving the ostium of the circumflex artery for whom the use of $\mathrm{PCl}$ has been approved by the heart team including cardiac surgeons.

$\mathrm{CABG}$, coronary artery bypass grafting; $\mathrm{LAD}$, left anterior descending coronary artery; $\mathrm{PCl}$, percutaneous coronary intervention.

\section{Indications for Coronary Revascularization (PCI/CABG) in Patients With Stable Coronary Artery Disease (Table 1)}

1. Lifestyle intervention and drug treatment are essential components of the treatment of stable CAD. Coronary revascularization should be performed for patients in whom the improvement of physical conditions and long-term prognosis are expected.

2. Patients with one- or two-vessel disease without proximal LAD involvement are indicated for PCI. Both PCI and CABG should be considered for patients with one- or twovessel disease with proximal LAD involvement. CABG should be considered for patients with ostial LAD lesions.

3. Patients with three-vessel disease should be treated with $\mathrm{CABG}$, in principle, but may be treated with PCI when they have risk factors that would make $\mathrm{CABG}$ a high-risk procedure, or when PCI is considered to be a safe procedure because of the absence of proximal LAD lesions or other lesions.
4. Basically, patients with unprotected left main disease should be treated with CABG, but PCI may be alternative to CABG when they have risk factors that would make CABG a highrisk procedure, or when PCI is considered to be a safe procedure because of targeting ostial/shaft lesions of left main trunk (LMT) or other lesions. PCI must be conducted in a condition where emergency CABG can be performed without delay.

The above indications are provided as basic principles. Treatment strategies for individual patients should be determined on the basis of their clinical and anatomical characteristics, the results and systems available in each institution, the long-term treatment goals, and others. Especially for patients with severe $\mathrm{CAD}$, interventional cardiologists and cardiac surgeons should discuss and decide optimal treatment options to be proposed to the patients.

A PCI/CABG registry must be established as soon as possible to prepare for the revision of the guideline documents on the basis of clinical evidence in Japan.

\section{Surgical Techniques}

\section{Conventional On-Pump and Off-Pump CABG}

The characteristic features of CABG in Japan include: (1) a significantly higher prevalence of PCI than other countries; (2) the number of patients undergoing $\mathrm{CABG}$ per institution is small; (3) the elderly account for a large proportion of patients undergoing $\mathrm{CABG}$; (4) OPCAB is prevalent; and (5) the use of arterial grafts is common.

With these differences, it is difficult to adopt CABG guidelines published in Western countries without modifications, and we should discuss matters to be considered to ensure wide use of OPCAB. In Japan, the Japanese Association for Thoracic Surgery has conducted academic research on $\mathrm{CABG}^{29}$ and the Japanese Association for Coronary Artery Surgery has published annual reports on the results of national questionnaires on coronary surgery..$^{30}$ The Japan Cardiovascular Surgery Database Organization has published the data of the Japan Adult
Cardiovascular Surgery Database (JACVSD), and the results of risk assessment. ${ }^{31,32} \mathrm{We}$ discussed the results of CABG in Japan reported as above and the results of large-scale studies of $\mathrm{CABG}$ in foreign countries to provide the following recommendations.

\section{Indications of Conventional On-Pump CABG $29,30,33-37$}

- Patients who are hemodynamically unstable and are not suitable for OPCAB or those who are undergoing cardiopulmonary bypass. [Class I, Level of Evidence: B]

- Patients in whom a significant stenosis is present in a coronary artery which cannot be surgically exposed or safely accessed in an off-pump fashion due to anatomical or hemodynamic characteristics and complete revascularization can be achieved using cardiopulmonary bypass. [Class IIa, Level of Evidence: B]

- Patients in whom the target artery may not be sufficiently exposed or safely accessed in an off-pump fashion due to 
anatomical or hemodynamic characteristics. [Class IIb, Level of Evidence: C]

- The following patients in whom the risk of complications during the acute phase of cardiopulmonary bypass such as cerebral infarction is high: [Class III, Level of Evidence: B]

1. Patients with significant calcification or atherosclerosis in the ascending aorta, aortic arch, or carotid artery.

2. Elderly patients.

3. Diabetic patients with poor glycemic control.

4. Patients with a history of cerebral infarction.

2. Comparison of Outcome of On-Pump vs. Off-Pump CABG ${ }^{30,34,35,38-42}$

- In low-risk patients, there are no significant differences in surgical mortality (death within 30 days after surgery) and one- or two-year mortality between OPCAB and CCAB. [Class I, Level of Evidence: A]

- In high-risk patients, OPCAB decreases short-term mortality as compared with CCAB. [Class I, Level of Evidence: B]

- The incidence of perioperative complications is lower in patients undergoing OPCAB than those undergoing CCAB. [Class I, Level of Evidence: A]

- Patients undergoing OPCAB have shorter durations of mechanical ventilation, intensive care unit (ICU) stay, and hospitalization, significantly smaller amount of bleeding, and significantly less use of blood products as compared with patients undergoing CCAB. [Class I, Level of Evidence: A]

\section{Short-Term Mortality ${ }^{30,31,40}$}

- In high-risk patients such as elderly patients and patients receiving hemodialysis, OPCAB decreases the risk of shortterm mortality as compared with patients undergoing CCAB. [Class I, Level of Evidence: B]

- Conversion from OPCAB to CCAB increases the risk of short-term mortality. [Class IIa, Level of Evidence: B]

\section{Brain Dysfunction43-55}

- Avoidance of surgical procedures involving the ascending aorta may decrease the risk of brain dysfunction. [Class I, Level of Evidence: A]

- The incidence of postoperative brain dysfunction is lower in patients undergoing OPCAB than those undergoing $\mathrm{CCAB}$. [Class IIa, Level of Evidence: A]

5. Deep Sternal Wound Infection and Mediastinitis $43,56-69$

- OPCAB decreases the risk of deep sternal wound infection (DSWI). [Class IIa, Level of Evidence: B]

- Skeletonization of the ITA decreases the risk of DSWI. [Class IIa, Level of Evidence: B]

- In patients with diabetes, BITA grafting may impair sternal wound healing, and is a risk factor for DSWI. [Class IIa, Level of Evidence: B]

- Appropriate glycemic control decreases the risk of DSWI. [Class IIa, Level of Evidence: B]

6. Renal Failure ${ }^{70-76}$

- In patients without renal dysfunction, OPCAB decreases the risk of postoperative renal dysfunction. [Class IIa, Level of Evidence: C]

- In patients with moderate or severe renal dysfunction, OPCAB is not superior to $\mathrm{CCAB}$ in terms of renal protective effect. [Class IIa, Level of Evidence: B]

- Renal function in the remote period after CABG is not affected by the type of CABG techniques. [Class IIa, Level of Evidence: B]

\section{Long-Term Outcome $42,77-87$}

- Grafting of the ITA to LAD artery has a favorable long-term patency rate, and may thereby improve long-term survival and prevent cardiac accidents. [Class I, Level of Evidence: B]

- The long-term outcome is better in patients undergoing BITA grafting than those undergoing single ITA (SITA) grafting. [Class IIa, Level of Evidence: B]

- The long-term outcome is better in patients undergoing revascularization using arterial grafts only than those using arterial and vein grafts. [Class IIa, Level of Evidence: B]

- Achievement of complete revascularization is effective in improving mid- and long-term survival and preventing cardiac accidents. [Class IIa, Level of Evidence: B]

- Assessment of graft patency during CABG procedures improves the long-term patency rate. [Class IIa, Level of Evidence: $\mathrm{C}$ ]

\section{Graft Vessels}

\section{Left Internal Thoracic Artery ${ }^{88-103}$}

- The LITA should be used preferentially to bypass the LAD artery. [Class I, Level of Evidence: B]

- The use of LITA to bypass the circumflex (Cx) artery is inferior to the use of LITA to bypass the LAD artery in terms of outcome. [Class IIa, Level of Evidence: B]

- Skeletonization of the LITA ensures a longer available length of the graft and higher blood flow. [Class IIa, Level of Evidence: $B$ ]

\section{Right Internal Thoracic Artery60,80,91,96,104-137}

- BITA grafting decreases both long-term mortality and morbidity after CABG. [Class IIa, Level of Evidence: B]

- In-situ RITA grafting to the left coronary artery system should be prioritized over those to the right coronary artery (RCA) system. [Class IIa, Level of Evidence: B]

\section{Right Gastroepiploic Artery ${ }^{107,138-175}$}

- The right GEA grafting to the RCA system is comparable to the results of RCA grafting using other arterial grafts, and is beneficial. [Class IIa, Level of Evidence: B]

- Right GEA grafts and SVGs are comparable in terms of the long-term prognosis after CABG to the RCA system. [Class IIa, Level of Evidence: B]

\section{Inferior Epigastric Artery}

The inferior epigastric artery (IEA) is used as a composite or free graft. Because the IEA cannot be harvested concomitantly with the ipsilateral ITA, indications for IEA grafts are limited, and no sufficient evidence to support the use of IEA grafts has 
been obtained.

\section{Radial Artery ${ }^{159,176-194}$}

- When the RA is used to bypass non-LAD arteries, its graft patency rate is comparable with the patency rate of the ITA and other arterial grafts. [Class IIa, Level of Evidence: B]

- Patency rate of the RA graft does not differ significantly between when the proximal side of the RA graft is anastomosed to the in-situ ITA and when it is anastomosed to the aorta (A-C bypass). [Class IIa, Level of Evidence: B]

- Patency rate of the RA graft is superior to that of the SVG when it is used in A-C bypass. [Class IIa, Level of Evidence: $B$ ]

- Patency rate of the RA graft is unfavorable when it is used to bypass moderately stenosed coronary arteries. [Class IIa, Level of Evidence: B]

\section{Saphenous Vein Grafts $160,187-190,195-214$}

Although SVG was used commonly in the earliest era of CABG, the use of arterial grafts rather than SVG is preferred as longterm patency rate of SVG for CABG is not favorable. However, SVG is still commonly used in CABG. SVG is the grafts of choice for emergency rescue CABG because SVG can be harvested without disturbing the surgical field.

- The 10-year patency rate of SVG is about $60 \%$. When it is used to graft the second target coronary artery in the presence of LITA grafted to the LAD, the patency rate and outcome of RA graft is superior to SVG. [Class IIb, Level of Evidence: B]

- Long-term patency rate of SVG is inferior to that of GEA grafts when used to graft the RCA. [Class IIb, Level of Evidence: $B$

- Endoscopic harvesting may decrease the incidences of wound complications and infections without affecting the nature and short-term patency rate of SVG. [Class I, Level of Evidence: A]

\section{Graft Arrangement}

\section{In-Situ Graft $77,88,89,91,96,100,102,108,113$, $114,119-121,123,124,134,149,153,167,215-223$}

- The in-situ LITA is the graft of choice for the LAD. [Class I, Level of Evidence: B]

- The quality of in-situ RITA is expected to be high as that of LITA when used to graft the LAD. [Class I, Level of Evidence: $B]$

- The long-term outcome of BITA grafting to the left coronary artery system is expected to be more favorable than SITA grafting because it decreases mortality and morbidity after CABG. [Class IIa, Level of Evidence: B]

- Although the flow capacity of in-situ ITA is lower than the SVG anastomosed to the aorta, it responds to the flow demand of the recipient coronary arteries and increases flow volume and internal diameter. When used to graft native coronary arteries with low-grade stenosis, competitive flow may occur readily. [Class I, Level of Evidence: B]

- Ultrasonic complete skeletonization increases the length of in-situ ITA. Skeletonization may also decrease the risk of sternal wound infection after BITA grafting. [Class IIa, Level of Evidence: B]

- The in-situ GEA to graft the RCA system is beneficial when the graft size is considered carefully in each case. [Class IIa, Level of Evidence: B]

\section{Free Grafts}

1. Anastomosis to the Ascending Aorta ${ }^{159,160,179,180,187,188,}$ $190,195,197,224-227$

- The 10-year patency rate of SVG anastomosed to the ascending aorta is about $50 \%$. Patency rate of SVG anasto- mosed to the LAD is higher than that of SVG anastomosed to non-LAD arteries. [Class IIa, Level of Evidence: B]

- Patency rate of RA grafts anastomosed to the ascending aorta in A-C bypass is superior to that of SVG. [Class IIa, Level of Evidence: B]

- When the RA is used to graft coronary arteries, competitive flow from the native coronary artery with low-grade stenosis can cause occlusion of the grafts even in cases of A-C bypass where graft blood flow is expected to be large. [Class IIa, Level of Evidence: B]

- When grafts are anastomosed during partial occlusion clamp of the ascending aorta, care should be taken to avoid the occurrence of atheromatous emboli from the aortic wall. [Class IIa, Level of Evidence: C]

- Anastomotic devices to avoid partial occlusion clamp of the ascending aorta during OPCAB have been developed. Further studies should be conducted to evaluate the efficacy and reliability of these devices. [Class III, Level of Evidence: C]

\section{Composite Grafts $159,173,179,187,228-242$}

- When a LITA graft is connected to either a RITA or RA graft to make a Y-composite graft, the LITA may provide flow capacity that satisfies the demand of the recipient coronary arteries. [Class I, Level of Evidence: B]

- LITA-RITA or LITA-RA composite grafts enable revascularization using arterial grafts, and are expected to provide high long-term patency rate. [Class I, Level of Evidence: B]

- Competitive flow with the recipient coronary arteries may occur in composite grafts. Care should be taken when composite grafts are anastomosed to coronary arteries with lowgrade stenosis. [Class IIa, Level of Evidence: B]

- Vein grafts should not be proximally anastomosed to the in-situ ITA to be used as branches of Y-composite grafts. [Class IIa, Level of Evidence: C] 


\section{Selection of Graft Vessels Suitable for the Target Vessels}

Graft selection should be based on the need for target vessel revascularization, available grafts (Table 2), long-term graft

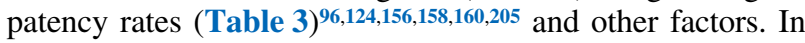
terms of the need for target vessel revascularization, the LAD is believed to be the most important coronary vessel due to the large size of myocardium perfused by the LAD. Table 2 lists graft vessels that can be used to bypass for each coronary artery. Physicians should select the most suitable graft for each target coronary artery from the available options.

\section{Left Anterior Descending \\ Artery $96,124,156,158,160,205,243$}

- Expected long-term patency rate after CABG is highest in the LAD artery. [Class IIa, Level of Evidence: B]

- The use of the ITA to bypass the LAD artery is expected to result in better long-term survival and lower incidence of cardiac accidents as compared with the use of the SVG. [Class I, Level of Evidence: B]

- When the RITA is used to bypass the LAD artery, the longterm patency rate is expected to be similar to the use of LITA. [Class I, Level of Evidence: B]

\section{Non-Left Anterior Descending \\ Arteries $160,187,190,225,235,244,245$}

The ITA is usually used to bypass the LAD artery. When bypass of non-LAD arteries (e.g., Cx artery or RCA) is indicated, appropriate procedures should be selected. The ITA, RA and SVG may be used to bypass non-LAD arteries.

- When the ITA is used to bypass the LAD artery, the other ITA should be used to graft the Cx artery rather than the RCA. [Class IIa, Level of Evidence: B]

- Long-term outcomes after CABG using the ITA to bypass non-LAD arteries are almost comparable to that using the RA. [Class IIa, Level of Evidence: B]

- Ten year results after CABG are better when ITA grafts were used to bypass non-LAD arteries than when SVGs were used to bypass non-LAD arteries. [Class IIa, Level of Evidence: B]

- No differences have been demonstrated between the longterm outcomes of RA grafts and SVGs to bypass non-LAD arteries. [Class IIb, Level of Evidence: C]

1. Circumflex Arteries ${ }^{244}$

- When the ITA is used to bypass the LAD artery, the other ITA should be used to graft the $\mathrm{Cx}$ artery rather than the RCA. [Class IIa, Level of Evidence: B]

\begin{tabular}{|lcc|}
\hline \multicolumn{2}{|c|}{ Table 2. List of Bypass Grafts Suitable for Each Coronary Artery } & \\
LAD artery & General use & Special use \\
Dx artery & LITA, RITA, RA, SVG & \\
Cx artery & LITA, RITA, RA, SVG & Composite RA, FITA \\
RCA (\#1-3) & LITA, RITA, RA, SVG & Composite RA, FITA \\
RCA (\#4) & RITA, GEA, RA, SVG & Composite RA, FITA \\
\hline
\end{tabular}

Cx, circumflex; Dx, diagonal; FITA, free internal thoracic artery; GEA, gastroepiploic artery; LAD, left anterior descending; LITA, left internal thoracic artery; RA, radial artery; RCA, right coronary artery; RITA, right internal thoracic artery; SVG, saphenous vein graft.

\begin{tabular}{|c|c|c|c|c|c|c|c|c|}
\hline \multirow{2}{*}{$\begin{array}{l}\text { Reference/ } \\
\text { Year }\end{array}$} & \multirow{2}{*}{$\begin{array}{l}\text { Mean follow-up } \\
\text { period after CABG }\end{array}$} & \multirow{2}{*}{$\begin{array}{c}\text { No. of } \\
\text { patients }\end{array}$} & \multicolumn{6}{|c|}{ Patency rate (\%) or risk of occlusion (odds ratio) } \\
\hline & & & Graft & LAD artery & Dx artery & Cx artery & RCA (\#1-3) & RCA (\#4) \\
\hline $124 / 2000$ & 5.6 & 962 & RITA" & 1 & 2.0 & 2.8 & 4.0 & 2.6 \\
\hline $158 / 2002$ & 2.3 & 109 & Composite RA & $83.3 \%{ }^{*}$ & & $75.2 \%$ & $70.0 \% \S$ & \\
\hline $205 / 2003$ & 8.3 & 1,607 & SVG & 1 & 1.29 & 1.39 & 1.63 & 1.34 \\
\hline \multirow[t]{2}{*}{$96 / 2004$} & 6.6 & 1,434 & LITA & $97.2 \%$ & $96.4 \%$ & $91.0 \%$ & & \\
\hline & & & RITAף & $96 \%$ & $93 \%$ & $90 \%$ & $79 \%$ & $87 \%$ \\
\hline \multirow[t]{2}{*}{$160 / 2004$} & 10 & 369 & ITA & $85 \%$ & & & & \\
\hline & & & SVG & $69 \% *$ & & $58 \%$ & $56 \% \S$ & \\
\hline \multirow[t]{5}{*}{$156 / 2004$} & 6.4 & 1,408 & LITA & $97.1 \% *$ & & $91.7 \%$ & & \\
\hline & & & RITA & $94.6 \%{ }^{*}$ & & $84.9 \%$ & $79.5 \% \S$ & \\
\hline & & & Free RITA & $96.2 \% *$ & & $91.9 \%$ & $88.8 \% \S$ & \\
\hline & & & RA & $87.1 \%{ }^{*}$ & & $91.6 \%$ & $88.2 \% \S$ & \\
\hline & & & SVG & $60.2 \% *$ & & $61.2 \%$ & $61.6 \% \S$ & \\
\hline
\end{tabular}

*LAD + Dx, ${ }^{\S} R C A$ (\#1-4), "lincluding free RITA.

CABG, coronary artery bypass grafting; Cx, circumflex; Dx, diagonal; ITA, internal thoracic artery; LAD, left anterior descending; LITA, left internal thoracic artery; RA, radial artery; RCA, right coronary artery; RITA, right internal thoracic artery; SVG, saphenous vein graft. 


\section{Right Coronary Artery $96,161,205$}

- Among the all coronary arteries, long-term graft patency rate is the lowest in the RCA (\#1-3). Long-term patency rate is expected to be high when the graft is anastomosed to the distal segment of the RCA (\#4), rather than to the proximal segments of the RCA (\#1-3). [Class IIa, Level of Evidence: $B$ ]

- The superiority of GEA graft to SVG has not clearly been demonstrated in terms of long-term outcome of CABG to the RCA. [Class IIb, Level of Evidence: B]

\section{Issues After CABG}

\section{Antiplatelet Therapy to Prolong the Patency of the Saphenous Vein Grafts $246-255$}

\section{- Aspirin should be used to prevent early-phase occlusion of vein grafts. Aspirin is a standard treatment for patients with vein grafts, and should be continued to prevent postopera- tive events. [Class I, Level of Evidence: A] \\ 2. Treatment With Calcium Channel Blockers After CABG Using Radial Artery Grafts}

Carpentier et al. first reported the use of the RA in CABG. ${ }^{256}$ However, no clinical studies have been conducted to date to evaluate the effect of calcium channel blockers on RA patency. ${ }^{187}$

\section{PCI to Treat Graft Lesions}

\section{Vein Grafts $88,257-269$}

- The use of coronary stents and embolic protection devices for peripheral applications may be considered for the treatment of vein graft lesions. [Class IIa, Level of Evidence: B]

\section{Arterial Grafts}

The initial success rate of stenting in ITA grafts is high, although the long-term restenosis rate is higher in ITA graft lesions treated with stenting than those with balloon angioplasty. ${ }^{270}$

\section{Drug Treatment for Hyperlipidemia253,271-273}

- All patients undergoing CABG should receive statin therapy, unless contraindicated. [Class I, Level of Evidence: A]

\section{Antihypertensive Treatment After CABG}

In the treatment of hypertension associated with angina, calcium channel blockers and $\beta$-blockers that exert antianginal effects are the drugs of choice. Although patients before CABG should be carefully monitored not to lead excessive antihypertensive treatment because it may induce anginal attacks, sufficient antihypertensive treatment using appropriate combinations of drugs should be performed after CABG to achieve secondary prevention of cardiovascular events.

However, because these finding have been obtained from studies in hypertensive patients with ischemic heart disease including a limited number of patients undergoing CABG, no sufficient evidence has been obtained regarding antihypertensive treatment after CABG.

\section{Hormone Therapy ${ }^{274,275}$}

- Hormone replacement therapy is not recommended for female patients after CABG. [Class III, Level of Evidence: B]

\section{Smoking Cessation ${ }^{276-281}$}

- All smokers should receive educational counseling and be offered smoking cessation therapy postoperatively. [Class I, Level of Evidence: B]

- Drug treatment such as nicotine replacement therapy and varenicline should only be administered to patients who are willing to stop smoking. [Class I, Level of Evidence: B]

\section{Cardiac Rehabilitation ${ }^{282-297}$}

- Cardiac rehabilitation is recommended for all eligible patients after CABG. [Class I, Level of Evidence: B]

\section{Selection of CABG Procedures and Grafts for Specific Patient Populations}

\section{Very Elderly Patients $\geq 80$ Years of Age $298-304$}

- The use of unilateral ITA to revascularize the LAD artery improves the prognosis of very elderly patients $\geq 80$ years of age. [Class IIa, Level of Evidence: B]

- OPCAB reduces the risk associated with surgery in very elderly patients $\geq 80$ years of age. [Class IIa, Level of Evidence: $\mathrm{C}]$

\section{Women ${ }^{305-352}$}

- Whenever possible, at least one ITA graft should be obtained and used to bypass the anterior descending artery. [Class I, Level of Evidence: B]

- Consideration on whether OPCAB is indicated should be made equally for both men and women, regardless of sex. [Class IIa, Level of Evidence: B] 


\section{Diabetes $6,21,60,66-69,77,134,217,348,353-384$}

- CABG is the procedure of choice for diabetic patients with multivessel disease. [Class I, Level of Evidence: B]

- It is desirable that postoperative plasma glucose should target $<180 \mathrm{mg} / \mathrm{dL}$. [Class I, Level of Evidence: B]

\section{Respiratory Dysfunction ${ }^{385-391}$}

- Avoidance of the use of cardiopulmonary bypass may reduce the risk associated with surgery in patients with chronic obstructive pulmonary disease (COPD). [Class IIa, Level of Evidence: B]

- Minimally invasive direct coronary artery bypass (MIDCAB) is useful in maintaining postoperative respiratory function in patients with COPD. [Class IIb, Level of Evidence C]

\section{Renal Failure ${ }^{392-405}$}

- Avoidance of the use of cardiopulmonary bypass may reduce the risk of perioperative complications in patients with chronic renal failure. [Class IIb, Level of Evidence: C]

\section{Cerebrovascular Disorders ${ }^{39,44,47,48,51,336,406-484}$}

Postoperative neurologic outcome is classified into type I outcome (e.g., cranial nerve disorders due to focal injury, or stupor or coma at discharge) and type II outcome (e.g., deterioration in intellectual function and memory deficit). ${ }^{47,336}$

- A prior history of cerebral infarction and advanced age are risk factors for perioperative cerebral events. These patients should be treated with CABG procedures that may prevent atheroembolism from the ascending aorta. [Class IIa, Level of Evidence: B]

- When severe atherosclerosis in the ascending aorta is observed during intraoperative echocardiography for the measurement of the ascending aorta, transesophageal echocardiography or palpation, switching to $\mathrm{CABG}$ procedures including OPCAB that do not clamp the ascending aorta may prevent the development of postoperative cerebrovascular disorders. [Class I, Level of: Evidence C]

- Four-week anticoagulation therapy using warfarin is indicated for patients with recurrent or long-lasting ( $\geq 24$ hours) atrial fibrillation after CABG. [Class IIb, Level of Evidence: $\mathrm{C}$ ]

- Long-term (3 to 6 month) anticoagulation therapy may be required for patients who recently experienced apical anterior myocardial infarction and show persistent asynergy after CABG. [Class IIa, Level of Evidence: C]

- Because the presence/absence of left ventricular thrombosis may affect how and when CABG is performed, patients with a recent history of anterior myocardial infarction should be considered for echocardiography to screen for the presence of left ventricular thrombosis. [Class IIb, Level of Evidence: $\mathbf{C}]$

- Carotid artery screening is probably indicated for the following patients: Patients $\geq 65$ years of age, those with left main disease, those with peripheral vascular disease, those with a history of smoking, those with a history of transient cerebral ischemia or cerebral infarction, and those with ca- rotid artery murmur. [Class IIa, Level of Evidence: C]

- Carotid endarterectomy (CEA) or carotid artery stenting (CAS) is recommended prior to or concomitantly with CABG in patients with symptomatic carotid artery disease and asymptomatic patients with $\geq 80 \%$ stenosis in either or both carotid arteries. [Class IIa, Level of Evidence: C]

- CEA and CAS should be performed by teams that have performed the procedures with an incidence of death and cerebral infarction at 30 days of $\leq 3 \%$ and $\leq 6 \%$ for patients with asymptomatic and symptomatic carotid artery disease, respectively. [Class I, Level of Evidence: A]

- A multidisciplinary team including neurologist should discuss and determine the indications for carotid angioplasty in individual patients. [Class I, Level of Evidence: C]

- Although even today CEA is a standard procedure to revascularize the carotid artery, a multidisciplinary team should discuss whether CEA or CAS should be selected for individual patients. [Class I, Level of Evidence: B]

\section{Porcelain Aorta 485,486}

- OPCAB without proximal anastomosis to the ascending aorta. [Class IIa, Level of Evidence: B]

- On-pump beating-heart CABG without involving the ascending aorta. [Class IIa, Level of Evidence: C]

- Use of an automatic anastomosis device for proximal anastomosis to the ascending aorta. [Class IIb, Level of Evidence: $\mathrm{C}$ ]

- Conventional procedures involving the ascending aorta. [Class III, Level of Evidence: B]

\section{Open-Heart Surgery in Patients With Cirrhosis ${ }^{487-495}$}

In patients with irreversible hepatic dysfunction especially cirrhosis, surgery is a high-risk procedure that often causes surgical complications such as excessive bleeding, infection, hepatic failure, renal failure and prolonged intubation, and may cause death when the indication is inappropriate. ${ }^{487}$

- OPCAB reduces the risk associated with surgery in patients with Child-Pugh classification B or C. [Class IIb, Level of Evidence: C]

\section{Valvular Disease}

\section{Aortic Stenosis ${ }^{496-510}$}

- Patients with severe aortic stenosis undergoing CABG should have concomitant aortic valve replacement. [Class I, Level of Evidence: B]

- Aortic valve replacement may be indicated for patients with moderate aortic stenosis undergoing $\mathrm{CABG}$ and in whom concomitant aortic valve replacement is not considered to increase the risk associated with surgery. [Class IIa, Level of Evidence: $\mathbf{C}$ ]

- Aortic valve replacement can be indicated for patients with mild aortic stenosis undergoing CABG and in whom concomitant aortic valve replacement is not considered to increase the risk associated with surgery. [Class IIb, Level of Evidence: C] 
2. Indications of Mitral Valve Surgery in Patients With Ischemic Mitral Valve Regurgitation ${ }^{511-530}$

- In patients undergoing CABG who have severe mitral valve regurgitation, concomitant mitral valve surgery should be performed. [Class IIa, Level of Evidence: B]

- In patients undergoing CABG who have moderate mitral valve regurgitation, concomitant mitral valve surgery is desirable. [Class IIb, Level of Evidence: C]

\section{Left Ventricular Aneurysm $531-535$}

- CABG concomitant with left ventricular aneurysm resection and reconstruction. [Class I, Level of Evidence: B]

- Endoventricular patch plasty for the treatment of left ventricular aneurysm. [Class IIa, Level of Evidence: B]

- Aneurysm resection and plain suture. [Class IIb, Level of Evidence: B]

\section{Aortic Aneurysm}

\section{Thoracic Aortic Aneurysm Associated With Ischemic Heart Disease}

As the population ages, the number of patients with thoracic aortic aneurysm associated with ischemic heart disease has increased. They account for 16 to $30 \%$ of patients with thoracic aortic aneurysm, ${ }^{536}$ and 15 to $30 \%$ of patients undergoing aortic arch replacement concomitantly receive CABG. ${ }^{537,538}$

\section{Abdominal Aortic Aneurysm Associated With Ischemic Heart Disease}

In a clinical study in patients under consideration for elective peripheral vascular reconstruction (e.g., abdominal aortic aneurysm, carotid artery diseases, and lower extremity atherosclerosis), coronary angiography revealed that $34 \%$ of them had CAD, and $25 \%$ of them required coronary angioplasty (CABG or percutaneous transluminal coronary angioplasty [PTCA] $)^{539}$

\section{Repeat CABG $496,540-544$}

- Repeat CABG is indicated for patients after CABG who have chest pain not responding to conservative treatment or PCI. When chest pain is atypical, myocardial ischemia must be demonstrated with stress testing and others. [Class I, Level of Evidence: B]

- Repeat CABG is indicated for patients after CABG when graft occlusion and native $\mathrm{CAD}$ requiring $\mathrm{CABG}$ (e.g., left main disease, and left main and three-vessel disease) are present. [Class I, Level of Evidence: B]

- Repeat CABG is recommended for patients after CABG when ischemia is present in a large myocardial territory supplied by an anastomosable peripheral vessel. [Class IIa, Level of Evidence: B]

- Repeat CABG should also be considered for patients after CABG when $\geq 50 \%$ stenosis due to atherosclerosis is present in the SVG supplying the LAD artery or a large myocardial territory. [Class IIa, Level of Evidence B]

\section{Peripheral Vascular Disease ${ }^{539,545-549}$}

It is well known that $\mathrm{CAD}$ and peripheral vascular disease are often present concurrently. It has been reported that 37 to $78 \%$ of patients undergoing surgical treatment of peripheral vascular disease have CAD. ${ }^{545}$

- In patients with peripheral vascular disease undergoing $\mathrm{CABG}$, the incidence of cerebral complications is lower in those not using cardiopulmonary bypass than those using it during CABG. [Class IIa, Level of Evidence: B]

\section{Left Ventricular Dysfunction $532,535,550-556$}

- CABG for patients with severe multivessel disease associated with left ventricular dysfunction and documented severe myocardial ischemia. [Class I, Level of Evidence: B]

- CABG and left ventricular plasty for patients with left ventricular dysfunction due to left ventricular remodeling after myocardial infarction. [Class IIa, Level of Evidence: B]

- CABG and left ventricular plasty for patients with severe left ventricular dysfunction due to myocardial infarction affecting multiple segments. [Class IIb, Level of Evidence: C]

\section{Malignant Tumor}

There are many issues to be solved when patients with malignant tumor undergo CABG. However, no evidence has been established regarding $\mathrm{CABG}$ in this patient population.

\section{Acute Coronary Syndromes $370,557-577$}

- In patients with myocardial infarction not associated with unstable angina or ST- elevation, CABG should be performed according to the indications for $\mathrm{CABG}$ in stable angina. [Class I, Level of Evidence: B]

- In patients with hemodynamically stable ST-elevation myocardial infarction, CABG should be performed according to the indications for CABG in stable angina. [Class I, Level of Evidence: B]

- In patients with hemodynamically unstable ST-elevation myocardial infarction, CABG should be performed when ischemia persists after PCI or when mechanical complications (e.g., ventricular septal perforation, free wall rupture, and mitral papillary muscle rupture) are present. [Class I, Level of Evidence: B]

\section{Fatal Ventricular Arrhythmias ${ }^{578-583}$}

- CABG for patients with severe multivessel disease who have adverse events such as cardiopulmonary resuscitation due to fatal ventricular arrhythmias. [Class I, Level of Evidence: B]

- CABG for patients with severe multivessel disease who have fatal ventricular arrhythmias and documented myocardial ischemia. [Class IIa, Level of Evidence: B]

- Left ventricular plasty for patients with ventricular tachycardia with scarred myocardium after myocardial infarction. [Class IIb, Level of Evidence: C] 


\begin{tabular}{|c|c|c|c|c|c|c|c|}
\hline & $\begin{array}{l}\text { Parsonnet } \\
\text { score }^{584}\end{array}$ & $\begin{array}{l}\text { Higgins } \\
\text { score }^{590}\end{array}$ & $\begin{array}{l}\text { French } \\
\text { score }^{594}\end{array}$ & $\begin{array}{c}\text { OPR } \\
\text { score }^{595}\end{array}$ & $\begin{array}{l}\text { Pons } \\
\text { score }^{599}\end{array}$ & EuroSCORE $^{600}$ & $\begin{array}{c}\text { STS risk } \\
\text { algorithm }\end{array}$ \\
\hline $\begin{array}{l}\text { Year of } \\
\text { publication }\end{array}$ & 1989 & 1992 & 1995 & 1995 & 1997 & 1999 & 1994 \\
\hline $\begin{array}{l}\text { No. of } \\
\text { institutions }\end{array}$ & Single center & Single center & 42 centers & 9 centers & 7 centers & 128 centers & Single center \\
\hline Country & USA & USA & France & Canada & Spain & $\begin{array}{l}8 \text { European } \\
\text { States }\end{array}$ & USA \\
\hline No. of patients & 3,500 & 5,051 & 7,181 & 13,098 & $1,309^{*}$ & 19,030 & 728 \\
\hline $\begin{array}{l}\text { Preoperative } \\
\text { factors }\end{array}$ & 14 & 13 & 8 & 6 & 11 & 23 & 10 \\
\hline Procedure & Heart surgery & For $\mathrm{CABG}$ & Heart surgery & Heart surgery & Heart surgery & Heart surgery & For CABG \\
\hline $\begin{array}{l}\text { Outcome } \\
\text { measure }\end{array}$ & Mortality & $\begin{array}{l}\text { Mortality, } \\
\text { Morbidity }\end{array}$ & $\begin{array}{l}\text { Mortality, } \\
\text { Morbidity }\end{array}$ & Mortality & Mortality & Mortality & $\begin{array}{l}\text { Mortality, } \\
\text { Morbidity }\end{array}$ \\
\hline Statistics & $\begin{array}{l}\text { Univariate and } \\
\text { logistic regres- } \\
\text { sion analysis }\end{array}$ & $\begin{array}{l}\text { Univariate and } \\
\text { logistic regres- } \\
\text { sion analysis }\end{array}$ & $\begin{array}{l}\text { Multivariate and } \\
\text { logistic regres- } \\
\text { sion analysis }\end{array}$ & $\begin{array}{l}\text { Multivariate and } \\
\text { logistic regres- } \\
\text { sion analysis }\end{array}$ & $\begin{array}{l}\text { Univariate and } \\
\text { logistic regres- } \\
\text { sion analysis }\end{array}$ & $\begin{array}{l}\text { Univariate and } \\
\text { logistic regres- } \\
\text { sion analysis }\end{array}$ & $\begin{array}{l}\text { Univariate and } \\
\text { logistic regres- } \\
\text { sion analysis }\end{array}$ \\
\hline How to use & $\begin{array}{l}\text { Calculate the } \\
\text { score using a } \\
\text { score table } \\
\text { based past } \\
\text { data }\end{array}$ & $\begin{array}{l}\text { Calculate the } \\
\text { score using a } \\
\text { score table } \\
\text { based past } \\
\text { data }\end{array}$ & $\begin{array}{l}\text { Calculate the } \\
\text { score using a } \\
\text { score table } \\
\text { based past } \\
\text { data }\end{array}$ & $\begin{array}{l}\text { Calculate the } \\
\text { score using a } \\
\text { score table } \\
\text { based past } \\
\text { data }\end{array}$ & $\begin{array}{l}\text { Calculate the } \\
\text { score using a } \\
\text { score table } \\
\text { based past } \\
\text { data }\end{array}$ & $\begin{array}{l}\text { Use a web } \\
\text { page to calcu- } \\
\text { late mortality } \\
\text { and morbidity }\end{array}$ & $\begin{array}{l}\text { Use a web } \\
\text { page to calcu- } \\
\text { late mortality } \\
\text { and morbidity }\end{array}$ \\
\hline
\end{tabular}

*Procedures.

CABG, coronary artery bypass grafting; EuroSCORE, European System for Cardiac Operative Risk Evaluation; OPR, Ontario Province Risk; STS, Society of Thoracic Surgeons.

\section{Methods of Patient Risk Assessment}

\section{Conventional Methods of Patient Risk Assessment}

A lot of reports have described patient risk assessment in heart surgery, ${ }^{39,187,189,423,584-618}$ and these reports have greatly contributed to the risk assessment of individual patients planned to undergo heart surgery and the improvement in hospital revenue and expenses through cost reduction, and have encouraged institutions to improve outcomes. Table 4 lists typical risk assessment methods reported to date. ${ }^{584,590,593,594,595,599,600}$

\section{Points to Consider for Patient Risk Assessment}

In patient risk assessment, users should be aware of (1) the results depends on the types of variables used, (2) variables may depend on patient characteristics and factors of healthcare providers, and (3) variables may change over time and as medical technology advances. The STS database and the EuroSCORE (European System for Cardiac Operative Risk Evaluation) are considered to be the international standards, and many surgeons have benefited from these methods. However, it is important and ideal to establish risk assessment methods considering the characteristic features in Japan and other areas.

\section{Selection of Patient Risk Assessment Methods}

Because there are no established databases and no methods of patient risk assessment have been validated in Japan, physicians are selecting suitable methods from currently available international assessment methods on the basis of the characteristics in each institution. The STS risk algorithm and the EuroSCORE, which are used as standards in many countries, are frequently selected.

\section{Risk Assessment Regarding Graft Selection}

In order to assess risk factors affecting graft patency rate after $\mathrm{CABG}$, mid- and long-term large-scale prospective studies must be conducted to follow-up patients after CABG with coronary angiography. Although the use of different grafts has been reported, risk factors affecting the outcome of CABG have not been precisely identified due to limited research funds.

\section{Current Recommendations in This Guideline Document}

In Japan, the JACVSD was established, and data of Japanese patients are being accumulated. It is realistic to use the STS database and the EuroSCORE to assess the risk of Japanese patients at this time. However, we recommend that risk assessment including morbidity assessment in Japan be based on factors characteristic of Japanese patients. 


\section{Economic Efficiency of CABG}

CABG is a medical procedure in natural science, and is also a treatment option provided as a part of the health care system. It is thus appropriate to describe measures for economic assessment of CABG in this guideline document. However, there are many challenges in establishing guidelines regarding the economic efficiency of CABG. The present guideline document summarizes standard economic efficiency of CABG mainly based on public data to provide issues to be considered in the future.

\section{Challenges in Establishing Guidelines Regarding the Economic Efficiency of CABG}

\section{Differences Among Countries}

Published reports that offer the highest level of evidence (such as multicenter randomized clinical studies comparing $\mathrm{CABG}$ and PCI in Western countries) are limited in terms of comparison of economic efficiency of the two procedures in Japan, because there are substantial differences between Western countries and Japan in health insurance system, prices of medical services, drugs and devices, and presence/absence of doctor's fee (surgeon's fee), among other factors.

\section{Two Systems in One Country}

As of 2005, there are two healthcare fee systems, i.e., the diagnosis procedure combination (DPC) system and the fee-forservice system in Japan. The DPC system is used in 82 advanced treatment hospitals and a small number of hospitals using the system as a trial. Because the economic efficiency of CABG differs between the two systems and cannot be described uniformly, this guideline document mainly describes the data of CABG conducted using the DPC system.

\section{Rapid Cycle Change}

In Japan, the National Health Insurance (NHI) prices are revised every other year. It is highly likely that the data described in this document will be significantly affected by the revision in 2006. As in the rapid advancement of devices used in PCI, the type, price and positioning of devices used for cardiac interventional procedures change in a very short period of time. On the other hand, the techniques of $\mathrm{CABG}$ have changed relatively slowly as compared with those of PCI, and cases of OPCAB account for more than $60 \%$ of all CABG cases in 2004. Currently available data are suitable for comparing economic efficiency of CCAB and OPCAB.

\section{Limited Data}

Unfortunately, data on the effects of DES (introduced in September 2004), which are essential in the discussion of the economic efficiency of CABG as compared with PCI, have not been published as formal data in Japan. Also, there are no sufficient data comparing economic efficiency of CABG and PCI between advance treatment hospitals and other hospitals. In this document, data accumulated and analyzed by a private research institute are partly provided.

\section{Health Economic Analysis of CABG in Japan: National Data on DPC}

In 2003, a study group on the use of the DPC combination system in acute-phase hospital treatment analyzed data on CABG throughout Japan. The mean total duration of hospitalization was 35.2 \pm 19.9 days (median 29 days; coefficient of variance 0.56 ), and consisted of $11.2 \pm 11.2$ days (median 7 days) before CABG and 23.2 \pm 14.7 days (median 19 days) after $\mathrm{CABG}$. The duration of hospitalization before CABG varied widely.

The average fee for hospital services, which was converted to the price based on the fee-for-service system, was $3,494,900 \pm 1,592,000$ yen (median 3,310,000 yen; coefficient of variance 0.46 ).

\section{Comparison Between Conventional On-Pump and Off-Pump CABG}

\section{1) Duration of Hospitalization}

The mean total duration of hospitalization was $34.2 \pm 20.1$ days and 36.7 \pm 19.6 days for OPCAB and $\mathrm{CCAB}$, respectively $(\mathrm{P}=0.01)$. The mean durations of hospitalization before $\mathrm{CABG}$ in the corresponding groups were $11.1 \pm 11.3$ days and 10.9 \pm

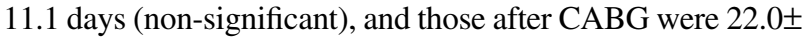
14.8 days and $25.0 \pm 14.5$ days $(\mathrm{P}<0.001)$. The duration of hospitalization after CABG was significantly shorter in OPCAB.

\section{2) Total Billing Amount}

The mean total billing amount was $3,100,000 \pm 1,140,000$ yen for OPCAB and 4,100,000 $\pm 1,960,000$ yen for $\mathrm{CCAB}(\mathrm{P}<0.001)$. The fee for OPCAB was significantly lower than that of $\mathrm{CCAB}$, and the difference was about 1,000,000 yen.

Although this finding represents the superior economic efficiency of OPCAB, the fee for services by physicians and hospitals, which is listed as the fee "surgery and others (technical fee)" in the NHI price listing, is set with an addition of $30 \%$ for OPCAB, but is unreasonably lower than $\mathrm{CCAB}$ by $\geq 200,000$ yen.

\section{Problems in Technical Fees}

The technical fee for CCAB is 487,000 yen for a single-graft procedure, and 813,000 yen for a multiple-graft procedure, while the technical fee listed as the " $30 \%$ addition" in OPCAB is 146,100 yen and 243,900 yen for a single- and multiplegraft procedures, respectively.

When OPCAB is conducted instead of $\mathrm{CCAB}$, the total billing fee does not include 255,000 yen for the technical fee for the use of cardiopulmonary bypass, and a $200 \%$ addition for cardiac anesthesia using cardiopulmonary bypass and hypothermia. The technical fee for the use of cardiopulmonary bypass is larger than the $30 \%$ addition for OPCAB.

\section{Problems on the Use of Medical Materials}

Although OPCAB, a technique not using expensive devices for cardiopulmonary bypass devices, greatly contributes to the reduction of healthcare cost, hospitals have almost no incentive to conduct OPCAB even in the DPC system era because devices for cardiopulmonary bypass used in on-pump techniques are classified as "special treatment materials" and may be added to the bill on the fee-for-service basis. Hospitals gain additional income from the difference between the NHI price and the purchase (market) price of such devices to supplement insufficient technical fees. CCAB in the era of OPCAB may be performed for financial reasons.

It has been suggested that single-use-devices for OPCAB are often reused. 


\section{Technical Innovations}

\section{Automatic Anastomotic Devices ${ }^{619-621}$}

\section{[Class IIb (Class III for Some Recommendations), Level of Evidence: $\mathrm{C}$ ]}

Automatic anastomotic devices currently available in Japan are limited to devices for proximal anastomosis of the SVG, and are classified into fully-automatic and semi-automatic anastomotic devices.

\section{Automatic Proximal Anastomotic Devices}

Automatic proximal anastomotic devices have been developed to ensure reliable anastomosis in a short period of time and decrease the incidence of cerebral infarction caused by clamping such as partial occlusion of the ascending aorta.

\section{Automatic Distal Anastomotic Devices}

Regarding automatic distal anastomotic devices, the MVP system and the St. Jude Medical ATG coronary connector system (St. Jude Medical, Inc., St. Paul, MN) are currently under clinical investigation. Only small-scale clinical studies have been conducted at this time.

\section{Robotic Surgery $622-626$}

[Class III, Level of Evidence: C] Surgery-assisting robots are classified into two types: One is endoscopic surgical robots such as AESOP (Intuitive Surgical, Inc., Sunnyvale, CA), and another one is surgical robots with a master-slave system such as da Vinci Surgical System (Intuitive Surgical, Inc., Sunnyvale, CA).

\section{Introduction of Robotically-Assisted Internal Thoracic Artery Harvesting}

There have been reports on robotic ITA harvesting during offpump procedures using conventional endoscopic devices and endoscopic surgical robots or using robotic forceps controlled with a master-slave surgical robot system.

\section{Introduction of Robotically-Assisted Anastomosis}

There have been reports on the use of a master-slave surgical robot system in anastomosis during on-pump and off-pump procedures.

Robotically-assisted CABG is still under development due to the difficulty in robotically-assisted anastomosis. Stabilizers and other devices to facilitate anastomosis have been developed. The indications for robotically-assisted CABG (e.g., onevessel vs. multivessel disease, or on-pump vs. off-pump procedure) have not been defined yet. It is expected that further innovations will define the indications and increase the use of these techniques.

\section{Awake Off-Pump CABG}

[Class III, Level of Evidence C] The first case of awake OPCAB in the awake spontaneously breathing patient under high thoracic epidural anesthesia (TEA) was reported in $2000 .^{627}$ It is believed that awake OPCAB helps ensure early ambulation and discharge, and that it provides an environment suitable for anastomosis in off-pump procedures because TEA decreases heart rate and ensures sufficient coronary blood flow, which helps prevent arrhythmias.

\section{Indications for Awake Off-Pump CABG}

When awake OPCAB was first reported, the technique was used only for the treatment of one-vessel disease involving the LAD artery or two-vessel disease involving the RCA.

The usefulness of awake OPCAB remains established due to the limited number of cases reported to date. However, this technique is expected to be beneficial because TEA may dilate coronary arteries and prevent arrhythmias, and intubation and general anesthesia may be avoided. When further studies are conducted and safer and more reliable awake OPCAB techniques are establsihed, physicians will be able to perform less invasive $\mathrm{CABG}$.

\section{Transmyocardial Laser Revascularization}

[Class IIa, Level of Evidence: A] Transmyocardial laser revascularization (TMLR) using $\mathrm{CO}_{2}$ laser is a technique to establish blood flow to ischemic myocardium by irradiating high-energy laser from the epicardium to the endocardium to create new channels between the left ventricular cavity and ischemic myocardium. It is believed that TMLR promotes angiogenesis as a result of a mechanism of repair.

\section{Indications}

TMLR is best indicated for patients with drug-resistant angina in whom revascularization procedures such as PCI and CABG are not feasible. ${ }^{628-634}$

\section{Lasers Used for TMLR}

Currently, TMLR is performed using a $\mathrm{CO}_{2}$ laser system (Heart Laser ${ }^{\mathrm{TM}}$ kit, PLC Medical Systems, Inc., Milford, MA) and a Holmium (Ho:) YAG laser (Eclipse ${ }^{\mathrm{TM}}$, CardioGenesis Corporation, Sunnyvale, CA). The use and effects differ between the two lasers that differ in wavelength and energy characteristics. $\mathrm{CO}_{2}$ laser, which has energy per pulse larger than Ho: YAG laser, can penetrate into the target myocardium in one pulse. On the other hand, Ho: YAG laser has a photoacoustic effect more potent than $\mathrm{CO}_{2}$ laser, and can block the afferent network of sympathetic fibers more effectively than $\mathrm{CO}_{2}$ laser. ${ }^{635}$

\section{Risk Factors for Poor Outcome After TMLR}

Outcome after TMLR depends on the presence/absence of (1) unstable angina, (2) global myocardial ischemia, and (3) left ventricular dysfunction.

The benefits of TMLR have been demonstrated in many prospective randomized clinical studies, and guidelines for the use of TMLR have been published. It is expected that the use of TMLR in combination with less invasive surgery such as OPCAB, cell transplantation therapy and neovascularization therapy will be proven to be effective in the future. 


\section{References}

1. Guidelines for the Diagnosis and Treatment of Cardiovascular Diseases (2004-2005 Joint Working Groups Report). Guidelines for the Clinical Application of Bypass Grafts and the Surgical Techniques (JCS 2006). Circ J 2006; 70(Suppl IV): 1477-1553 (in Japanese).

2. Guidelines for the Diagnosis and Treatment of Cardiovascular Diseases (1998-1999 Joint Working Groups Report). Guidelines on Indications of Elective Intervention (including CABG) in the Treatment of Coronary Artery Disease. Jpn Circ J 2000; 64(Suppl IV): 1009-1022 (in Japanese).

3. Wijns W, Kolh P, Danchin N, Di Mario C, Falk V, Folliguet T, et al; Task Force on Myocardial Revascularization of the European Society of Cardiology (ESC) and the European Association for Cardio-Thoracic Surgery (EACTS); European Association for Percutaneous Cardiovascular Interventions (EAPCI). Guidelines on myocardial revascularization. Eur Heart J 2010; 31: 2501-2555.

4. Katritsis DG, Ioannidis JP. Percutaneous coronary intervention versus conservative therapy in nonacute coronay artery disease: A metaanalysis. Circulation 2005; 111: 2906-2912.

5. Boden WE, O'Rourke RA, Teo KK, Hartigan PM, Maron DJ, Kostuk WJ, et al; COURAGE Trial Research Group. Optimal medical therapy with or without PCI for stable coronary disease. $N$ Engl J Med 2007; 356: 1503-1516.

6. BARI 2D Study Group, Frye RL, August P, Brooks MM, Hardison $\mathrm{RM}$, Kelsey SF, et al. A randomized trial of therapies for type 2 diabetes and coronary artery disease. $N$ Engl J Med 2009; 360: $2503-2515$.

7. Chaitman BR, Hardison RM, Adler D, Gebhart S, Grogan M, Ocampo S, et al; Bypass Angioplasty Revascularization Investigation 2 Diabetes (BARI 2D) Study Group. The Bypass Angioplasty Revascularization Investigation 2 Diabetes randomized trial of different treatment strategies in type 2 diabetes mellitus with stable ischemic heart disease: Impact of treatment strategy on cardiac mortality and myocardial infarction. Circulation 2009; 120: 2529-2540.

8. Weintraub WS, Spertus JA, Kolm P, Maron DJ, Zhang Z, Jurkovitz C, et al; COURAGE Trial Research Group. Effect of PCI on quality of life in patients with stable coronary disease. $N$ Engl $\mathrm{J}$ Med 2008; 359: 677-687.

9. Nishigaki K, Yamazaki T, Kitabatake A, Yamaguchi T, Kanmatsuse K, Kodama I, et al; Japanese Stable Angina Pectoris Study Investigators. Percutaneous coronary intervention plus medical therapy reduces the incidence of acute coronary syndrome more effectively than initial medical therapy only among patients with low-risk coronary artery disease: A randomized, comparative, multicenter study. JACC Cardiovasc Interv 2008; 1: 469-479.

10. Kirtane AJ, Gupta A, Iyengar S, Moses JW, Leon MB, Applegate $\mathrm{R}$, et al. Safety and efficacy of drug-eluting and bare metal stents: Comprehensive meta-analysis of randomized trials and observational studies. Circulation 2009; 119: 3198-3206.

11. Trikalinos TA, Alsheikh-Ali AA, Tatsioni A, Nallamothu BK, Kent DM. Percutaneous coronary interventions for non-acute coronary artery disease: A quantitative 20-year synopsis and a network metaanalysis. Lancet 2009; 373: 911-918.

12. Yusuf S, Zucker D, Peduzzi P, Fisher LD, Takaro T, Kennedy JW, et al. Effect of coronary artery bypass graft surgery on survival: Overview of 10-year results from randomized trials by the Coronary Artery Bypass Graft Surgery Trialists Collaboration. Lancet 1994; 344: 563-570.

13. Cameron A, Davis KB, Green G, Schaff HV. Coronary bypass surgery with internal-thoracic-artery grafts--effects on survival over a 15-year period. $N$ Engl J Med 1996; 334: 216-219.

14. Taggart DP, D'Amico R, Altman DG. Effect of arterial revascularisation on survival: A systematic review of studies comparing bilateral and single internal mammary arteries. Lancet 2001; 358: $870-875$.

15. Hueb W, Lopes NH, Gersh BJ, Soares P, Machado LA, Jatene FB, et al. Five-year follow-up of the Medicine, Angioplasty, or Surgery Study (MASS II): A randomized controlled clinical trial of 3 therapeutic strategies for multivessel coronary artery disease. Circulation 2007; 115: 1082-1089.

16. Hueb W, Lopes N, Gersh BJ, Soares PR, Ribeiro EE, Pereira AC, et al. Ten-year follow-up survival of the Medicine, Angioplasty, or Surgery Study (MASS II): A randomized controlled clinical trial of 3 therapeutic strategies for multivessel coronary artery disease. Circulation 2010; 122: 949-957.

17. Brooks MM, Chung SC, Helmy T, Hillegass WB, Escobedo J, Melsop KA, et al; Bypass Angioplasty Revascularization Investigation 2 Diabetes (BARI 2D) Study Group. Health status after treatment for coronary artery disease and type 2 diabetes mellitus in the
Bypass Angioplasty Revascularization Investigation 2 Diabetes trial. Circulation 2010; 122: 1690-1699.

18. Gersh BJ, Frye RL. Methods of coronary revascularization--things may not be as they seem. $N$ Engl J Med 2005; 352: 2235-2237.

19. Serruys PW, Morice MC, Kappetein AP, Colombo A, Holmes DR, Mack MJ, et al; SYNTAX Investigators. Percutaneous coronary intervention versus coronary-artery bypass grafting for severe coronary artery disease. $N$ Engl J Med 2009; 360: $961-972$.

20. Kappetein AP, Feldman TE, Mack MJ, Morice MC, Holmes DR, Ståhle E, et al. Comparison of coronary bypass surgery with drugeluting stenting for the treatment of left main and/or three-vessel disease: 3-year follow-up of the SYNTAX trial. Eur Heart J 2011; 32: $2125-2134$

21. Hlatky MA, Boothroyd DB, Bravata DM, Boersma E, Booth J, Brooks MM, et al. Coronary artery bypass surgery compared with percutaneous coronary interventions for multivessel disease: A collaborative analysis of individual patient data from ten randomised trials. Lancet 2009; 373: 1190-1197.

22. Kimura T, Morimoto T, Furukawa Y, Nakagawa Y, Shizuta S, Ehara $\mathrm{N}$, et al. Long-term outcomes of coronary-artery bypass graft surgery versus percutaneous coronary intervention for multivessel coronary artery disease in the bare-metal stent era. Circulation 2008; 118(14 Suppl): S199-S209.

23. Hannan EL, Wu C, Walford G, Culliford AT, Gold JP, Smith CR, et al. Drug-eluting stents vs. coronary-artery bypass grafting in multivessel coronary disease. $N$ Engl J Med 2008; 358: 331-341.

24. Marui A, Kimura T, Tanaka S, Furukawa Y, Kita T, Sakata R; CREDO-Kyoto Investigators. Siginificance of off-pump coronary artery bypass grafting compared with percutaneous coronary intervention: A propensity score analysis. Eur J Cardiothorac Surg 2012; 41: $94-101$

25. Park SJ, Kim YH, Park DW, Yun SC, Ahn JM, Song HG, et al. Randomized trial of stents versus bypass surgery for left main coronary artery disease. $N$ Engl J Med 2011; 364: 1718-1727.

26. Patel MR, Dehmer GJ, Hirshfeld JW, Smith PK, Spertus JA. ACCF/ SCAI/STS/AATS/AHA/ASNC 2009 Appropriateness Criteria for Coronary Revascularization: A Report of the American College of Cardiology Foundation Appropriateness Criteria Task Force, Society for Cardiovascular Angiography and Interventions, Society of Thoracic Surgeons, American Association for Thoracic Surgery, American Heart Association, and the American Society of Nuclear Cardiology: Endorsed by the American Society of Echocardiography, the Heart Failure Society of America, and the Society of Cardiovascular Computed Tomography. Circulation 2009; 119: 1330 1352.

27. Kushner FG, Hand M, Smith SC Jr, King SB 3rd, Anderson JL, Antman EM, et al; American College of Cardiology Foundation/ American Heart Association Task Force on Practice Guidelines. 2009 Focused Updates: ACC/AHA Guidelines for the Management of Patients With ST-Elevation Myocardial Infarction (updating the 2004 Guideline and 2007 Focused Update) and ACC/AHA/SCAI Guidelines on Percutaneous Coronary Intervention (updating the 2005 Guideline and 2007 Focused Update): A report of the American College of Cardiology Foundation/American Heart Association Task Force on Practice Guidelines. Circulation 2009; 120: 2271 2306

28. Toyofuku M, Kimura T, Morimoto T, Hayashi Y, Ueda H, Kawai $\mathrm{K}$, et al; j-Cypher Registry Investigators. Three-year outcomes after sirolimus-eluting stent implantation for unprotected left main coronary artery disease: Insights from the j-Cypher registry. Circulation 2009; 120: 1866-1874.

29. Sakata R, Fujii Y, Kuwano H. Thoracic and cardiovascular surgery in Japan during 2008: Annual report by The Japanese Association for Thoracic Surgery. Gen Thorac Cardiovasc Surg 2010; 58: $356-383$.

30. Sezai Y. Coronary artery surgery: Current practice in Japan. National questionnaire survey for coronary artery surgery in 2010 . Presented at the 16th Annual Meeting of the Japanese Association for Coronary Artery Surgery, Matsumoto, Japan. 14-15th, July, 2011 (in Japanese).

31. Japan Adult Cardiovascular Surgery Database. http://www.jacvsd. umin.jp/top.html (in Japanese).

32. Motomura N, Miyata H, Tsukihara H, Okada M, Takamoto S; Japan Cardiovascular Surgery Database Organization. First report on 30day and operative mortality in risk model of isolated coronary artery bypass grafting in Japan. Ann Thorac Surg 2008; 86: 18661872.

33. Khan NE, De Souza A, Mister R, Flather M, Clague J, Davies S, et al. A randomized comparison of off-pump and on-pump multivessel coronary-artery bypass surgery. N Engl J Med 2004; 350: 
$21-28$.

34. Shroyer AL, Grover FL, Hattler B, Collins JF, McDonald GO, Kozora E, et al; Veterans Affairs Randomized On/Off Bypass (ROOBY) Study Group. On-pump versus off-pump coronary-artery bypass surgery. $N$ Engl J Med 2009; 361: 1827-1837.

35. Hueb W, Lopes NH, Pereira AC, Hueb AC, Soares PR, Favarato D, et al. Five-year follow-up of a randomized comparison between off-pump and on-pump stable multivessel coronary artery bypass grafting: The MASS III Trial. Circulation 2010; 122(11 Suppl): S48-S52.

36. Puskas JD, Williams WH, Mahoney EM, Huber PR, Block PC, Duke PG, et al. Off-pump vs conventional coronary artery bypass grafting: Early and 1-year graft patency, cost, and quality-of-life outcomes: A randomized trial. JAMA 2004; 291: 1841-1849.

37. Puskas JD, Williams WH, O’Donnell R, Patterson RE, Sigman SR, Smith AS, et al. Off-pump and on-pump coronary artery bypass grafting are associated with similar graft patency, myocardial ischemia, and freedom from reintervention: Long-term follow-up of a randomized trial. Ann Thorac Surg 2011; 91: 1836-1842; discussion $1842-1843$.

38. Kuss O, von Salviati B, Börgermann J. Off-pump versus on-pump coronary artery bypass grafting: A systematic review and metaanalysis of propensity score analyses. J Thorac Cardiovasc Surg 2010; 140: 829-835. 835. e1-e13.

39. Wijeysundera DN, Beattie WS, Djaiani G, Rao V, Borger MA, Karkouti K, et al. Off-pump coronary artery surgery for reducing mortality and morbidity: Meta-analysis of randomized and observational studies. J Am Coll Cardiol 2005; 46: 872-882.

40. Bridgewater B, Gummert J, Kinsman R, Walton P, editors. Towards global benchmarking: The fourth EACTS adult cardiac surgical database report, 4th edn. Oxfordshire: Dendrite Clinical Systems Ltd., 2010.

41. Calafiore AM, Di Mauro M, Contini M, Di Giammarco G, Pano M, Vitolla G, et al. Myocardial revascularization with and without cardiopulmonary bypass in multivessl disease; impact of the strategy on early outcome. Ann Thorac Surg 2001; 72: 456-462; discussion $462-463$.

42. Angelini GD, Culliford L, Smith DK, Hamilton MC, Murphy GJ, Ascione R, et al. Effects of on- and off-pump coronary artery surgery on graft patency, survival, and health-related quality of life: Long-term follow-up of 2 randomized controlled trials. J Thorac Cardiovasc Surg 2009; 137: 295-303.

43. Kouchoukos NT, Wareing TH, Murphy SF, Pelate C, Marshall WG Jr. Risks of bilateral internal mammary artery bypass grafting. Ann Thorac Surg 1990; 49: 210-217; discussion 217-219.

44. Beuer AC, Furlan AJ, Hanson MR, Lederman RJ, Loop FD, Cosgrove DM, et al. Central nervous system complications of coronary artery bypass graft surgery: Prospective analysis of $421 \mathrm{pa}-$ tients. Stroke 1983; 14: 682-687.

45. Shahian DM, O'Brien SM, Filardo G, Ferraris VA, Haan CK, Rich JB, et al; Society of Thoracic Surgeons Quality Measurement Task Force. The Society of Thoracic Surgeons 2008 cardiac surgery risk models: Part 1--coronary artery bypass grafting surgery. Ann Thorac Surg 2009; 88(1 Suppl): S2-S22.

46. Kappetein AP, SYNTAX investigators. Optimal revascularization strategy in patients with three-vessel disease and/or left main disease. The 3-year outcomes of the SYNTAX trial. Presented at the 24th EACTS annual meeting, Geneva, Switzerland. 11-15th, Sep 2010.

47. Roach GW, Kanchuger M, Mangano CM, Newman M, Nussmeier $\mathrm{N}$, Wolman R, et al. Adverse cerebral outcomes after coronary bypass surgery: Multicenter Study of Perioperative Ischemia Research Group and the Ischemia Research and Education Foundation Investigators. N Engl J Med 1996; 335: 1857-1863.

48. Gardner TJ, Horneffer PJ, Manolio TA, Pearson TA, Gott VL, Baumgartner WA, et al. Stroke following coronary artery bypass grafting: A ten-year study. Ann Thorac Surg 1985; 40: 574-581.

49. van der Linden J, Hadjinikolaou L, Bergman P, Lindblom D. Postoperative stroke in cardiac surgery is related to the location and extent of atherosclerotic disease in the ascending aorta. $\mathrm{J} \mathrm{Am} \mathrm{Coll}$ Cardiol 2001; 38: 131-135.

50. Kobayashi J, Tashiro T, Ochi M, Yaku H, Watanabe G, Satoh T, et al; Japanese Off-Pump Coronary Revascularization Investigation (JOCRI) Study Group. Early outcome of a randomized comparison of off -pump and on-pump multiple arterial coronary revascularization. Circulation 2005; 112(9 Suppl): I338-I343.

51. Athanasiou T, Al-Ruzzeh S, Kumar P, Crossman MC, Amrani M, Pepper JR, et al. Off-pump myocardial revascularization is associated with less incidence of stroke in elderly patients. Ann Thorac Surg 2004; 77: 745-753.
52. Sharony R, Grossi EA, Saunders PC, Galloway AC, Applebaum R, Ribakove GH, et al. Propensity case-matched analysis of off-pump coronary artery bypass grafting in patients with atheromatous aortic disease. J Thorac Cardiovasc Surg 2004; 127: 406-413.

53. Lev-Ran O, Braunstein R, Sharony R, Kramer A, Paz Y, Mohr R, et al. No-touch aorta off-pump coronary surgery: The effect on stroke. J Thorac Cardiovasc Surg 2005; 129: 307-313.

54. Puskas JD, Stringer A, Hwang SN, Hatfield B, Smith AS, Kilgo PD, et al. Neurocognitive and neuroanatomic changes after off-pump versus on-pump coronary artery bypass grafting: Long-term followup of a randomized trial. J Thorac Cardiovasc Surg 2011; 141: $1116-1127$.

55. Kurlansky PA. Is there a hypercoagulable state after off-pump coronary artery bypass surgery? What do we know and what can we do? J Thorac Cardiovasc Surg 2003; 126: 7-10.

56. Filsoufi F, Castillo JG, Rahmanian PB, Broumand SR, Silvay G, Carpentier A, et al. Epidemiology of deep sternal wound infection in cardiac surgery. J Cardiothorac Vasc Anesth 2009; 23: 488-494.

57. Ståhle E, Tammelin A, Bergström R, Hambreus A, Nyström SO, Hansson HE. Sternal wound complications--incidence, microbiology and risk factors. Eur J Cardiothorac Surg 1997; 11: 11461153.

58. Ariyaratnam P, Bland M, Loubani M. Risk factors and mortality associated with deep sternal wound infections following coronary bypass surgery with or without concomitant procedures in a UK population: A basis for a new risk model? Int CardioVasc Thorac Surg 2010; 11: 543-546.

59. Medalion B, Katz MG, Lorberboym M, Bder O, Schachner A, Cohen AJ. Decreased sternal vascularity after internal thoracic artery harvesting resolves with time: an assessment with single photon emission computed tomography. J Thorac Cardiovasc Surg 2002; 123: $508-511$.

60. Peterson MD, Borger MA, Rao V, Peniston CM, Feindel CM. Skeletonization of bilateral internal thoracic artery grafts lowers the risk of sternal infection in patients with diabetes. J Thorac Cardiovasc Surg 2003; 126: 1314-1319.

61. De Paulis R, de Notaris S, Scaffa R, Nardella S, Zeitani J, Del Giudice $\mathrm{C}$, et al. The effect of bilateral internal thoracic artery harvesting on superficial and deep sternal infection: The role of skeletonization. J Thorac Cardiovasc Surg 2005; 129: 536-543.

62. Kamiya H, Akhyari P, Martens A, Karck M, Haverich A, Lichtenberg A. Sternal microcirculation after skeletonized versus pedicled harvesting of the internal thoracic artery: A randomized study. $J$ Thorac Cardiovasc Surg 2008; 135: 32-37.

63. Nakano J, Okabayashi H, Hanyu M, Soga Y, Nomoto T, Arai Y, et al. Risk factors for wound infection after off-pump coronary artery bypass grafting: Should bilateral internal thoracic arteries be harvested in patients with diabetes? J Thorac Cardiovasc Surg 2008; 135: $540-545$.

64. Saso S, James D, Vecht JA, Kidher E, Kokotsakis J, Malinovski V, et al. Effect of skeletonization of the internal thoracic artery for coronary revascularization on the incidence of sternal wound infection. Ann Thorac Surg 2010; 89: 661-670.

65. Kinoshita T, Asai T, Nishimura O, Suzuki T, Kambara A, Matsubayashi K. Off-Pump bilateral versus single skeletonized internal thoracic artery grafting in patients with diabetes. Ann Thorac Surg 2010; 90: 1173-1179.

66. Gansera B, Schmidtler F, Gillrath G, Angelis I, Wenke K, Weingartner J, et al. Does bilateral ITA grafting increase perioperative complications? Outcome of 4462 patients with bilateral versus 4204 patients with single ITA bypass. Eur J Cardiothorac Surg 2006; 30: 318-323.

67. Toumpoulis IK, Theakos N, Dunning J. Does bilateral internal thoracic artery harvest increase the risk of mediastinitis? Interactive CardioVasc thoracic Surg 2007; 6: 787-791.

68. Bhamidipati CM, LaPar DJ, Stukenborg GJ, Morrison CC, Kern JA, Kron IL, et al. Superiority of moderate control of hyperglycemia to tight control in patients undergoing coronary artery bypass grafting. J Thorac Cardiovasc Surg 2011; 141: 543-551.

69. Lazar HL, McDonnell M, Chipkin SR, Furnary AP, Engelman RM, Sadhu AR, et al; Society of Thoracic Surgeons Blood Glucose Guideline Task Force. The Society of Thoracic Surgeons practice guideline series: Blood glucose management during adult cardiac surgery. Ann Thorac Surg 2009; 87: 663-669.

70. Mangano CM, Diamondstone LS, Ramsey JG, Aggarwal A, Herskowitz A, Mangano DT. Renal dysfunction after myocardial revascularization: Risk factors, adverse outcomes, and hospital resource utilization: The Multicenter Study of Perioperative Ischemia Research Group. Ann Intern Med 1998; 128: 194-203.

71. Cooper WA, O'Brien SM, Thourani VH, Guyton RA, Bridges CR, 
Szczech LA, et al. Impact of renal dysfunction on outcomes of coronary artery bypass surgery: Results from the Society of Thoracic Surgeons National Adult Cardiac Database. Circulation 2006; 113: $1063-1070$.

72. Yu HY, Li JY, Sun S, Hung KY, Wang JL, Chen YS, et al. Late dialysis rate for coronary artery bypass grafting patients with moderate-to-severe renal impairment: Comparison between off-pump and conventional method. Eur J Cardiothorac Surg 2008; 33: 364-369.

73. Di Mauro M, Gagliardi M, Iacò AL, Contini M, Bivona A, Bosco $\mathrm{P}$, et al. Does off-pump coronary surgery reduce postoperative acute renal failure? The importance of preoperative renal function. Ann Thorac Surg 2007; 84: 1496-1502.

74. Asimakopoulos G, Karagounis AP, Valencia O, Alexander N, Howlader M, Sarsam MA, et al. Renal function after cardiac surgery off- versus on-pump coronary artery bypass: Analysis using the Cockroft-Gault formula for estimating creatinine clearance. Ann Thorac Surg 2005; 79: 2024-2031.

75. Sajja LR, Mannam G, Chakravarthi RM, Sompalli S, Naidu SK, Somaraju B, et al. Coronary artery bypass grafting with or without cardiopulmonary bypass in patients with preoperative non-dialysis dependent renal insufficiency: A randomized study. J Thorac Cardiovasc Surg 2007; 133: 378-388.

76. Shroff GR, Li S, Herzog CA. Survival of patients on dialysis having off-pump versus on-pump coronary artery bypass surgery in the United States. J Thorac Cardiovasc Surg 2010; 139: 1333-1338.

77. Lytle BW, Blackstone EH, Loop FD, Houghtaling PL, Arnold JH, Akhrass R, et al. Two internal thoracic artery grafts are better than one. J Thorac Cardiovasc Surg 1999; 117: 855-872.

78. Zacharias A, Schwann TA, Riordan CJ, Durham SJ, Shah AS, Habib RH. Late results of conventional versus all-arterial revascularization based on internal thoracic and radial artery grafting. Ann Thorac Surg 2009; 87: 19-26. e2.

79. Tatoulis J, Buxton BF, Fuller JA, Meswani M, Theodore S, Powar $\mathrm{N}$, et al. Long-term patency of 1108 radial arterial-coronary angiograms over 10 years. Ann Thorac Surg 2009; 88: 23-29; discussion $29-30$.

80. Lytle BW, Blackstone EH, Sabik JF, Houghtaling P, Loop FD, Cosgrove DM. The effect of bilateral internal thoracic artery grafting on survival during 20 postoperative years. Ann Thorac Surg 2004; 78: 2005-2012; discussion 2012-2014.

81. Veeger NJ, Panday GF, Voors AA, Grandjean JG, van der Meer J, Boonstra PW. Excellent long-term clinical outcome after coronary artery bypass surgery using three pedicled arterial grafts in patients with three-vessel disease. Ann Thorac Surg 2008; 85: 508-512.

82. Kim WS, Lee J, Lee YT, Sung K, Yang JH, Jun TG, et al. Total arterial revascularization in triple-vessel disease with off-pump and aortic no-touch technique. Ann Thorac Surg 2008; 86: 1861 - 1865.

83. Li Y, Zheng Z, Hu S. Early and long-term outcomes in the elderly: Comparison between off-pump and on-pump techniques in 1191 patients undergoing coronary artery bypass grafting. J Thorac Cardiovasc Surg 2008; 136: 657-664.

84. Synnergren MJ, Ekroth R, Odén A, Rexius H, Wiklund L. Incomplete revascularization reduces survival benefit of coronary artery bypass grafting: Role of off-pump surgery. J Thorac Cardiovasc Surg 2008; 136: 29-36.

85. Booth J, Clayton T, Pepper J, Nugara F, Flather M, Sigwart U, et al; SoS Investigators. Randomized, controlled trial of coronary artery bypass surgery versus percutaneous coronary intervention in patients with multivessel coronary artery disease: Six-year followup from the Stent or Surgery Trial (SoS). Circulation 2008; 118: $381-388$.

86. Jokinen JJ, Werkkala K, Vainikka T, Peräkylä T, Simpanen J, Ihlberg L. Clinical value of intra-operative transit-time flow measurement for coronary artery bypass grafting: A prospective angiographycontrolled study. Eur J Cardiothorac Surg 2011; 39: 918-923.

87. Di Giammarco G, Pano M, Cirmeni S, Pelini P, Vitolla G, Di Mauro M. Predictive value of intraoperative transit-time flow measurement for short-term graft patency in coronary surgery. $J$ Thorac Cardiovasc Surg 2006; 132: 468-474.

88. Lytle BW, Loop FD, Cosgrove DM, Ratliff NB, Easley K, Taylor PC. Long-term (5 to 12 years) serial studies of internal mammary artery and saphenous vein coronary bypass grafts. $J$ Thorac Cardiovasc Surg 1985; 89: 248-258.

89. Loop FD, Lytle BW, Cosgrove DM, Stewart RW, Goormastic M, Williams GW, et al. Influence of the internal-mammary-artery graft on 10-year survival and other cardiac events. N Engl J Med 1986; 314: $1-6$.

90. Boylan MJ, Lytle BW, Loop FD, Taylor PC, Borsh JA, Goormastic $\mathrm{M}$, et al. Surgical treatment of isolated left anterior descending coro- nary stenosis: Comparison of the left internal mammary artery and venous autograft at 18 to 20 years of follow-up. J Thorac Cardiovasc Surg 1994; 107: 657-662.

91. Kitamura S, Kawachi K, Taniguchi S, Kawata T, Kobayashi S, Nishioka $\mathrm{H}$, et al. Long-term benefits of internal thoracic arterycoronary artery bypass in Japanese patients. Jpn J Thorac Cardiovasc Surg 1998; 46: 1-10.

92. Cameron AA, Green GE, Brogno DA, Thornton J. Internal thoracic artery grafts: 20-year clinical follow-up. J Am Coll Cardiol 1995; 25: $188-192$.

93. Zeff RH, Kongtahworn C, Iannone LA, Gordon DF, Brown TM, Phillips SJ, et al. Internal mammary artery versus saphenous vein graft to the left anterior descending coronary artery: Prospective randomized study with 10-year follow-up. Ann Thorac Surg 1988; 45: $533-536$.

94. Dabel RJ, Goss JR, Maynard C, Aldea GS. The effect of left internal mammary artery utilization on short-term outcomes after coronary revascularization. Ann Thorac Surg 2003; 76: 464-470.

95. Grover FL, Johnson RR, Marshall G, Hammermeister KE. Impact of mammary grafts on coronary bypass operative mortality and morbidity: Department of Veterans Affairs Cardiac Surgeons. Ann Thorac Surg 1994; 57: 559-568; discussion 568-569.

96. Shah PJ, Durairaj M, Gordon I, Fuller J, Rosalion A, Seevanayagam $\mathrm{S}$, et al. Factors affecting patency of internal thoracic artery graft: Clinical and angiographic study in 1434 symptomatic patients operated between 1982 and 2002. Eur J Cardiothoracic Surg 2004; 26: $118-124$

97. Shah PJ, Bui K, Blackmore S, Gordon I, Hare DL, Fuller J, et al. Has the in situ right internal thoracic artery been overlooked? An angiographic study of the radial artery, internal thoracic arteries and saphenous vein graft patencies in symptomatic patients. Eur J Cardiothoracic Surg 2005; 27: 870-875.

98. Kawata T, Taniguchi S, Nishioka H, Kobayashi S, Mizuguchi K, Kameda Y, et al. Benefits accruing to grafting of the right internal thoracic artery to the left anterior descending artery in coronary artery bypass grafting. Jpn J Thorac Cardiovasc Surg 1999; 47: 388-393.

99. Mert M, Yildiz CE, Arat-Ozkan A, Bakir I, Bakay C. Mid to longterm results of circumflex coronary artery revascularization with left internal thoracic artery grafts. Jpn Heart J 2004; 45: 23-30.

100. Higami T, Yamashita T, Nohara H, Iwahashi K, Shida T, Ogawa K. Early results of coronary grafting using ultrasonically skeletonized internal thoracic arteries. Ann Thorac Surg 2001; 71: 1224-1228.

101. Gaudino M, Toesca A, Glieca F, Girola F, Luciani N, Possati G. Skeletonization does not influence internal thoracic artery innervation. Ann Thorac Surg 2004; 77: 1257-1261.

102. Wendler O, Tscholl D, Huang Q, Schäfers HJ. Flee flow capacity of skeletonized versus pedicled internal thoracic artery grafts in coronary artery bypass grafts. Eur J Cardiothorac Surg 1999; 15: $247-250$.

103. Higami T, Maruo A, Yamashita T, Shida T, Ogawa K. Histologic and physiologic evaluation of skeletonized internal thoracic artery harvesting with an ultrasonic scalpel. J Thorac Cardiovasc Surg 2000; 120: $1142-1147$.

104. Ura M, Sakata R, Nakayama Y, Arai Y, Saito T. Long-term results of bilateral internal thoracic artery grafting. Ann Thorac Surg 2000; 70: $1991-1996$.

105. Ioannidis JP, Galanos O, Katritsis D, Connery CP, Drossos GE, Swistel DG, et al. Early mortality and morbidity of bilateral versus single internal thoracic artery revascularization: Propensity and risk modeling. J Am Coll Cardiol 2001; 37: 521-528.

106. Tector AJ, McDonald ML, Kress DC, Downey FX, Schmahl TM. Purely internal thoracic artery grafts: Outcomes. Ann Thorac Surg 2001; 72: 450-455.

107. Nishida H, Tomizawa Y, Endo M, Koyanagi H, Kasanuki H. Coronary artery bypass with only in situ bilateral internal thoracic arteries and right gastroepiploic artery. Circulation 2001; 104(12 Suppl 1): I76-I80.

108. Endo M, Nishida H, Tomizawa Y, Kasanuki H. Benefit of bilateral over single internal mammary artery grafts for multiple coronary artery bypass grafting. Circulation 2001; 104: 2164-2170.

109. Berreklouw E, Rademakers PP, Koster JM, van Leur L, van der Wielen BJ, Westers P. Better ischemic event-free survival after two internal thoracic artery grafts: 13 years of follow-up. Ann Thorac Surg 2001; 72: 1535-1541.

110. Hirotani T, Shirota S, Cho Y, Takeuchi S. Feasibility and suitability of the routine use of bilateral internal thoracic arteries. Ann Thorac Surg 2002; 73: 511-515.

111. Ura M, Sakata R, Nakayama Y, Arai Y. Bilateral pedicled internal thoracic artery grafting. Eur J Cardiothorac Surg 2002; 21: 1015- 
1019.

112. Sauvage LR, Rosenfeld JG, Roby PV, Gartman DM, Hammond WP, Fisher LD. Internal thoracic artery grafts for the entire heart at a mean of 12 years. Ann Thorac Surg 2003; 75: 501-504.

113. Calafiore AM, Di Giammarco G, Teodori G, Di Mauro M, Iacò AL, Bivona A, et al. Late results of first myocardial revascularization in multiple vessel disease: Single versus bilateral internal mammary artery with or without saphenous vein grafts. Eur J Cardiothorac Surg 2004; 26: 542-548.

114. Stevens LM, Carrier M, Perrault LP, Hébert Y, Cartier R, Bouchard $\mathrm{D}$, et al. Single versus bilateral internal thoracic artery grafts with concomitanat saphenous vein grafts for multivessel coronary artery bypass grafting: Effects on mortality and event-free suevival. $J$ Thorac Cardiovasc Surg 2004; 127: 1408-1415.

115. Kramer A, Mastsa M, Paz Y, Locker C, Pevni D, Gurevitch J, et al. Bilateral skeletonized internal thoracic artery grafting in 303 patients. J Thorac Cardiovasc Surg 2000; 120: 290-297.

116. Jones JW, Schmidt SE, Miller CC 3rd, Beall AC Jr, Baldwin JC. Bilateral internal thoracic operation in the elderly. $J$ Cardiovasc Surg (Torino) 2000; 41: 165-170.

117. Gurevitch J, Matsa M, Paz Y, Kramer A, Pevni D, Shapira I, et al. Effect of age on outcome of bilateral skeletonized internal thoracic artery grafting. Ann Thorac Surg 2001; 71: 549-554.

118. Hirotani T, Nakamichi T, Munakata M, Takeuchi S. Extended use of bilateral internal thoracic arteries for coronary artery bypass grafting in the elderly. Jpn J Thorac Cardiovasc Surg 2003; 51: $488-$ 495.

119. Lev-Ran O, Pevni D, Mastsa M, Paz Y, Kramer A, Mohr R. Arterial myocardialrevascularization with in situ crossover right internal thoracic artery to left anterior descending artery. Ann Thorac Surg 2001; 72: 798-803.

120. Al-Ruzzeh S, George S, Bustami M, Nakamura K, Ilsley C, Amrani M. Early clinical and angiographic outcome of the pedicled right internal thoracic artery graft to the left anterior descending artery. Ann Thorac Surg 2002; 73: 1431-1435.

121. Ura M, Sakata R, Nakayama Y, Arai Y, Oshima S, Noda K. Analysis by early angiography of right internal thoracic artery grafting via the transverse sinus: Predictors of graft failure. Circulation 2000; 101: $640-646$.

122. Ura M, Sakata R, Nakayama Y, Arai Y, Oshima S, Noda K, et al. Technical aspects and outcome of in situ right internal thoracic artery grafting to the major branches of the circumflex artery via the transverse sinus. Ann Thorac Surg 2001; 71: 1485-1490.

123. Bonacchi M, Prifti E, Battaglia F, Frati G, Sani G, Popoff G. In situ retrocaval skeletonized right internal thoracic artery anastomosed to the circumflex system via transverse sinus: Technical aspects and postoperative outcome. J Thorac Cardiovasc Surg 2003; 126: $1302-1313$.

124. Buxton BF, Ruengsakulrach P, Fuller J, Rosalion A, Reid CM, Tatoulis J. The right internal thoracic artery graft--benefits of grafting the left coronary system and native vessels with a high grade stenosis. Eur J Cardiothorac Surg 2000; 18: 255-261.

125. Sabik JF 3rd, Lytle BW, Blackstone EH, Houghtaling PL, Cosgrove DM. Comparison of saphenous vein and internal thoracic artery graft patency by coronary system. Ann Thorac Surg 2005; 79: 544-551; discussion 544-551.

126. Shin H, Yozu R, Hashizume K, Iino Y, Enoki C, Koizumi K, et al. Free right internal thoracic artery as a second arterial conduit: Modification of proximal anastomosis for improvement of graft patency. Ann Thorac Cardiovasc Surg 2001; 7: 155-158.

127. Wendler O, Hennen B, Demertzis S, Markwirth T, Tscholl D, Lausberg $\mathrm{H}$, et al. Complete arterial revascularization in multivessel coronary artery disease with 2 conduits (skeletonized grafts and T grafts). Circulation 2000; 102(19 Suppl 3): III79-III83.

128. Calafiore AM, Contini M, Vitolla G, Di Mauro M, Mazzei V, Teodori G, et al. Bilateral internal thoracic artery grafting: Longterm clinical and angiographic results of in situ versus $Y$ grafts. $J$ Thorac Cardiovasc Surg 2000; 120: 990-996.

129. Fukuda I, Osaka M, Unno H, Kaminishi Y, Kamiya H. Bilateral internal thoracic artery $\mathrm{T}$ grafting for coronary artery revascularization: Angiographic assessment and mid-term outocome. Jpn J Thorac Cardiovasc Surg 2001; 49: 160-164.

130. Pevni D, Kramer A, Paz Y, Lev-Run O, Locker C, Matsa M, et al. Composite arterial grafting with double skeletonized internal thoracic arteries. Eur J Cardiothorac Surg 2001; 20: 299-304.

131. Hosono M, Shimizu Y, Takanashi S, Minamimura H, Ishikawa T, Murakami T, et al. Early angiographic and clinical results of branch conduits attached proximally to left internal thoracic arteries. Ann Thorac Cardiovasc Surg 2002; 8: 145-150.

132. Lev-Ran O, Paz Y, Pevni D, Kramer A, Shapira I, Locker C, et al.
Bilateral internal thoracic artery grafting: Midterm results of composite versus in situ crossover graft. Ann Thorac Surg 2002; 74: 704-710; discussion 710-711.

133. Grossi EA, Esposito R, Harris LJ, Crooke GA, Galloway AC, Colvin SB, et al. Sternal wound infections and use of internal mammary artery grafts. J Thorac Cardiovasc Surg 1991; 102: 342-346; discussion 346-347.

134. Matsa M, Paz Y, Gurevitch J, Shapira I, Kramer A, Pevny D, et al. Bilateral skeletonized internal thoracic artery grafts in patients with diabetes mellitus. J Thorac Cardiovasc Surg 2001; 121: 668-674.

135. Loop FD, Lytle BW, Cosgrove DM, Mahfood S, McHenry MC, Goormastic M, et al. J. Maxwell Chamberlain memorial paper. Sternal wound complications after isolated coronary artery bypass grafting: Early and late mortality, morbidity, and cost of care. Ann Thorac Surg 1990; 49: 179-186; discussion 186-187.

136. Lev-Ran O, Mohr R, Pevni D, Weissman Y, Loberman D, Uretzky G. Bilateral internal thoracic artery grafting in diabetic patients: Short-term and long-term results of a 515-patient series. $J$ Thorac Cardiovasc Surg 2004; 127: 1145-1150.

137. Lytle BW. Skeletonized internal theoracic artery grafts and wound complications. J Thorac Cardiovasc Surg 2001; 121: 625-627.

138. Suma H, Fukumoto H, Takeuchi A. Coronary artery bypass grafting by in situ right gastroepiploic artery: Basic study and clinical application. Ann Thorac Surg 1987; 44: 394-397.

139. Pym J, Brown PM, Charrette EJ, Parker JO, West RO. Gastroepiploic-coronary anastomosis: A viable alternative bypass graft. $J$ Thorac Cardiovasc Surg 1987; 94: 256-259.

140. Hirose H, Amano A, Takanashi S, Takahashi A. Coronary artery bypass grafting using the gastroepiploic artery in 1,000 patients. Ann Thorac Surg 2002; 73: 1371-1379.

141. Pym J, Brown P, Pearson M, Parker J. Right gastroepiploic-tocoronary artery bypass. The first decade of use. Circulation 1995; 92(9 Suppl): II $45-$ III49.

142. Grandjean JG, Voors AA, Boonstra PW, den Heyer P, Ebels T. Exclusive use of arterial grafts in coronary artery bypass operations for three-vessel disease: Use of both thoracic arteries and the gastroepiploic artery in 256 consecutive patients. J Thorac Cardiovasc Surg 1996; 112: 935-942.

143. Nakao T, Kawaue Y. Effect of coronary revascularization with the right gastroepiploic artery: Comparative examination of angiographic findings in the early postoperative period. $J$ Thorac Cardiovasc Surg 1993; 106: 149-153.

144. Albertini A, Lochegnies A, El Khoury G, Verhelst R, Noirhomme $\mathrm{P}$, Matta A, et al. Use of the right gastroepiploic artery as a coronary artery bypass graft in 307 patients. Cardiovasc Surg 1998; 6: 419423.

145. Kamiya H, Watanabe G, Takemura H, Tomita S, Nagamine H, Kanamori T. Skeletonization of gastroepiploic artery graft in offpump coronary artery bypass grafting: Early clinical and angiographic assessment. Ann Thorac Surg 2004; 77: 2046-2050.

146. Uchida N, Kawaue Y. Flow competition of the right gastroepiploic artery graft in coronary revascularization. Ann Thorac Surg 1996; 62: $1342-1346$.

147. Fukui T, Takanashi S, Hosoda Y, Suehiro S. Total arterial myocardial revascularization using composite and sequential grafting with the off-pump technique. Ann Thorac Surg 2005; 80: 579-585.

148. Suma H, Wanibuchi Y, Terada Y, Fukuda S, Takayama T, Furuta $\mathrm{S}$. The right gastroepiploic artery graft: Clinical and angiographic midterm results in 200 patients. J Thorac Cardiovasc Surg 1993; 105: 615-622; discussion 623 .

149. Ochi M, Bessho R, Saji Y, Fujii M, Hatori N, Tanaka S. Sequential grafting of the right gastroepiploic artery in coronary artery bypass surgery. Ann Thorac Surg 2001; 71: 1205-1209.

150. Ishida T, Kurosawa H, Nishida H, Aomi S, Endo M. Sequential bypass using the right gastroepiploic artery for coronary artery bypass grafting. Jpn J Thorac Cardiovasc Surg 2003; 51: 277-281.

151. Takemura H, Watanabe G, Takahashi M, Tomita S, Higashidani K. Beating heart coronary artery bypass grafting: Results from 402 patients and the usefulness of gastroepiploic artery composite grafting. Jpn J Thorac Cardiovasc Surg 2003; 51: 173-177.

152. Nishida H, Endo M, Koyanagi H, Koyanagi T, Nakamura K. Coronary artery bypass grafting with the right gastroepiploic artery and evaluation of flow with transcutaneous Doppler echocardiography. J Thorac Cardiovasc Surg 1994; 108: 532-538; discussion 538539.

153. Suma H, Isomura T, Horii T, Sato T. Late angiographic result of using the right gastroepiploic artery as a graft. J Thorac Cardiovasc Surg 2000; 120: 496-498.

154. Voutilainen S, Verkkala K, Järvinen A, Keto P. Angiographic 5-year follow-up study of right gastroepiploic artery grafts. Ann Thorac 
Surg 1996; 62: 501-505.

155. Suma H, Tanabe H, Takahashi A, Horii T, Isomura T, Hirose H, et al. Twenty years experience with the gastroepiploic artery graft for CABG. Circulation 2007; 116(11 Suppl): I188-I191.

156. Tatoulis J, Buxton BF, Fuller JA. Patencies of 2127 arterial to coronary conduits over 15 years. Ann Thorac Surg 2004; 77: 93-101.

157. Dietl CA, Benoit CH, Gilbert CL, Woods EL, Pharr WF, Berkheimer $\mathrm{MD}$, et al. Which is the graft of choice for the right coronary and posterior descending arteries? Comparison of the right internal mammary artery and the right gastroepiploic artery. Circulation 1995; 92 (9 Suppl): II92-III97.

158. Maniar HS, Sundt TM, Barner HB, Prasad SM, Peterson L, Absi T, et al. Effect of target stenosis and location on radial artery graft patency. J Thorac Cardiovasc Surg 2002; 123: 45-52.

159. Maniar HS, Barner HB, Bailey MS, Prasad SM, Moon MR, Pasque MK, et al. Radial artery patency: Are aortocoronary conduitts superior to composite grafting? Ann Thorac Surg 2003; 76: 1498 1503; discussion 1503-1504.

160. Goldman S, Zadina K, Moritz T, Ovitt T, Sethi G, Copeland JG, et al; VA Cooperative Study Group \#207/297/364. Long-term patency of saphenous vein and left internal mammary artery grafts after coronary artery bypass surgery: Results from a Department of Veterans Affairs Cooperative Study. J Am Coll Cardiol 2004; 44: $2149-2156$.

161. Lev-Ran O, Mohr R, Uretzky G, Pevni D, Locker C, Paz Y, et al. Graft of choice to right coronary system in left-sided bilateral internal thoracic artery grafting. Ann Thorac Surg 2003; 75: 88-92.

162. Esaki J, Koshiji T, Okamoto M, Tsukashita M, Ikuno T, Sakata R. Gastroepiploic artery grafting does not improve the late outcome in patients with bilateral internal thoracic artery grafting. Ann Thorac Surg 2007; 83: 1024-1029.

163. Shimizu T, Suesada H, Cho M, Ito S, Ikeda K, Ishimaru S. Flow capacity of gastroepiploic artery versus vein grafts for intermediate coronary artery stenosis. Ann Thorac Surg 2005; 80: 124-130.

164. Shimizu T, Ito S, Kikuchi Y, Misaka M, Hirayama T, Ishimaru S, et al. Arterial conduit shear stress following bypass grafting for intermediate coronary artery stenosis: A comparative study with saphenous vein grafts. Eur J Cardiothorac Surg 2004; 25: 578-584

165. Hashimoto H, Isshiki T, Ikari Y, Hara K, Saeki F, Tamura T, et al. Effect of competitive blood flow on arterial graft patency and diameter: Medium-term postoperative follow-up. J Thorac Cardiovasc Surg 1996; 111: 399-407.

166. Gagliardotto P, Coste P, Lazreg M, Dor V. Skeletonized right gastroepiploic artery used for coronary artery bypass grafting. Ann Thorac Surg 1998; 66: 240-242.

167. Amano A, Li R, Hirose H. Off-Pump Coronary Artery Bypass Using Skeletonized Gastroepiploic Artery, a Pilot Atudy. Heart Surg Forum 2004; 7: 101-104.

168. Li R, Amano A, Miyagawa H, Dohi S, Hayashi I, Kajimoto K, et al. Skeletonozed gastroepiploic artery for off-pump coronary artery bypass grafting. Heart Surg Forum 2004; 7: E164-E169.

169. Asai T, Tabata S. Skeletonization of the right gastroepiploic artery using an ultrasonic scalpel. Ann Thorac Surg 2002; 74: 1715-1717.

170. Santos GG, Stolf NA, Moreira LF, Haddad VL, Simões RM, Carvalho SR, et al. Randomized comparative study of radial artery and right gastroepiploic artery in composite arterial graft for CABG. Eur J Cardiothorac Surg 2002; 21: 1009-1014.

171. Ryu SW, Ahn BH, Choo SJ, Na KJ, Ahn YK, Jeong MH, et al. Skeletonized gastroepiploic artery as a composite graft for total arterial revascularization. Ann Thorac Surg 2005; 80: 118-123.

172. Sato T, Isomura T, Suma H, Horii T, Kikuchi N. Coronary artery bypass grafting with gastroepiploic artery composite graft. Ann Thorac Surg 2000; 69: 65-69.

173. Kamiya $\mathrm{H}$, Watanabe $\mathrm{G}$, Takemura $\mathrm{H}$, Tomita $\mathrm{S}$, Nagamine $\mathrm{H}$, Kanamori T. Total arterial revascularization with composite skeletonized gastroepiploic artery graft in off-pump coronary artery bypass grafting. J Thorac Cardiovasc Surg 2004; 127: 1151-1157.

174. Beretta L, Lemma M, Vanelli P, Botta M, Antonacci C, Bevilacqua M, et al. Gastroepiploic artery free graft for coronary bypass. Eur J Cardiothorac Surg 1990; 4: 323-327; discussion 328.

175. Matsuura A, Yasuura K, Yoshida K, Oshima H, Tomari S, Ishida $\mathrm{H}$, et al. Transplantation of the enbloc vascular system for coronary revascularization. J Thorac Cardiovasc Surg 2001; 121: 520-525.

176. Tatoulis J, Royse AG, Buxton BF, Fuller JA, Skillington PD, Goldblatt JC, et al. The radial artery in coronary surgery: A 5-year experience-clinical and angiographic results. Ann Thorac Surg 2002; 73: 143 - 147; discussion 147-148.

177. Amano A, Hirose H, Takahashi A, Nagano N. Coronary artery bypass grafting using the radial artery: Midterm results in a Japanese institute. Ann Thorac Surg 2001; 72: 120-125.
178. Gaudino M, Alessandrini F, Pragliola C, Cellini C, Glieca F, Luciani $\mathrm{N}$, et al. Effect of target artery location and severity of stenosis on mid-term patency of aorta-anastomosed vs. internal thoracic arteryanastomosed radial artery grafts. Eur J Cardio Thorac Surg 2004; 25: $424-428$

179. Lemma M, Mangini A, Gelpi G, Innorta A, Spina A, Antona C. Is it better to use the radial artery as a composite graft? Clinical and angiographic results of aorto-coronary versus Y-graft. Eur J Cardio Thorac Surg 2004; 26: 110-117.

180. Iacò AL, Teodori G, Di Giammarco G, Di Mauro M, Storto L, Mazzei V, et al. Radial artery for myocardial revascularization: Long-term clinical and angiographic results. Ann Thorac Surg 2001; 72: 464-468; discussion 468-469.

181. Tagusari O, Kobayashi J, Bando K, Niwaya K, Nakajima H, Nakatani $\mathrm{T}$, et al. Total arterial off-pump coronary artery bypass grafting for revascularization of the total coronary system: Clinical outcome and angiographic evaluation. Ann Thorac Surg 2004; 78: 13041311; discussion 1304-1311.

182. Orlov B, Gurevitch J, Kogan A, Rubchevsky V, Zlotnick AY, Aravot D. Multiple arterial revascularization using the tangential K-graft technique. Ann Thorac Surg 2005; 80: 1948-1950.

183. Cameron J, Trivedi S, Stafford G, Bett JH. Five-year angiographic patency of radial artery bypass grafts. Circulation 2004; 110(11 suppl 1): II23-II26.

184. Borger MA, Cohen G, Buth KJ, Rao V, Bozinovski J, LiaghatiNasseri N, et al. Multiple arterial grafts: Radial versus right internal thoracic arteries. Circulation 1998; 98(19 Suppl): II7-II13; discussion III3-III4.

185. Lemma M, Gelpi G, Mangini A, Vanelli P, Carro C, Condemi A, et al. Myocardial revascularization with multiple arterial grafts: Comparison between the radial artery and the right internal thoracic artery. Ann Thorac Surg 2001; 71: 1969-1973.

186. Georghiou GP, Vidne BA, Dunning J. Does the radial artery provide better long-term patency than the saphenous vein? Int Cardiovasc Thorac Surg 2005; 4: 304-310.

187. Desai ND, Cohen EA, Naylor CD, Fremes SE; Radial Artery Patency Study Investigators. A randomized comparison of radial-artery and saphenous-vein coronary bypass grafts. N Engl J Med 2004; 351: $2302-2309$

188. Cohen G, Tamariz MG, Sever JY, Liaghati N, Guru V, Christakis GT, et al. The radial artery versus the saphenous vein graft in contemporary CABG: A case-matched study. Ann Thorac Surg 2001; 71: 180-185; discussion 185-186.

189. Khot UN, Friedman DT, Pettersson G, Smedira NG, Li J, Ellis SG. Radial artery bypass grafts have an increased occurrence of angiographically severe stenosis and occlusion compared with left internal mammary arteries and saphenous vein grafts. Circulation 2004; 109: 2086-2091.

190. Buxton BF, Raman JS, Ruengsakulrach P, Gordon I, Rosalion A, Bellomo R, et al. Radial artery patency and clinical outcomes: Fiveyear interism results of a randomized trial. $J$ Thorac Cardiovasc Surg 2003; 125: $1363-1371$

191. Meharwal ZS, Trehan N. Functional status of the hand after radial artery harvesting: Results in 3,977 cases. Ann Thorac Surg 2001; 72: $1557-1561$.

192. Denton TA, Trento L, Cohen M, Kass RM, Blanche C, Raissi S, et al. Radial artery harvesting for coronary bypass operations: Neurologic complications and their potential mechanisms. J Thorac Cardiovasc Surg 2001; 121: 951 -956.

193. Hata M, Shiono M, Sezai A, Iida M, Saitoh A, Hattori T, et al. Determining the best procedure for radial artery harvest: Prospective randomized trial for early postharvest complications. J Thorac Cardiovasc Surg 2005; 129: 885-889.

194. Agrifoglio M, Dainese L, Pasotti S, Galanti A, Cannata A, Roberto $\mathrm{M}$, et al. Preoperative assessment of the radial artery for coronary artery bypass grafting: Is the clinical Allen test adequate? Ann Thorac Surg 2005; 79: 570-572.

195. Bourassa MG, Fisher LD, Campeau L, Gillespie MJ, McConney M, Lespérance J. Long-term fate of bypass grafts: The Coronary Artery Surgery Study (CASS) and Montreal Heart Institute experiences. Circulation 1985; 72(6 Pt 2): V71-V78.

196. Lawrie GM, Morris GC Jr, Chapman DW, Winters WL, Lie JT. Patterns of patency of 596 vein grafts up to seven years after aortacoronary bypass. J Thorac Cardiovasc Surg 1977; 73: 443-448.

197. Fremes SE, Levinton C, Naylor CD, Chen E, Christakis GT, Goldman BS. Optimal antithrombotic therapy following aortocoronary bypass: A meta-analysis. Eur J Cardiothorac Surg 1993; 7: $169-180$

198. Horii T, Suma H, Wanibuchi Y, Fukuda S, Kigawa I. The long-term patency rate of saphenous vein grafts and vein graft disease in 
Japanese patients. Nihon Kyobu Geka Gakkai Zasshi 1993; 41: 1447-1451 (in Japanese).

199. Shiroma K, Suma K, Inoue K, Koyama Y, Kaneko H, Kawai Y, et al. A study of the long-term graft patency using a saphenous vein graft following aorto-coronary bypass surgery. Nihon Kyobu Geka Gakkai Zasshi 1990; 38: 2353-2357 (in Japanese).

200. Arima M, Kanoh T, Suzuki T, Kuremoto K, Tanimoto K, Oigawa $\mathrm{T}$, et al. Serial angiographic follow-up beyond 10 years after coronary artery bypass grafting. Circ $J$ 2005; 69: 896-902.

201. Collins P, Webb CM, Chong CF, Moat NE; Radial Artery Versus Saphenous Vein Patency (RSVP) Trial Investigators. Radial artery versus saphenous vein patency randomized trial: Five-year angiographic follow-up. Circulation 2008; 117: 2859-2864.

202. Hayward PA, Gordon IR, Hare DL, Matalanis G, Horrigan ML, Rosalion A, et al. Comparable patencies of the radial artery and right internal thoracic artery or saphenous vein beyond 5 years: Results from the Radial Artery Patency and Clinical Outcomes trial. J Thorac Cardiovasc Surg 2010; 139: 60-65; discussion 65-67.

203. Cataldo G, Braga M, Pirotta N, Lavezzari M, Rovelli F, Marubini E. Factors influencing 1-year patency of coronary artery saphenous vein grafts: Studio Indobufene nel Bypass Aortocoronarico (SINBA). Circulation 1993; 88(5 Pt 2): II93-II98.

204. Roth JA, Cukingnan RA, Brown BG, Gocka E, Carey JS. Factors influencing patency of saphenous vein grafts. Ann Thorac Surg 1979; 28: $176-183$.

205. Shah PJ, Gordon I, Fuller J, Seevanayagam S, Rosalion A, Tatoulis $\mathrm{J}$, et al. Factors affecting saphenous vein graft patency: Clinical and angiographic study in 1402 symptomatic patients operated on between 1977 and 1999. J Thorac Cardiovasc Surg 2003; 126: 1972 1977.

206. Eckstein FS, Bonilla LF, Englberger L, Stauffer E, Berg TA, Schmidli J, et al. Minimizing aortic manipulation during OPCAB using the symmetry aortic connector system for proximal vein graft anastomoses. Ann Thorac Surg 2001; 72: S995-S998.

207. Yun KL, Wu Y, Aharonian V, Mansukhani P, Pfeffer TA, Sintek CF, et al. Randomized trial of endoscopic versus open vein harvest for coronary artery bypass grafting: Six-month patency rates. J Thorac Cardiovasc Surg 2005; 129: 496-503.

208. Puskas JD, Wright CE, Miller PK, Anderson TE, Gott JP, Brown WM 3rd, et al. A randomized trial of endoscopic versus open saphenous vein harvest in coronary bypass surgery. Ann Thorac Surg 1999; 68: 1509-1512.

209. Kiaii B, Moon BC, Massel D, Langlois Y, Austin TW, Willoughby A, et al. A prospective randomized trial of endoscopic versus conventional harvesting of the saphenous vein in coronary artery bypass surgery. J Thorac Cardiovasc Surg 2002; 123: 204-212.

210. Allen KB, Griffith GL, Heimansohn DA, Robison RJ, Matheny RG, Schier JJ, et al. Endoscopic versus traditional saphenous vein harvesting: A prospective, randomized trial. Ann Thorac Surg 1998; 66: $26-31$; discussion $31-32$.

211. Crouch JD, O'Hair DP, Keuler JP, Barragry TP, Werner PH, Kleinman LH. Open versus endoscopic saphenous vein harvesting: Wound complications and vein quality. Ann Thorac Surg 1999; 68: $1513-1516$.

212. Perrault LP, Jeanmart H, Bilodeau L, Lespérance J, Tanguay JF, Bouchard D, et al. Early quantitative coronary angiography of saphenous vein grafts for coronary artery bypass grafting harvested by means of open versus endoscopic saphenectomy: A prospective randomized trial. J Thorac Cardiovasc Surg 2004; 127: 1402-1407.

213. Davis Z, Garber D, Clark S, Roth H, Bufalino V, Budoff MJ, et al. Long-term patency of coronary grafts with endoscopically harvested saphenous veins determined by contrast-enhanced electron beam computed tomography. J Thorac Cardiovasc Surg 2004; 127: $823-$ 828.

214. Lopes RD, Hafley GE, Allen KB, Ferguson TB, Peterson ED, Harrington RA, et al. Endoscopic versus open vein-graft harvesting in coronary-artery bypass surgery. N Engl J Med 2009; 361: $235-$ 244.

215. Tavilla G, Kappetein AP, Braun J, Gopie J, Tjien AT, Dion RA. Long-term follow-up of coronary artery bypass grafting in threevessel disease using exclusively pedicled bilateral internal thoracic and right gastroepiploic arteries. Ann Thorac Surg 2004; 77: 794799; discussion 799 .

216. Hirotani T, Nakamichi T, Munakata M, Takeuchi S. Risks and benefits of bilateral internal thoracic artery grafting in diabetic patients. Ann Thorac Surg 2003; 76: 2017-2022.

217. Lev-Ran O, Braunstein R, Nesher N, Ben-Gal Y, Bolotin G, Uretzky G. Bilateral versus single internal thoracic artery grafting in oraltreated diabetic subsets: Comparative seven-year outcome analysis. Ann Thorac Surg 2004; 77: 2039-2045.
218. Ochi M, Yamada K, Ishii Y, Ogasawara H, Fujii M, Yajima T, et al. Impact of sequential grafting of the internal thoracic or right gastroepiploic arteries on multiple coronary revascularization. Cardiovasc Surg 2000; 8: 386-392.

219. Seki T, Kitamura S, Kawachi K, Morita R, Kawata T, Mizuguchi K, et al. A quantitative study of postoperative luminal narrowing of the internal thoracic artery graft in coronary artery bypass surgery. $J$ Thorac Cardiovasc Surg 1992; 104: 1532-1538.

220. Sabik JF 3rd, Lytle BW, Blackstone EH, Khan M, Houghtaling PL, Cosgrove DM. Does competitive flow reduce internal thoracic artery graft patency? Ann Thorac Surg 2003; 76: 1490-1496; discussion 1497.

221. Tedoriya T, Kawasuji M, Sakakibara N, Ueyama K, Watanabe Y. Pressure characteristics in arterial grafts for coronary bypass surgery. Cardiovasc Surg 1995; 3: 381-385.

222. Ochi M, Hatori N, Fujii M, Saji Y, Tanaka S, Honma H. Limited flow capacity of the right gastroepiploic artery graft: Postoperative echocardiographic and angiographic evluation. Ann Thorac Surg 2001; 71: 1210-1214.

223. Takami Y, Ina H. Effect of skeletonization on intraoperative flow and anastomosis diameter of internal thoracic arteries in coronary artery bypass grafting. Ann Thorac Surg 2002; 73: 1441-1445.

224. Possati G, Gaudino M, Prati F, Alessandrini F, Trani C, Glieca F, et al. Long-term results of the radial artery used for myocardial revascularization. Circulation 2003; 108: 1350-1354.

225. Caputo M, Reeves B, Marchetto G, Mahesh B, Lim K, Angelini GD. Radial versus right internal thoracic artery as a second arterial conduit for coronary surgery: Early and midterm outcomes. $J$ Thorac Cardiovasc Surg 2003; 126: 39-47.

226. Royse AG, Royse CF, Tatoulis J, Grigg LE, Shah P, Hunt D, et al. Postoperative radial artery angiography for coronary artery bypass surgery. Eur J Cardio Thorac Surg 2000; 17: 294-304.

227. Moran SV, Baeza R, Guarda E, Zalaquett R, Irarrazaval MJ, Marchant E, et al. Predictors of radial artery patency for coronary bypass operations. Ann Thorac Surg 2001; 72: 1552-1556.

228. Prifti E, Bonacchi M, Frati G, Proietti P, Giunti G, Leacche M. Lambda graft with the radial artery or free left internal mammary artery anastomosed to the right internal mammary artery: Flow dynamics. Ann Thorac Surg 2001; 72: 1275-1281.

229. Fukushima S, Kobayashi J, Niwaya K, Tagusari O, Bando K, Nakajima $\mathrm{H}$. Accelerated graft disease in a composite saphenous vein with internal thoracic artery in chronic renal dialysis patient. Jpn J Thorac Cardiovasc Surg 2004; 52: 372-374.

230. Gaudino M, Alessandrini F, Pragliola C, Luciani N, Trani C, Burzotta $\mathrm{F}$, et al. Composite $\mathrm{Y}$ internal thoracic artery-saphenous vein grafts: Short-term angiographic results and vasoreactive profile. $J$ Thorac Cardiovasc Surg 2004; 127: 1139-1144.

231. Tector AJ, Amundsen S, Schmahl TM, Kress DC, Peter M. Total arterial revascularization with T grafts. Ann Thorac Surg 1994; 57: 33-38; discussion 39.

232. Royse AG, Royse CF, Groves KL, Bus B, Yu G. Blood flow in composite arterial grafts and effect of native coronary flow. Ann Thorac Surg 1999; 68: 1619-1622.

233. Wendler O, Hennen B, Markwirth T, König J, Tscholl D, Huang Q, et al. T grafts with the right internal thoracic artery to the left internal thoracic artery versus the left internal thoracic artery and radial artery: Flow dynamics in the internal thoracic artery main stem. $J$ Thorac Cardiovasc Surg 1999; 118: 841-848.

234. Muneretto C, Negri A, Bisleri G, Manfredi J, Terrini A, Metra M, et al. Is total arterial myocardial revascularization with composite grafts a safe and useful procedure in the elderly? Eur J Cardio Thorac Surg 2003; 23: 657-664; discussion 664.

235. Muneretto C, Bisleri G, Negri A, Manfredi J, Carone E, Morgan JA, et al. Left internal thoracic artery-radial artery composite grafts as the technique of choice for myocardial revascularization in elderly patients: A prospective randomized evaluation. $J$ Thorac Cardiovasc Surg 2004; 127: 179-184.

236. Nakamura Y, Kobayashi J, Tagusari O, Bando K, Niwaya K, Nakajima H, et al. Early results of complete off-pump coronary revascularization using left internal thoracic artery with composite radial artery. Jpn J Thorac Cardiovasc Surg 2003; 51: 10-15.

237. Ochi M, Hatori N, Bessho R, Fujii M, Saji Y, Tanaka S, et al. Adequacy of flow capacity of bilateral internal thoracic artery $\mathrm{T}$ graft. Ann Thorac Surg 2001; 72: 2008-2011; discussion 2012.

238. Sakaguchi G, Tadamura E, Ohnaka M, Tambara K, Nishimura K, Komeda M. Composite arterial Y graft has less coronary flow reserve than independent grafts. Ann Thorac Surg 2002; 74: 493-496.

239. Lemma M, Mangini A, Gelpi G, Innorta A, Spina A, Antona C. Are composite Y-graft able to fully respond to the left coronary system flow demand early after coronary bypass graft? Ann Thorac Surg 
2003; 75: 1339-1340; author reply 1340 .

240. Al-Attar N. Coronary flow reserve in composite arterial Y grafts. Ann Thorac Surg 2003; 76: 659-660; author reply 660.

241. Lemma M, Mangini A, Gelpi G, Innorta A, Spina A, Antona C. Analysis of Y-graft blood flow and flow reserve in conditions of increased myocardial oxygen consumption. Ital Heart J 2004; 5: 290-294.

242. Tagusari O, Kobayashi J, Bando K, Niwaya K, Nakajima H, Ishida $\mathrm{M}$, et al. Early adaptation of the left internal thoracic artery as a blood source of y-composite radial artery grafts in off-pump coronary artery bypass grafting. Heart Surg Forum 2003; 6: E93-E98.

243. Lev-Ran O, Mohr R, Aviram G, Matsa M, Nesher N, Pevni D, et al. Repeat median sternotomy after prior ante-aortic crossover right internal thoracic artery grafting. J Card Surg 2004; 19: 151-154.

244. Schmidt SE, Jones JW, Thornby JI, Miller CC 3rd, Beall AC Jr. Improved survival with multiple left-sided bilateral internal thoracic artery grafts. Ann Thorac Surg 1997; 64: 9-14; discussion 15.

245. Calafiore AM, Di Mauro M, D'Alessandro S, Teodori G, Vitolla G, Contini M, et al. Revascularization of the lateral wall: Long-term angiographic and clinical results of radial artery versus right internal thoracic artery grafting. J Thorac Cardiovasc Surg 2002; 123: $225-231$.

246. Sethi GK, Copeland JG, Goldman S, Moritz T, Zadina K, Henderson WG. Implications of preoperative administration of aspirin in patients undergoing coronary artery bypass grafting: Department of Veterans Affairs Cooperative Study on Antiplatelet Therapy. J Am Coll Cardiol 1990; 15: 15-20.

247. Chesebro JH, Fuster V, Elveback LR, Clements IP, Smith HC, Holmes DR Jr, et al. Efftect of dipyridamole and aspirin on late vein-graft patency after coronary bypass operations. $N$ Engl J Med 1984; 310: 209-214.

248. Lorenz RL, Schacky CV, Weber M, Meister W, Kotzur J, Reichardt $\mathrm{B}$, et al. Improved aortocoronary bypass patency by low-dose aspirin (100 mg daily): Effects on platelet aggregation and thromboxane formation. Lancet 1984; 1: $1261-1264$.

249. Sharma GV, Khuri SF, Josa M, Folland ED, Parisi AF. The effect of antiplatelet therapy on saphenuos vein coronary artery bypass graft patency. Circulation 1983; 68(3 Pt 2): II218-II221.

250. Mangano DT; Multicenter Study of Perioperative Ischemia Research Group. Aspirin and mortality from coronary bypass surgery. N Engl J Med 2002; 347: 1309-1317.

251. Limet R, David JL, Magotteaux P, Larock MP, Rigo P. Prevention of aorta-coronary bypass graft occlusion: Beneficial effect of ticlopidine on early and late patency rates of venous coronary bypass grafts: A double-blind study. J Thorac Cardiovasc Surg 1987; 94: $773-$ 783.

252. CAPRIE Steering Committee. A randomized, blinded, trial of clopidogrel versus aspirin in patients at risk of ischemic events (CAPRIE): CAPRIE Steering Committee. Lancet 1996; 348: 1329-1339.

253. The effect of aggressive lowering of low-density lipoprotein cholesterol levels and low-dose anticoagulation on obstructive changes in saphenous-vein coronary-artery bypass grafts: The Post Coronary Artery Bypass Graft Trial Investigators. N Engl J Med 1997; 336: $153-162$

254. Yli-Mäyry S, Huikuri HV, Korhonen UR, Airaksinen KE, Ikäheimo MJ, Linnaluoto MK, et al. Efficacy and safety of anticoagulant therapy started pre-operatively in preventing coronary vein graft occlusion. Eur Heart J 1992; 13: 1259-1264

255. Fox KA, Mehta SR, Peters R, Zhao F, Lakkis N, Gersh BJ, et al; Clopidogrel in Unstable angina to prevent Recurrent ischemic Events Trial. Benefits and risks of the combination of clopidogrel and aspirin in patients undergoing surgical revascularization for non-STelevation acute coronary syndrome: The Clopidogrel in Unstable angina to prevent Recurrent ischemic Events (CURE) Trial. Circulation 2004; 110: $1202-1208$

256. Carpentier A, Guermonprez JL, Deloche A, Frechette C, DuBost C. The aorta-to-coronary radial artery bypass graft: A technique avoiding pathological changes in grafts. Ann Thorac Surg 1973; 16: $111-121$.

257. Bourassa MG, Enjalbert M, Campeau L, Lesperance J. Progression of atherosclerosis in coronary arteries and bypass grafts: Ten years later. Am J Cardiol 1984; 53: 102C-107C

258. FitzGibbon GM, Leach AJ, Kafka HP, Keon WJ. Coronary bypass grafts fate: Long-term angiographic study. J Am Coll Cardiol 1991; 17: $1075-1080$

259. Foster ED, Fisher LD, Kaiser GC, Myers WO. Comparison of operative mortality and morbidity for initial and repeat coronary artery bypass grafting: The Coronary Artery Surgery Study (CASS) registry experience. Ann Thorac Surg 1984; 38: 563-570.

260. Lamas GA, Mudge GH Jr, Collins JJ Jr, Koster K, Cohn LH, Flatley
$\mathrm{M}$, et al. Clinical response to coronary artery reoperations. $J \mathrm{Am}$ Coll Cardiol 1986; 8: 274-279.

261. Cameron A, Kemp HG Jr, Green GE. Reoperation for coronary disease: 10 years of clinical follow-up. Circulation 1988; 76(3 Pt 2): I158-I162.

262. Platko WP, Hollman J, Whitlow PL, Franco I. Percutaneous transliminal angioplasty of saphenuos vein graft stenosis: Long-term follow-up. J Am Coll Cardiol 1989; 14: 1645-1650.

263. de Feyter PJ, van Suylen RJ, de Jaegere PP, Topol EJ, Serruys PW Balloon angioplasty for the treatment of lesions in saphenous vein bypass grafts. J Am Col Cardiol 1993; 21: 1539-1549.

264. Reeves F, Bonan R, Côté G, Crépeau J, deGuise P, Gosselin G, et al. Long-term angiographic follow-up after angioplasty of venous coronary bypass grafts. Am Heart J 1991; 122 (3 Pt 1): 620-627.

265. Hirshfeld JW Jr, Schwartz JS, Jugo R, MacDonald RG, Goldberg $\mathrm{S}$, Savage MP, et al. Restenosis after coronary angioplasty: A multivariate statistical model to relate lesion and procedure variables to restenosis: The M-HEART Investigators. J Am Coll Cardiol 1991; 18: $647-656$

266. Savage MP, Douglas JS Jr, Fischman DL, Pepine CJ, King SB 3rd, Werner JA, et al. Stent placement compared with balloon angioplasty for obstructed coronary bypass grafts: Saphenous Vein De Novo Trial Investigators. N Engl J Med 1997; 337: 740-747.

267. Chakravarty T, Morrissey RP, Wertman B, Naghi J, Chou S, Goykhman P, et al. Comparison of long-term outcomes of drugeluting stents and bare metal stents for saphenous vein graft stenosis. Catheter Cardiovasc Interv 2011; 79: 903-909.

268. Baim DS, Wahr D, George B, Leon MB, Greenberg J, Cutlip DE, et al; Saphenous vein graft Angioplasty Free of Emboli Randomized (SAFER) Trial Investigators. Randomized trial of a distal embolic protection device during percutaneous intervention of saphneous vein aorto-coronary bypass grafts. Circulation 2002; 105: $1285-1290$.

269. Stone GW, Rogers C, Hermiller J, Feldman R, Hall P, Haber R, et al; FilterWire EX Randomized Evaluation Investigators. Randomized comparison of distal protection with a filter-based catheter and balloon occlusion and aspiration system during percutaneous intervention of diseased saphenous vein aorto-coronary bypass grafts. Circulation 2003; 108: 548-553.

270. Köckeritz U, Reynen K, Knaut M, Strasser RH. Results of angioplasty (with or without stent) at the site of a narrowed coronary anastomosis of the left internal mammary artery graft or via the internal mammary artery. Am J Cardiol 2004; 93: 1531-1533.

271. Third Report of the National Cholesterol Education Program (NCEP) Expert Panel on Detection, Evaluation, and Treatment of High Blood Cholesterol in Adults (Adult Treatment Panel III): Executive Summary. Rockville, MD: U.S. Department of Health and Human Services. Public Health Service, National Institutes of Health National Heart, Lung, and Blood Institute. NIH Publication No. 01-3670. May 2001.

272. Medical Research Council/British Heart Foundation Heart Protection Study. www.ctsu.ox.ac.uk/ hps/pr.shtml (available in February 2012).

273. Fonarow GC, Gawlinski A, Moughrabi S, Tillisch JH. Improved treatment of coronary heart disease by implementation of a Cardiac Hospitalization Atherosclerosis Management Program (CHAMP). Am J Cardiol 2001; 87: 819-822.

274. Hulley S, Grady D, Bush T, Furberg C, Herrington D, Riggs B, et al. Randomized trial of estrogen plus progestin for secondary prevention of coronary heart disease in postmenopausal women. Heart and Estrogen/progestin Replacement Study (HERS) Research Group. JAMA 1998; 280: 605-613.

275. Manson JE, Hsia J, Johnson KC, Rossouw JE, Assaf AR, Lasser $\mathrm{NL}$, et al; Women's Health Initiative Investigators. Estrogen plus progestin and the risk of coronary heart disease. N Engl J Med 2003; 349: $523-534$

276. Wasley MA, McNagny SE, Phillips VL, Ahluwalia JS. The costeffectiveness of the nicotine transdermal patch for smoking cesation. Prev Med 1997; 26: 264-270.

277. Cavender JB, Rogers WJ, Fisher LD, Gersh BJ, Coggin CJ, Myers WO. Effects of smoking on survival and morbidity in patients randomized to medical or surgical therapy in the Coronary Artery Surgery Study (CASS): 10-year follow-up. CASS Investigators. $J$ Am Coll Cardiol 1992; 20: 287-294.

278. van Domburg RT, Meeter K, van Berkel DF, Veldkamp RF, van Herwerden LA, Bogers AJ. Smoking cessation reduces mortality after coronary artery bypass surgery: A 20 -year follow-up study. $J$ Am Coll Cardiol 2000; 36: 878-883.

279. Domanski MJ, Borkowf CB, Campeau L, Knatterud GL, White C, Hoogwerf B, et al. Prognostic factors for atherosclerosis progres- 
sion in saphenous vein grafts: The postcoronary artery bypass graft (Post-CABG) trial: Post-CABG Trial Investigators. J Am Coll Cardiol 2000; 36: 1877-1883.

280. Rigotti NA, Pipe AL, Benowitz NL, Arteaga C, Garza D, Tonstad S. Efficacy and safety of varenicline for smoking cessation in patients with cardiovascular disease: A randomized trial. Circulation 2010; 121: 221-229.

281. Fiore MC, Jaén CR, Baker TB, Bailey WC, Benowitz NL, Curry SJ, et al. Treating Tobacco Use and Dependence: 2008 Update. Clinical Practice Guideline. Rockville, MD: U.S. Department of Health and Human Services. Public Health Service. May 2008.

282. Wenger NK, Hellerstein HK. Rehabilitation of the coronary patient, 2nd edn. New York: John Wiley \& Sons Inc., 1984.

283. Mclane M, Krop H, Mehta J. Psychosexual adjustment and counseling after myocardial infarction. Ann Intern Med 1980; 92: 514-519.

284. Oldridge NB, Guyatt GH, Fischer ME, Rimm AA. Cardiac rehabilitation after myocardial infarction. Combined experience of randomized clinical trials. JAMA 1988; 260: 945-950.

285. O'Connor GT, Buring JE, Yusuf S, Goldhaber SZ, Olmstead EM, Paffenbarger RS Jr, et al. An overview of randomized trials of rehabilitation with exercise after myocardial infarction. Circulation 1989; 80: $234-244$

286. Milani RV, Lavie CJ. Prevalence and effects of cardiac rehabilitation on depression in the elderly with coronary heart disease. Am J Cardiol 1998; 81: 1233-1236.

287. Milani RV, Lavie CJ. The effects of body composition changes to observed improvements in cardiopulmonary parameters after exercise training with cardiac rehabilitation. Chest 1998; 113: 599-601.

288. Harlan WR 3rd, Sandler SA, Lee KL, Lam LC, Mark DB. Importance of baseline functional and socioeconomic factors for participation in cardiac rehabilitation. Am J Cardiol 1995; 76: 36-39.

289. Lavie CJ, Milani RV, Littman AB. Benefits of cardiac rehabilitation and exercise training in secondary coronary prevention in the elderly. J Am Coll Cardiol 1993; 22: 678-683.

290. Lavie CJ, Milani RV. Effects of cardiac rehabilitation and exercise training programs in patients $>$ or $=75$ years of age. Am J Cardiol 1996; 78: 675-677.

291. Lavie CJ, Milani RV. Effects of cardiac rehabilitation and exercise training on exercise capacity, coronary risk factors, behavioral characteristics, and quality of life in women. Am J Cardiol 1995; 75: $340-343$.

292. Cannistra LB, Balady GJ, O’Malley CJ, Weiner DA, Ryan TJ. Comparison of the clinical profile and outcome of women and men in cardiac rehabilitation. Am J Cardiol 1992; 69: 1274-1279.

293. Friedman DB, Williams AN, Levine BD. Compliance and efficacy of cardiac rehabilitation and risk factor modification in the medically indigent. Am J Cardiol 1997; 79: 281-285.

294. Engblom E, Korpilahti K, Hämäläinen H, Rönnemaa T, Puukka P. Quality of life and return to work 5 years after coronary artery bypass surgery: Long-term results of cardiac rehabilitation. $J$ Cardpulm Rehabil 1997; 17: 29-36.

295. Shiran A, Kornfeld S, Zur S, Laor A, Karelitz Y, Militianu A, et al. Determinants of improvement in exercise capacity in patients undergoing cardiac rehabilitation. Cardiology 1997; 88: 207-213.

296. Ades PA, Huang D, Weaver SO. Cardiac rehabilitation participation predicts lower rehospitalization costs. Am Heart J 1992; 123: 916-921.

297. Herdy AH, Marcchi PL, Vila A, Tavares C, Collaço J, Niebauer J, et al. Pre- and postoperative cardiopulmonary rehabilitation in hospitalized patients undergoing coronary artery bypass surgery: A randomized controlled trial. Am J Phys Med Rehabil 2008; 87: 714 719.

298. Acinapura AJ, Jacobowitz IJ, Kramer MD, Adkins MS, Zisbrod Z, Cunningham JN Jr. Demographic changes in coronary artery bypass surgery and its effect on mortality and morbidity. Eur J Cardiothorac Surg 1990; 4: 175-181.

299. Freeman WK, Schaff HV, O'Brien PC, Orszulak TA, Naessens JM, Tajik AJ. Cardiac surgery in the octogenarian: Perioperative outcome and clinical follow-up. J Am Coll Cardiol 1991; 18: 29-35.

300. Hoff SJ, Ball SK, Coltharp WH, Glassford DM Jr, Lea JW 4th, Petracek MR. Coronary artery bypass in patients 80 years and over; is off-pump the operation of choice? Ann Thorac Surg 2002; 74: S1340-S1343.

301. Gardner TJ, Greene PS, Rykiel MF, Baumgartner WA, Cameron DE, Casale AS, et al. Routine use of the left internal mammary artery graft in the elderly. Ann Thorac Surg 1990; 49: 188-193; discussion 193-194.

302. Moon MR, Sundt TM 3rd, Pasque MK, Barner HB, Gay WA Jr, Damiano RJ Jr. Influence of internal mammary artery grafting and completeness of revascularization on long-term outcome in octoge- narians. Ann Thorac Surg 2001; 72: 2003-2007.

303. Kurlansky PA, Williams DB, Traad EA, Carrillo RG, Schor JS, Zucker M, et al. Arterial grafting results in reduced operative mortality and enhanced long-term quality of life in octogenarians. Ann Thorac Surg 2003; 76: 418-426; discussion 427.

304. He GW, Acuff TE, Ryan WH, Mack MJ. Risk factors for operative mortality in elderly patients undergoing internal mammary artery grafting. Ann Thorac Surg 1994; 57: 1453-1460; discussion 14601461.

305. Findlay IN. Coronary bypass surgery in women. Curr Opin Cariol 1994; 9: 650-657.

306. Brandrup-Wognsen G, Berggren H, Hartford M, Hjalmarson A, Karlsson T, Herlitz J. Female sex is associated with increased mortality and morbidity early, but not late, after coronary artery bypass grafting. Eur Heart J 1996; 17: 1426-1431.

307. Risum O, Abdelnoor M, Nitter-Hauge S, Levorstad K, Svennevig $\mathrm{JL}$. Coronary artery bypass surgery in womem and in men; early and long-term results: A study of the Norwegian population adjusted be age and sex. Eur J Cardiothoracic Surg 1997; 11: 539-546.

308. Hochman JS, McCabe CH, Stone PH, Becker RC, Cannon CP, DeFeo-Fraulini T, et al. Outcome and profile of women and men presenting with acute coronary syndromes: A report from TIMI IIIB. TIMI Investigators: Thrombolysis in Myocardial Infarction. $J$ Am Coll Cardiol 1997; 30: 141-148.

309. Hammar N, Sandberg E, Larsen FF, Ivert T. Comparison of early and late mortality in men and women after isolated coronary artery bypass surgery in Stockholm, Sweden, 1980 to 1989. J Am Coll Cardiol 1997; 29: 659-664.

310. Abramov D, Tamariz MG, Sever JY, Christakis GT, Bhatnagar G, Heenan AL, et al. The influence of gender on the outcome of coronary artery bypass surgery. Ann Thorac Surg 2000; 70: 800-805; discussion 806 .

311. O'Connor GT, Morton JR, Diehl MJ, Olmstead EM, Coffin LH, Levy DG, et al. Differences between men and women in hospital mortality associated with coronary artery bypass graft surgery: The Northern New England Cardiovascular Disease Study Group. Circulation 1993; 88: 2104-2110.

312. King KB, Clark PC, Hicks GL Jr. Patterns of referral and recovery in women and men undergoing coronary artery bypass grafting. Am J Cardiol 1992; 69: 179-182.

313. Czajkowski SM, Terrin M, Lindquist R, Hoogwerf B, Dupuis G, Shumaker SA, et al. Comparison of preoperative characteristics of men and women undergoing coronary artery bypass grafting (the Post Coronary Artery Bypass Graft [CABG] Biobehavioral Study). Am J Cardiol 1997; 79: 1017-1024.

314. Ayanian JZ, Guadagnoli E, Cleary PD. Physical and psychosocial functioning of women and men after coronary artery bypass surgery. JAMA 1995; 274: 1767-1770.

315. Utley JR, Wilde EF, Leyland SA, Morgan MS, Johnson HD. Intraoperative blood transfusion is a major risk factor for coronary artery bypass grafting in women. Ann Thorac Surg 1995; 60: 570-574; $574-575$

316. Ramström J, Lund O, Cadavid E, Thuren J, Oxelbark S, Henze A. Multiarterial coronary artery bypass grafting with special reference to small vessel disease and results in women. Eur Heart J 1993; 14: 634-639.

317. Rahimtoola SH, Bennett AJ, Grunkemeier GL, Block P, Starr A. Survival at 15 to 18 years after coronary bypass surgery for angina in women. Circulation 1993; 88(5 Pt 2): II71-II78.

318. Barbir M, Lazem F, Ilsley C, Mitchell A, Khaghani A, Yacoub M. Coronary artery surgery in women compared with men: Analysis of coronary risk factors and in-hospital mortality in a single centre. Br Heart J 1994; 71: 408-412.

319. Jacobs AK, Kelsey SF, Brooks MM, Faxon DP, Chaitman BR, Bittner V, et al. Better outcome for women compared with men undergoing coronary revascularization: A report from the bypass angiography revascularization investigation (BARI). Circulation 1998; 98: 1279-1285.

320. Aldea GS, Gaudiani JM, Shapira OM, Jacobs AK, Weinberg J, Cupples AL, et al. Effect of gender on postoperative outcomes and hospital stays after coronary artery bypass grafting. Ann Thorac Surg 1999; 67: 1097-1103.

321. Koch CG, Khandwala F, Nussmeier N, Blackstone EH. Gender profiling in coronary artery bypass grafting. $J$ Thorac Cardiovasc Surg 2003; 126: 2044-2051.

322. Guru V, Fremes SE, Tu JV. Time-related mortality for women after coronary artery bypass graft surgery: A population-based study. $J$ Thorac Cardiovasc Surg 2004; 127: 1158-1165.

323. Hassan A, Chiasson M, Buth K, Hirsch G. Women have worse longterm outcomes after coronary aetery bypass grafting than men. Can 
J Cardiol 2005; 21: 757-762

324. Blankstein R, Ward RP, Arnsdorf M, Jones B, Lou YB, Pine M. Female gender is an independent predictor of operative mortality after coronary artery bypass graft surgery: Contemporary analysis of 31 Midwestern hospitals. Circulation 2005; 112(9 Suppl): I323 I327.

325. Guru V, Fremes SE, Austin PC, Blackstone EH, Tu JV. Gender differences in outcomes after hospital discharge from coronary artery bypass grafting. Circulation 2006; 113: 507-516.

326. Humphries KH, Gao M, Pu A, Lichtenstein S, Thompson CR. Significant improvement in short-term mortality in women undergoing coronary artery bypass surgery (1991 to 2004). J Am Coll Cardiol 2007; 49: $1552-1558$

327. Carey JS, Cukingnan RA, Singer LK. Health status after myocardial revascularization: Inferior results in women. Ann Thorac Surg 1995; 59: $112-117$

328. Edwards FH, Carey JS, Grover FL, Bero JW, Hartz RS. Impact of gender on coronary bypass operative mortality. Ann Thorac Surg 1998; 66: 125-131.

329. Khan SS, Nessim S, Gray R, Czer LS, Chaux A, Matloff J. Increased mortality of women in coronary artery bypass surgery: Evidence for referral bias. Ann Intern Med 1990; 112: 561-567.

330. Vaccarino V, Abramson JL, Veledar E, Weintraub WS. Sex differences in hospital mortality after coronary artery bypass surgery: Evidence for a higher mortality in younger women. Circulation 2002; 105: 1176-1181

331. Woods SE, Noble G, Smith JM, Hasselfeld K. The influence of gender in patients undergoing coronary artery bypass graft surgery: An eight-year prospective hospitalized cohort study. J Am Coll Surg 2003; 196: $428-434$.

332. Zitser-Gurevich Y, Simchen E, Galai N, Mandel M; ISCAB Consortium. Effect of perioperative complications on excess mortality among women after coronary bypass: The Israeli Coronary Bypass Graft Study (ISCAB). J Thorac Cardiovasc Surg 2002; 123: 517 524.

333. Hannan EL, Bernard HR, Kilburn HC Jr, O'Donnell JF. Gender differences in mortality rates for coronary artery bypass surgery. Am Heart J 1992; 123(4 Pt 1): 866-872.

334. Koch CG, Khandwala F, Nussmeier N, Blackstone EH. Gender and outcomes after coronary artery bypass grafting: A propensitymatched comparison. J Thorac Cardiovasc Surg 2003; 126: 2032 2043.

335. Mickleborough LL, Takagi Y, Maruyama H, Sun Z, Mohamed S. Is sex a factor in determining operative risk for aortocoronary bypass graft surgery? Circularion 1995; 92(9 Suppl): II80-II84.

336. Eagle KA, Guyton RA, Davidoff R, Edwards FH, Ewy GA, Gardner TJ, et al; American College of Cardiology/American Heart Association Task Force on Practice Guidelines Committee to Update the 1999 Guidelines for Coronary Artery Bypass Graft Surgery; American Society for Thoracic Surgery; Society of Thoracic Surgeons. ACC/AHA 2004 guideline update for coronary artery bypass graft surgery: Summary article. A report of the American College of Cardiology/American Heart Association Task Force on Practice Guidelines (Committee to Update the 1999 Guidelines for Coronary Artery Bypass Graft Surgery). J Am Coll Cardiol 2004; 44: e213-e310.

337. Edwards FH, Clark RE, Schwartz M. The impact of internal mammary artery conduits on operative mortality in coronary revascularization. Ann Thorac Surg 1994; 57: 27-32.

338. Leavitt BJ, O'Connor GT, Olmstead EM, Morton JR, Maloney CT, Dacey LJ, et al. Use of the internal mammary artery graft and inhospital mortality and other adverse outcomes associated with coronary artery bypass surgery. Circulation 2001; 103: 507-512

339. Dignan RJ, Yeh T Jr, Dyke CM, Lutz HA 3rd, Wechsler AS. The influence of age and sex on human internal mammary artery size and reactivity. Ann Thorac Surg 1992; 53: 792-797.

340. Mickleborough LL, Carson S, Ivanov J. Gender differences in quality of distal vessels: Effect on results of coronary artery bypass grafting. J Thorac Cardiovasc Surg 2003; 126: 950-958.

341. O'Connor NJ, Morton JR, Birkmeyer JD, Olmstead EM, O'Connor GT. Effect of coronary artery diameter in patients undergoing coronary bypass surgery: Northern New England Cardiovascular Disease Study Group. Circulation 1996; 93: 652-655.

342. Brown PP, Mack MJ, Simon AW, Battaglia S, Tarkington L, Horner $\mathrm{S}$, et al. Outcomes experience with off-pump coronary artery bypass surgery in women. Ann Thorac Surg 2002; 74: 2113-2119; discussion 2120

343. Athanasiou T, Al-Ruzzeh S, Del Stanbridge R, Casula RP, Glenville $\mathrm{BE}$, Amrani M. Is the female gender an independent predictor of adverse outcome after off-pump coronary artery bypass grafting?
Ann Thorac Surg 2003; 75: 1153-1160.

344. Capdeville M, Chamogeogarkis T, Lee JH. Effect of gender on outcomes of beating heart operations. Ann Thorac Surg 2001; 72: S1022-S1025.

345. Kurlansky PA, Traad EA, Galbut DL, Zucker M, Ebra G. Efficacy of single versus bilateral internal mammary artery grafting in women: A long-term study. Ann Thorac Surg 2001; 71: 1949-1957; discussion 1957-1958.

346. Kurlansky PA, Traad EA, Galbut DL, Singer S, Zucker M, Ebra G. Coronary artery surgery in women: A long-term comparative study of quality of life after bilateral internal mammary artery grafting in men and women. Ann Thorac Surg 2002; 74: 1517-1525.

347. Kurlansky PA, Dorman MJ, Galbut DL, Moreno NL, Traad EA, Carrillo RG, et al. Bilateral internal mammary artery grafting in women: A 21-year experience. Ann Thorac Surg 1996; 62: 63-69.

348. Edwards FH, Ferraris VA, Shahian DM, Peterson E, Furnary AP, Haan CK, et al; Society of Thoracic Surgeons. Gender-specific practice guidelines for coronary artery bypass surgery: Perioperative management. Ann Thorac Surg 2005; 79: 2189-2194.

349. Lawton JS, Brister SJ, Petro KR, Dullum M. Surgical revascularization in women: Unique intraoperative factors and considerations. $J$ Thorac Cardiovasc Surg 2003; 126: 936-938.

350. Bucerius J, Gummert JF, Walther T, Borger MA, Doll N, Falk V, et al. Impact of off-pump coronary bypass grafting on the prevalence of adverse perioperative outcome in women undergoing coronary artery bypass grafting surgery. Ann Thorac Surg 2005; 79: 807-812; discussion 812-813.

351. Mack MJ, Brown P, Houser F, Katz M, Kugelmass A, Simon A, et al. On-pump versus off-pump coronary artery bypass surgery in a matched sample of women: A comparison of outcomes. Circulation 2004; 110(11 Suppl 1): II1 - II6.

352. Puskas JD, Kilgo PD, Kutner M, Pusca SV, Lattouf O, Guyton RA Off-pump techniques disproportionately benefit women and narrow the gender disparity in outcomes after coronary artery bypass surgery. Circulation 2007; 116(11 Suppl): I192-I199.

353. Ministry of Health, Labour and Welfare. The National Health and Nutrition Survey in Japan, 2007. http://www.mhlw.go.jp/bunya/ kenkou/eiyou09/01.html (in Japanese).

354. Aronson D, Rayfield EJ. Diabetes and obesity. In: Fuster V, Ross R, Topol EJ, editors. Atherosclerosis and coronary artery disease. Philadelphia: Lippincott-Raven, 1996: 327-359.

355. Lee CD, Folsom AR, Pankow JS, Brancati FL; Atherosclerosis Risk in Communities (ARIC) Study Investigators. Cardiovascular events in diabetic and nondiabetic adults with or without history of myocardial infarction. Circulation 2004; 109: 855-860.

356. Haffner SM, Lehto S, Rönnemaa T, Pyörälä K, Laakso M. Mortality from coronary heart disease in subjects with type 2 diabetes and in nondiabetic subjects with and without prior myocardial infarction. N Engl J Med 1998; 339: 229-234.

357. Sprafka JM, Burke GL, Folsom AR, McGovern PG, Hahn LP Trends in prevalence of diabetes mellitus with myocardial infarction and effect of diabetes on survival: The Minnesota Heart Survey. Diabetes Care 1991; 14: 537-543.

358. Stone PH, Muller JE, Hartwell T, York BJ, Rutherford JD, Parker $\mathrm{CB}$, et al. The effect of diabetes mellitus on prognosis and serial left ventricular function after acute myocardial infarction: Contribution of both coronary disease and diastolic left ventricular dysfunction to the adverse prognosis: The MILIS Study Group. J Am Coll Cardiol 1989; 14: 49-57.

359. Herlitz J, Malmberg K, Karlson BW, Rydén L, Hjalmarson A. Mortality and morbidity during a five-year follow-up of diabetics with myocardial infarction. Acta Med Scand 1988; 224: 31-38.

360. Fava S, Azzopardi J, Agius-Muscat H. Outcome of unstable angina in patients with diabetes mellitus. Diabet Med 1997; 14: 209-213.

361. Barzilay JI, Kronmal RA, Bittner V, Eaker E, Evans C, Foster ED. Coronary artery disease and coronary artery bypass grafting in diabetic patients aged $>$ or $=65$ years (report from the Coronary Artery Surgery Study [CASS] Registry). Am J Cardiol 1994; 74: 334-339.

362. Herlitz J, Wognsen GB, Emanuelsson H, Haglid M, Karlson BW, Karlsson T, et al. Mortality and morbidity in diabetic and nondiabetic patients during a 2-year period after coronary artery bypass grafting. Diabetes Care 1996; 19: 698-703.

363. Carson JL, Scholz PM, Chen AY, Peterson ED, Gold J, Schneider $\mathrm{SH}$. Diabetes melitus increase short-term mortality and morbidity in patients undergoing coronary artery bypass graft surgery. $J \mathrm{Am}$ Coll Cardiol 2002; 40: 418-423.

364. Luciani N, Nasso G, Gaudino M, Abbate A, Glieca F, Alessandrini $\mathrm{F}$, et al. Coronary artery bypass grafting in type II diabetic patients: A comparison between insulin-dependent and non-insulin-dependent patients at short- and mid-term follow-up. Ann Thorac Surg 
2003; 76: 1149-1154.

365. Szabó Z, Håkanson E, Svedjeholm R. Early postoperative outcome and medium-term survival in 540 diabetic and 2239 nondiabetic patients undergoing coronary artery bypass grafting. Ann Thorac Surg 2002; 74: 712-719.

366. Kubal C, Srinivasan AK, Grayson AD, Fabri BM, Chalmers JA. Effect of risk-adjusted diabetes on mortality and morbidity after coronary artery bypass surgery. Ann Thorac Surg 2005; 79: 1570 1576.

367. Wit MA, de Mulder M, Jansen EK, Umans VA. Diabetes mellitus and its impact on long-term outcomes after coronary artery bypass graft surgery. Acta Diabetol 2010 September 21, doi:10.1007/ s00592-010-0223-3 [Epub ahead of print].

368. Miyazaki S, Yoshitani K, Miura N, Irie T, Inatomi Y, Ohnishi Y, et al. Risk factors of stroke and delirium after off-pump coronary artery bypass surgery. Interact CardioVasc Thorac Surg 2011; 12: 379-383.

369. Deaton C, Thourani V. Patients with type 2 diabetes undergoing coronary artery bypass graft surgery: Predictors of outcomes. Eur J Cardiovasc Nurs 2009; 8: 48-56.

370. Comparison of coronary bypass surgery with angioplasty in patients with multivessel disease: The Bypass Angioplasty Revascularization Investigation (BARI) Investigators. N Engl J Med 1996; 335: $217-225$.

371. Seven-year outcome in the Bypass Angioplasty Revascularization Investigation (BARI) by treatment and diabetic status. $J$ Am Coll Cardiol 2000; 35: 1122-1129.

372. BARI Investigators. The final 10-year follow-up results from the BARI randomized trial. J Am Coll Cardiol 2007; 49: 1600-1606.

373. Stevens LM, Carrier M, Perrault LP, Hébert Y, Cartier R, Bouchard $\mathrm{D}$, et al. Influence of diabetes and bilateral internal thorac artery grafts on long-term outcome for multivessel coronary artery bypass grafting. Eur J Cardiothorac Surg 2005; 27: 281-288.

374. Hirose H, Amano A, Takanashi S, Takahashi A. Skeletonized bilateral internal mammary artery grafting for patients with diabetes. Interact Cardiovasc Thorac Surg 2003; 2: 287-292.

375. Higami T, Kozawa S, Asada T, Shida T, Ogawa K. Skeletonization and harvest of the internal thoracic artery with an ultrasonic scalpel. Ann Thorac Surg 2000; 70: 307-308.

376. Choi JS, Cho KR, Kim KB. Does diabetes affect the postoperative outcomes after total arterial off-pump coronary artery bypass surgery in multivessel disease? Ann Thorac Surg 2005; 80: 1353-1360.

377. Srinivasan AK, Grayson AD, Fabri BM. On-pump versus off-pump coronary artery bypass grafting in diabetic patients: A propensity score analysis. Ann Thorac Surg 2004; 78: 1604-1609.

378. Magee MJ, Dewey TM, Acuff T, Edgerton JR, Hebeler JF, Prince SL, et al. Influence of diabetes on mortality and morbidity: Offpump coronary artery bypass grafting versus coronary artery bypass grafting with cardiopulmonary bypass. Ann Thorac Surg 2001; 72: 776-780; discussion 780-781.

379. Furnary AP, Zerr KJ, Grunkemeier GL, Heller CA. Hyperglycemia: A predictor of mortality following $\mathrm{CABG}$ in diabetics. Circulation 1999; 100(Suppl): 1591.

380. Estrada CA, Young JA, Nifong LW, Chitwood WR Jr. Outcomes and perioperative hyperglycemia in patients with or without diabetes mellitus undergoing coronary artery bypass grafting. Ann Thorac Surg 2003; 75: 1392-1399.

381. Furnary AP, Zerr KJ, Grunkemeier GL, Starr A. Continuous intravenous insulin infusion reduces the incidence of deep sternal wound infection in diabetic patients after cardiac surgical procedures. Ann Thorac Surg 1999; 67: 352-360; discussion 360-362.

382. McAlister FA, Man J, Bistritz L, Amad H, Tandon P. Diabetes and coronary artery bypass surgery: An examination of perioperative glycemic control and outcomes. Diabetic Care 2003; 26: 1518-1524.

383. Zerr KJ, Furnary AP, Grunkemeier GL, Bookin S, Kanhere V, Starr A. Glucose control lowers the risk of wound infection in diabetics after open heart operations. Ann Thorac Surg 1997; 63: 356-361.

384. Furnary AP, Gao G, Grunkemeier GL, Wu Y, Zerr KJ, Bookin SO, et al. Continuous insulin infusion reduces mortality in patients with diabetes undergoing coronary artery bypass grafting. J Thorac Cardiovasc Surg 2003; 125: 1007-1021.

385. Medalion B, Katz MG, Cohen AJ, Hauptman E, Sasson L, Schachner A. Long-term beneficial effect of coronary artery bypass grafting in patients with COPD. Chest 2004; 125: 56-62.

386. Royston D, Fleming JS, Desai JB, Westaby S, Taylor KM. Increased production of peroxidation products associated with cardiac operations: Evidence for free radical generation. J Thorac Cardiovasc Surg 1986; 91: 759-766.

387. Hammerschmidt DE, Stroncek DF, Bowers TK, Lammi-Keefe CJ, Kurth DM, Ozalins A, et al. Complement activation and neutrope- nia during cardiopulmonary bypass. J Thorac Cardiovasc Surg 1981; 81: $370-377$

388. McGowan FX Jr, Ikegami M, del Nido PJ, Motoyama EK, Kurland $\mathrm{G}$, Davis PJ, et al. Cardiopulmonary bypass significantly reduces surfactant activity in children. J Thorac Cardiovasc Surg 1993; 106: 968-977.

389. Güler M, Kirali K, Toker ME, Bozbuğa N, Omeroğlu SN, Akinci $\mathrm{E}$, et al. Different CABG methods in patients with chronic obstructive pulmonary disease. Ann Thorac Surg 2001; 71: 152-157.

390. Covino E, Santise G, Di Lello F, De Amicis V, Bonifazi R, Bellino I, et al. Surgical myocardial revascularization (CABG) in patients with pulmonary disease: Beating heart versus cardiopulmonary bypass. J Cardiovasc Surg (Torino) 2001; 42: 23-26.

391. Goyal V, Pinto RJ, Mukherjee K, Trivedi A, Sharma S, Bhattacharya S. Alteration in pulmonary mechanics after coronary artery bypass surgery: Comparison using internal mammary artery and saphenous vein grafts. Indian Heart $J$ 1994; 46: 345-348.

392. Liu JY, Birkmeyer NJ, Sanders JH, Morton JR, Henriques HF, Lahey SJ, et al. Risks of morbidity and mortality in dialysis patients undergoing coronary artery bypass surgery: Northern New England Cardiovascular Disease Study Group. Circulation 2000; 102: 2973 2977.

393. Labrousse L, de Vincentiis C, Madonna F, Deville C, Roques X, Baudet E. Early and long term results of coronary artery bypass grafts in patients with dialysis dependent renal failure. Eur J Cardiothorac Surg 1999; 15: 691-696.

394. Khaitan L, Sutter FP, Goldman SM. Coronary artery bypass grafting in patients who require long-term dialysis. Ann Thorac Surg 2000; 69: 1135-1139.

395. Hirose H, Amano A, Takahashi A, Nagano N. Coronary artery bypass grafting for patients with non-dialysis-dependent renal dysfunction (serum creatinine $>$ or $=2.0 \mathrm{mg} / \mathrm{dl}$ ). Eur J Cardiothorac Surg 2001; 20: 565-572.

396. Fukushima S, Kobayashi J, Tagusari O, Bando K, Niwaya K, Nakajima $\mathrm{H}$, et al. Early results of off-pump coronary artery bypass grafting for patients on chronic renal dialysis. Jpn J Thorac Cardiovasc Surg 2005; 53: 186-192.

397. Tabata M, Takanashi S, Fukui T, Horai T, Uchimuro T, Kitabayashi $\mathrm{K}$, et al. Off-pump coronary artery bypass grafting in patients with renal dysfunction. Ann Thorac Surg 2004; 78: 2044-2049.

398. Hirose H, Amano A, Takahashi A, Ozaki S, Nagano N. Coronary artery bypass grafting for hemodialysis-dependent patients. Artif Organs 2001; 25: 239-247.

399. Tashiro T, Nakamura K, Morishige N, Iwakuma A, Tachikawa Y, Shibano R, et al. Off-pump coronary artery bypass grafting in patients with end-stage renal disease on hemodialysis. J Card Surg 2002; 17: 377-382.

400. Yokoyama T, Baumgartner FJ, Gheissari A, Capouya ER, Panagiotides GP, Declusin RJ. Off-pump versus on-pump coronary bypass in high-risk subgroups. Ann Thorac Surg 2000; 70: 15461550.

401. Hirose H, Amano A, Takahashi A. Efficacy of off-pump coronary artery bypass grafting for the patients on chronic hemodialysis. Jpn J Thorac Cardiovasc Surg 2001; 49: 693-699.

402. Ascione R, Nason G, Al-Ruzzeh S, Ko C, Ciulli F, Angelini GD. Coronary revascularization with or without cardiopulmonary bypss in patients with preoperative nondialysis-dependent renal insufficiency. Ann Thorac Surg 2001; 72: 2020-2025.

403. Papadimitriou LJ, Marathias KP, Alivizatos PA, Michalis A, Palatianos GM, Stavridis GT, et al. Safety and efficacy of off-pump coronary artery bypass grafting in chronic dialysis patients. Artif Organs 2003; 27: 174-180.

404. Blakeman BP, Sullivan HJ, Foy BK, Sobotka PA, Pifarre R. Internal mammary artery revascularization in the patient in long-term renal dialysis. Ann Thorac Surg 1990; 50: 776-778.

405. Nakayama Y, Sakata R, Ura M. Bilateral internal thoracic artery use for dialysis patients: Does it increase operative risk? Ann Thorac Surg 2001; 71: 783-787.

406. Mora CT. The central nervous system: Response to cardiopulmonary bypass. In: Mora CT, editor. Cardiopulmonary bypass: Principles and techniques of extracorporeal circulation, 4th edn. New York: Springer-Verlag, 1995: 114-146.

407. Furlan AJ, Breuer AC. Central nervous system complications of open heart surgery. Stroke 1984; 15: 912-915.

408. Dacey LJ, Likosky DS, Leavitt BJ, Lahey SJ, Quinn RD, Hernandez F Jr, et al; Northern New England Cardiovascular Disease Study Group. Perioperative stroke and long-term survival after coronary bypass graft surgery. Ann Thorac Surg 2005; 79: 532-536; discussion 537.

409. McKhann GM, Grega MA, Borowicz LM Jr, Baumgartner WA, 
Selnes OA. Stroke and encephalopathy after cardiac surgery: An update. Stroke 2006; 37: 562-571.

410. Filsoufi F, Rahmanian PB, Castillo JG, Bronster D, Adams DH. Incidence, topography, predictors and long-term survival after stroke in patients undergoing coronary artery bypass grafting. Ann Thorac Surg 2008; 85: 862-870.

411. Nishiyama K, Horiguchi M, Shizuta S, Doi T, Ehara N, Tanuguchi $\mathrm{R}$, et al. Temporal pattern of strokes after on-pump and off-pump coronary artery bypass graft surgery. Ann Thorac Surg 2009; 87: $1839-1844$.

412. Brennan RW, Patterson RH, Kessler J. Cerebral blood flow and metabolism during cardiopulmonary bypass: Evidence of microembolic encephalopathy. Neurology 1971; 21: 665-672.

413. Mills NL, Everson CT. Atherosclerosis of the ascending aorta and coronary artery bypass: Pathology, clinical correlates, and operative management. J Thorac Cardiovasc Surg 1991; 102: 546-553.

414. Boivie P, Edström C, Engström KG. Side differences in cerebrovascular accidents after cardiac surgery: A statistical analysis of neurologic symptoms and possible implications for anatomic mechanisms of aortic particle embolization. J Thorac Cardiovasc Surg 2005; 129: 591-598.

415. Borger MA, Ivanov J, Weisel RD, Rao V, Peniston CM. Stroke during coronary bypass surgery: Principal role of cerebral macroemboli. Eur J Cardiothorac Surg 2001; 19: 627-632.

416. Sylivris S, Calafiore P, Matalanis G, Rosalion A, Yuen HP, Buxton $\mathrm{BF}$, et al. The intraoperative assessment of ascending aortic atheroma: Epiaortic imaging is superior to both transesophageal echocardiography and direct palpation. J Cardiothorac Vasc Anesth 1997; 11: 704-707.

417. Rosenberger P, Shernan SK, Löffler M, Shekar PS, Fox JA, Tuli $\mathrm{JK}$, et al. The influence of epiaortic ultrasonography on intraoperative surgical management in 6051 cardiac surgical patients. Ann Thorac Surg 2008; 85: 548-553.

418. Barbut D, Lo YW, Hartman GS, Yao FS, Trifiletti RR, Hager DN, et al. Aortic atheroma is related to outcome but not numbers of emboli during coronary bypass. Ann Thorac Surg 1997; 64: 454459.

419. Ohteki H, Itoh T, Natsuaki M, Minato N, Suda H. Intraoperative ultrasonic imaging of the ascending aorta in ischemic heart disease. Ann Thorac Surg 1990; 50: 539-542.

420. Katz ES, Tunick PA, Rusinek H, Ribakove G, Spencer FC, Kronzon I. Protruding aortic atheromas predict stroke in elderly patients undergoing cardiopulmonary bypass: Experience with intraoperative transesophageal echocardiography. J Am Coll Cardiol 1992; 20: $70-77$.

421. Wareing TH, Davila-Roman VG, Daily BB, Murphy SF, Schechtman $\mathrm{KB}$, Barzilai B, et al. Strategy for the reduction of stroke incidence in cardiac surgical patients. Ann Thorac Surg 1993; 55: 1400-1407; discussion 1407-1408.

422. Akins CW. Noncardioplegic myocardial preservation for coronary revascularization. J Thorac Cardiovasc Surg 1984; 88: 174-181.

423. Ozatik MA, Göl MK, Fansa I, Uncu H, Küçüker SA, Küçükaksu S, et al. Risk factors for stroke following coronary artery bypass operations. J Card Surg 2005; 20: 52-57.

424. Hangler HB, Nagele G, Danzmayr M, Mueller L, Ruttmann E, Laufer G, et al. Modification of surgical technique for ascending aortic atherosclerosis: Impact on stroke reduction in coronary artery bypass grafting. J Thorac Cardiovasc Surg 2003; 126: 391-400.

425. Culliford AT, Colvin SB, Rohrer K, Baumann FG, Spencer FC. The atherosclerotic ascending aorta and transverse arch: A new technique to prevent cerebral injury during bypass: Experience with 13 patients. Ann Thorac Surg 1986; 41: $27-35$.

426. Van Dijk D, Jansen EW, Hijman R, Nierich AP, Diephuis JC, Moons KG, et al; Octopus Study Group. Cognitive outcome after off-pump coronary bypass graft surgery: A randomized trial. JAMA 2002; 287: $1405-1412$.

427. Légaré JF, Buth KJ, King S, Wood J, Sullivan JA, Hancock Friesen $\mathrm{C}$, et al. Coronary bypass surgery performed off pump does not result in lower in-hospital morbidity than coronary artery bypass grafting performed on pump. Circulation 2004; 109: 887-892.

428. Sedrakyan A, Wu AW, Parashar A, Bass EB, Treasure T. Off-pump surgery is associated with reduced occurrence of stroke and other morbidity as compared with traditional coronary artery bypass grafting: A meta-analysis of systemically reviewed trials. Stroke 2006; 37: $2759-2769$

429. Puskas JD, Thourani VH, Kilgo P, Cooper W, Vassiliades T, Vega $\mathrm{JD}$, et al. Off-pump coronary artery bypass disproportionately benefits high-risk patients. Ann Thorac Surg 2009; 88: 1142-1147.

430. Hosokawa K, Nakajima Y, Umenai T, Ueno H, Taniguchi S, Matsukawa T, et al. Predictors of atrial fibrillation after off-pump coronary artery bypass graft surgery. Br J Anaesth 2007; 98: 575580.

431. Mathew JP, Parks R, Savino JS, Friedman AS, Koch C, Mangano DT, et al. Atrial fibrillation following coronary artery bypass graft surgery: Predictors, outcomes, and resource utilization: MultiCenter Study of Perioperative Ischemia Research Group. JAMA 1996; 276: 300-306.

432. Lahtinen J, Biancari F, Salmela E, Mosorin M, Satta J, Rainio P, et al. Postoperative atrial fibrillation is a major cause of stroke after on-pump coronary artery bypass surgery. Ann Thorac Surg 2004; 77: $1241-1244$.

433. Klein AL, Grimm RA, Murray RD, Apperson-Hansen C, Asinger RW, Black IW, et al; Assessment of Cardioversion Using Transesophageal Echocardiography Investigators. Use of transesophageal echocardiography to guide cardioversion in patients with atrial fibrillation. N Engl J Med 2001; 344: 1411 - 1420.

434. Laupacis A, Albers G, Dalen J, Dunn MI, Jacobson AK, Singer DE. Antithrombotic therapy in atrial fibrillation. Chest 1998; 114(5 Suppl): 579S-589S.

435. Fuster V, Rydén LE, Asinger RW, Cannom DS, Crijns HJ, Frye RL, et al; American College of Cardiology/American Heart Association Task Force on Practice Guidelines; European Society of Cardiology Committee for Practice Guidelines and Policy Conferences (Committee to Develop Guidelines for the Management of Patients With Atrial Fibrillation); North American Society of Pacing and Electrophysiology. ACC/AHA/ESC Guidelines for the Management of Patients with Atrial Fibrillation: Executive Summary. A Report of the American College of Cardiology/American Heart Association Task Force on Practice Guidelines and the European Society of Cardiology Committee for Practice Guidelines and Policy Conferences (Committee to Develop Guidelines for the Management of Patients With Atrial Fibrillation). Developed in Collaboration With the North American Society of Pacing and Electrophysiology. Circulation 2001; 104: 2118-2150.

436. Pugsley W, Klinger L, Paschalis C, Treasure T, Harrison M, Newman $\mathrm{S}$. The impact of microemboli during cardiopulmonary bypass on neuropsychological functioning. Stroke 1994; 25: 1393-1399.

437. Keren A, Goldberg S, Gottlieb S, Klein J, Schuger C, Medina A, et al. Natural history of left ventricular thrombi: Their appearance and resolution in the posthospitalization period of acute myocardial infarction. J Am Coll Cardiol 1990; 15: 790-800.

438. Johannessen KA, Nordrehaug JE, von der Lippe G. Left ventricular thrombi after short-term high-dose anticoagulants in acute myocardial infarction. Eur Heart J 1987; 8: 975-980.

439. McKhann GM, Goldsborough MA, Borowicz LM Jr, Mellits ED, Brookmeyer R, Quaskey SA, et al. Predictors of stroke risk in coronary artery bypass patients. Ann Thorac Surg 1997; 63: 516-521.

440. Doi K, Yaku H. Importance of cerebral artery risk evaluation before off-pump coronary artery bypass grafting to avoid perioperative stroke. Eur J Cardiothorac Surg 2010; 38: 568-572.

441. Salasidis GC, Latter DA, Steinmetz OK, Blair JF, Graham AM. Carotid artery duplex scanning in preoperative assessment for coronary artery revascularization: The association between peripheral vascular disease, carotid artery stenosis, and stroke. J Vasc Surg 1995; 21: 154-160; discussion 161-162.

442. Nicolaides AN, Kakkos SK, Kyriacou E, Griffin M, Sabetai M, Thomas DJ, et al; Asymptomatic Carotid Stenosis and Risk of Stroke (ACSRS) Study Group. Asymptomatic internal carotid artery stenosis and cerebrovascular risk stratification. J Vasc Surg 2010; 52: 1486-1496. e1-e5.

443. Rizzo RJ, Whittemore AD, Couper GS, Donaldson MC, Aranki SF, Collins JJ Jr, et al. Combined carotid and coronary revascularization: The preferred approach to the severe vasculopath. Ann Thorac Surg 1992; 54: 1099-1108; discussion 1108-1109.

444. Akins CW. The case for concomitant carotid and coronary artery surgery. Br Heart J 1995; 74: 97-98.

445. Endarterectomy for asymptomatic carotid artery stenosis: Executive Committee for the Asymptomatic Carotid Atherosclerosis Study. JAMA 1995; 273: 1421 -1428.

446. Endarterectomy for moderate symptomatic carotid stenosis: Interim results from MRC European Carotid Surgery Trial. Lancet 1996; 347: $1591-1593$

447. North American Symptomatic Carotid Endarterectomy Trial: Methods, patient characteristics, and progress. Stroke 1991; 22: 711-720.

448. Akins CW, Moncure AC, Daggett WM, Cambria RP, Hilgenberg $\mathrm{AD}$, Torchiana DF, et al. Safety and efficacy of concomitant carotid and coronary artery operations. Ann Thorac Surg 1995; 60: 311-317; discussion 318 .

449. Wennberg DE, Lucas FL, Birkmeyer JD, Bredenberg CE, Fisher ES. Variation in carotid endarterectomy mortality in the Medicare 
population: Trial hospitals, volume, and patient characteristics. JAMA 1998; 279: 1278-1281.

450. Cebul RD, Snow RJ, Pine R, Hertzer NR, Norris DG. Indications, outcomes, and provider volumes for carotid endarterectomy. JAMA 1998; 279: 1282-1287.

451. Kolh P, Wijns W, Danchin N, Di Mario C, Falk V, Folliguet T, et al; Task Force on Myocardial Revascularization of the European Society of Cardiology (ESC) and the European Association for Cardio-Thoracic Surgery (EACTS); European Association for Percutaneous Cardiovascular Interventions (EAPCI). Guidelines on myocardial revascularization. Eur J Cardiothorac Surg 2010; 38(Suppl): S1-S52.

452. Coyle KA, Gray BC, Smith RB 3rd, Salam AA, Dodson TF, Chaikof EL, et al. Morbidity and mortality associated with carotid endareterectomy: Effect of adjunctive coronary revascularization. Ann Vasc Surg 1995; 9: 21-27.

453. Kolh PH, Comte L, Tchana-Sato V, Honore C, Kerzmann A, Mauer $\mathrm{M}$, et al. Concurrent coronary and carotid artery surgery: Factors influencing perioperative outcome and long-term results. Eur Heart J 2006; 27: 49-56.

454. Guibaud JP, Roques X, Laborde N, Elia N, Roubertie F, Ewald J, et al. Extracorporeal circulation as an additional method for cerebral protection in simultaneous carotid endarterectomy and coronary artery surgical revascularization. J Card Surg 2004; 19: 415419.

455. Gopaldas RR, Chu D, Dao TK, Huh J, LeMaire SA, Lin P, et al. Staged versus synchronous carotid endarterectomy and coronary artery bypass grafting: Analysis of 10-year nationwide outcomes. Ann Thorac Surg 2011; 91: 1323-1329; discussion 1329.

456. Hertzer NR, Loop FD, Beven EG, O'Hara PJ, Krajewski LP. Surgical staging for simultaneous coronary and carotid disease: A study including prospective randomization. J Vasc Surg 1989; 9: 455-463.

457. Illuminati G, Ricco JB, Caliò F, Pacilè MA, Miraldi F, Frati G, et al. Short-term results of a randomized trial examining timeing of carotid endarterectomy in patients with severe asymptomatic unilateral carotid stenosis undergoing coronary artery bypass grafting. J Vasc Surg 2011; 54: 993-999; discussion 998-999.

458. International Carotid Stenting Study investigators, Ederle J, Dobson J, Featherstone RL, Bonati LH, van der Worp HB, et al. Carotid artery stenting compared with endarterectomy in patients with symptomatic carotid stenosis (International Carotid Stenting Study): An interim analysis of a randomised controlled trial. Lancet 2010; 375: 985-997.

459. Guzman LA, Costa MA, Angiolillo DJ, Zenni M, Wludyka P, Silliman S, et al. A systematic review of outcomes in patients with staged carotid artery stenting and coronary artery bypass graft surgery. Stroke 2008; 39: 361-365.

460. Versaci F, Reimers B, Del Giudice C, Schofer J, Giacomin A, Saccà $\mathrm{S}$, et al. Simultaneous hybrid revascularization by carotid stenting and coronary artery bypass grafting: The SHARP study. JACC Cardiovasc Interv 2009; 2: 393-401.

461. Mishra Y, Wasir H, Kohli V, Meharwal ZS, Malhotra R, Mehta Y, et al. Concomitant carotid endarterectomy and coronary bypass surgery: Outcome of on-pump and off-pump techniques. Ann Thorac Surg 2004; 78: 2037-2042; discussion 2042-2043.

462. Newman MF, Kirchner JL, Phillips-Bute B, Gaver V, Grocott H, Jones RH, et al; Neurological Outcome Research Group and the Cardiothoracic Anesthesiology Research Endeavors Investigators. Longitudinal assessment of neurocognitive function after coronaryartery bypass surgery. $N$ Engl J Med 2001; 344: 395-402.

463. Murkin JM, Martzke JS, Buchan AM. Cognitive and neurological function after coronary artery surgery: A prospective study (abstract). Anesth Analg 1992; 74(2 Suppl): S215.

464. Stump DA, Rogers AT, Hammon JW, Newman SP. Cerebral emboli and cognitive outcome after cardiac surgery. $J$ Cardiothorac Vasc Anesth 1996; 10: 113-118; quiz 118-119.

465. Stump DA, Rogers AT, Kon ND, Wallenhaupt SL, Hammon JW When emboli occur during coronary artery bypass graft surgery (abstract). Anesthesiology 1993; 79: A49.

466. Albin MS, Hantler C, Bunegin L. Intracranial air embolism is detected by transcranial Doppler (TCD) during cardiopulmonary bypass procedures (abstract). Anesthesiology 1990; 73: A458.

467. Moody DM, Bell MA, Challa VR, Johnston WE, Prough DS. Brain microemboli during cardiac surgery or aortography. Ann Neurol 1990; 28: 477-486.

468. Hammon JW, Stump DA, Butterworth JB, Moody DM. Approaches to reduce neurologic complications during cardiac surgery. Semin Thorac Cardiovasc Surg 2001; 13: 184-191.

469. Murkin JM, Boyd WD, Ganapathy S, Adams SJ, Peterson RC. Beating heart surgery: Why expect less central nervous sytem morbid- ity? Ann Thorac Surg 1999; 68: 1498-1501.

470. Bucerius J, Gummert JF, Borger MA, Walther T, Doll N, Falk V, et al. Predictors of delirium after cardiac surgery delirium: Effect of beating-heart (off-pump) surgery. J Thorac Cardiovasc Surg 2004; 127: $57-64$.

471. Baba T, Goto T, Maekawa K, Ito A, Yoshitake A, Koshiji T. Early neuropsychological dysfunction in eldery high-risk patients after on-pump and off-pump coronary bypass surgery. J Anesth 2007; 21: $452-458$

472. Diegeler A, Hirsch R, Schneider F, Schilling LO, Falk V, Rauch T, et al. Neuromonitoring and neurocognitive outcome in off-pump versus conventional coronary bypass operation. Ann Thorac Surg 2000; 69: $1162-1166$.

473. Marasco SF, Sharwood LN, Abramson MJ. No improvement in neurocognitive outcomes after off-pump versus on-pump coronary revascularization: A meta-analysis. Eur J Cardiothorac Surg 2008; 33: $961-970$.

474. Motallebzadeh R, Kanagasabay R, Bland M, Kaski JC, Jahangiri M. S100 protein and its relation to cerebral microemboli in on-pump and off-pump coronary artery bypass surgery. Eur J Cardiothorac Surg 2004; 25: 409-414.

475. Arom KV, Cohen DE, Strobl FT. Effect of intraoperative intervention on neurological outcome based on electroencephalographic monitoring during cardiopulmonary bypass. Ann Thorac Surg 1989; 48: $476-483$.

476. Edmonds HL Jr, Griffiths LK, van der Laken J, Slater AD, Shields CB. Quantitative electroencephalographic monitoring during myocardial revascularization predicts postoperative disorientation and improves outcome. J Thorac Cardiovasc Surg 1992; 103: 555-563.

477. Murkin JM, Martzke JS, Buchan AM, Bentley C, Wong CJ. A randomized study of the influence of perfusion technique and $\mathrm{pH}$ management strategy in 316 patients undergoing coronary artery bypass surgery. II: Neurologic and cognitive outcomes. $J$ Thorac Cardiovasc Surg 1995; 110: 349-362.

478. Engelman RM, Pleet AB, Rousou JA, Flack JE 3rd, Deaton DW, Kulshrestha $\mathrm{P}$, et al. Does cardiopulmonary bypass temperature correlate with postoperative central nervous system dysfunction? $J$ Card Surg 1995; 10: 493-497.

479. Nathan HJ, Munson J, Wells G, Mundi C, Balaa F, Wynands JE. The management of temperature during cardiopulmonary bypass: Effect on neuropsychological outcome. J Card Surg 1995; 10: 481 487

480. Christakis GT, Abel JG, Lichtenstein SV. Neurological outcomes and cardiopulmonary temperature: A clinical review. J Card Surg 1995; 10: 475-480.

481. Guyton RA, Mellitt RJ, Weintraub WS. A critical assessment of neurological risk during warm heart surgery. J Card Surg 1995; 10: $488-492$.

482. Badner NH, Murkin JM, Lok P. Differences in $\mathrm{pH}$ management and pulsatile/nonpulsatile perfusion during cardiopulmonary bypass do not influence renal function. Anesth Analg 1992; 75: 696-701.

483. Henze T, Stephan H, Sonntag H. Cerebral dysfunction following extracorporeal circulation for aortocoronary bypass surgery: No differences in neuropsychological outcome after pulsatile versus nonpulsatile flow. Thorac Cardiovasc Surg 1990; 38: 65-68.

484. Murkin JM, Martzke JS, Buchan AM. Pulsatile perfusion during hypothermic cardiopulmonary bypass significantly influences morbidity and mortality after coronary artery bypass surgery (abstract). Anesth Analg 1993; 76: S280.

485. Lev-Ran O, Ben-Gal Y, Matsa M, Paz Y, Kramer A, Pevni D, et al. 'No touch' techniques for porcelain ascending aorta: Comparison between cardiopulmonary bypass with femoral artery cannulation and off-pump myocardial revascularization. J Card Surg 2002; 17: $370-376$

486. Leyh RG, Bartels C, Nötzold A, Sievers HH. Management of porcelain aorta during coronary artery bypass grafting. Ann Thorac Surg 1999; 67: 986-988.

487. Doberneck RC, Sterling WA Jr, Allison DC. Morbidity and mortality after operation in nonbleeding cirrhotic patients. Am J Surg 1983; 146: 306-309.

488. Hayashida N, Shoujima T, Teshima H, Yokokura Y, Takagi K, Tomoeda $\mathrm{H}$, et al. Clinical outcome after cardiac operations in patients with cirrhosis. Ann Thorac Surg 2004; 77: 500-505.

489. Suman A, Barnes DS, Zein NN, Levinthal GN, Connor JT, Carey WD. Predicting outcome after cardiac surgery in patients with cirrhosis: A comparison of Child-Pugh and MELD scores. Clin Gastroenterol Hepatol 2004; 2: 719-723.

490. Kaplan M, Cimen S, Kut MS, Demirtas MM. Cardiac operations for patients with chronic liver disease. Heart Surg Forum 2002; 5: $60-65$. 
491. Bizouarn P, Ausseur A, Desseigne P, Le Teurnier Y, Nougarede B, Train M, et al. Early and late outcome after elective cardiac surgery in patients with cirrhosis. Ann Thorac Surg 1999; 67: 1334-1338

492. Klemperer JD, Ko W, Krieger KH, Connolly M, Rosengart TK, Altorki NK, et al. Cardiac operations in patients with cirrhosis. Ann Thorac Surg 1998; 65: 85-87.

493. Carr C, Desai J. OPCAB surgery in a cirrhotic hepatocellular carcinoma patient awaiting liver transplant. Ann Thorac Surg 2004; 78: $1460-1462$

494. Yamamoto T, Takazawa K, Hariya A, Ishikawa N, Dohi S, Matsushita S. Off-pump coronary artery bypass grafting in a patient with liver cirrhosis. Jpn J Thorac Cardiovasc Surg 2002; 50: 526 529.

495. Gaudino M, Santarelli P, Bruno P, Piancone FL, Possati G. Palliative coronary artery surgery in patients with severe noncardiac diseases. Am J Cardiol 1997; 80: 1351-1352.

496. Kazui T, Wada H, Fujita H; Japanese Association for Thoracic Surgery Committee of Science. Thoracic and cardiovascular surgery in Japan during 2003: Annual report by The Japanese Association for Thoracic Surgery. Jpn J Thoracic Surg 2005; 53: 517-536.

497. Hilton TC. Aortic valve replacement for patients with mild to moderate aortic stenosis undergoing coronary artery bypass surgery. Clin Cardiol 2000; 23: 141-147.

498. Lester SJ, Heilbron B, Gin K, Dodek A, Jue J. The natural history and rate of progression of aortic stenosis. Chest 1998; 113: 11091114.

499. Schwarz F, Baumann P, Manthey J, Hoffmann M, Schuler G, Mehmel HC, et al. The effect of aortic valve replacement on survival. Circulation 1982; 66: 1105-1110.

500. Peterson GE, Hochrein J, Harrison JK, Bashore TM. Managing clinically insignificant aortic valve disease in patients undergoing CABG. ACC Current Journal Review 1997; 6: 61-64.

501. Herlitz J, Brandrup-Wognsen G, Caidahl K, Haglid M, Karlsson BW, Karlsson T, et al. Mortality and morbidity among patients who undergo combined valve and coronary artery bypass surgery: Early and late results. Eur J Cardiothorac Surg 1997; 12: 836-846.

502. Collins JJ Jr, Aranki SF. Management of mild aortic stenosis during coronary artery bypass graft surgery. J Card Surg 1994; 9: 145 147.

503. Odell JA, Mullany CJ, Schaff HV, Orszulak TA, Daly RC, Morris JJ. Aortic valve replacement after previous coronary artery bypass grafting. Ann Thorac Surg 1996; 62: 1424-1430.

504. Fighali SF, Avendaño A, Elayda MA, Lee VV, Hernandez C, Siero $\mathrm{V}$, et al. Early and late mortality of patients undergoing aortic valve replacement after previous coronary artery bypass graft surgery. Circulation 1995; 92(9 Suppl): II163-II168.

505. Rahimtoola SH. Should patients with asymptomatic mild or moderate aortic stenosis undergoing coronary artery bypass surgery also have valve replacement for their aortic stenosis? Heart 2001; 85: $337-341$.

506. Otto CM, Pearlman AS, Gardner CL. Hemodynamic progression of aortic stenosis in adults assessed by Doppler echocardiography. J Am Coll Cardiol 1989; 13: 545-550.

507. Peter M, Hoffmann A, Parker C, Lüscher T, Burckhardt D. Progression of aortic stenosis: Role of age and concomitant coronary artery disease. Chest 1993; 103: 1715-1719.

508. Brener SJ, Duffy CI, Thomas JD, Stewart WJ. Progression of aortic stenosis in 394 patients: Relation to changes in myocardial and mitral valve dysfunction. J Am Coll Cardiol 1995; 25: 305-310.

509. Nestico PF, DePace NL, Kimbiris D, Hakki AH, Khanderia B, Iskandrian AS, et al. Progression of isolated aortic stenosis: Analysis of 29 patients having more than 1 cardiac catheterization. Am J Cardiol 1985; 52: 1054-1058.

510. Smith WT 4th, Ferguson TB Jr, Ryan T, Landolfo CK, Peterson ED. Should coronary artery bypass graft surgery patients with mild to moderate aortic stenosis undergo concomitant aortic valve replacement? J Am Coll Cardiol 2004; 44: 1241 - 1247.

511. Levine RA, Hung J, Otsuji Y, Messas E, Liel-Cohen N, Nathan N, et al. Mechanistic insights into functional mitral regurgitation. Curr Cardiol Rep 2002; 4: 125-129.

512. Carpentier A. Cardiac valve surgery--the "French correction". $J$ Thorac Cardiovasc Surg 1983; 86: 323-327.

513. Gillinov AM, Wierup PN, Blackstone EH, Bishay ES, Cosgrove $\mathrm{DM}$, White $\mathrm{J}$, et al. Is repair preferable to replacement for ischemic mitral regurgitation? J Thorac Cardiovasc Surg 2001; 122: 1125 1141.

514. Miller DC. Ischemic mitral regurgitation redux--to repair or to replace? J Thorac Cardiovasc Surg 2001; 122: 1059-1062.

515. Filsoufi F, Aklog L, Byrne JG, Cohn LH, Adams DH. Current results of combined coronary artery bypass grafting and mitral an- nuloplasty in patients with moderate ischemic mitral regurgitation. J Heart Valve Dis 2004; 13: 747-753.

516. Calafiore AM, Di Mauro M, Gallina S, Di Giammarco G, Iacò AL, Teodori G, et al. Mitral valve surgery for chronic ischemic mitral regurgitation. Ann Thorac Surg 2004; 77: 1989-1997.

517. Grossi EA, Goldberg JD, LaPietra A, Ye X, Zakow P, Sussman M, et al. Ischemic mitral valve reconstruction and replacement: Comparison of long-term survival and complications. J Thorac Cardiovasc Surg 2001; 122: 1107-1124.

518. Diodato MD, Moon MR, Pasque MK, Barner HB, Moazami N, Lawton JS, et al. Repair of ischemic mitral regurgitation does not increase mortality or improve long-term survival in patients undergoing coronary artery revascularization: A propensity analysis. Ann Thorac Surg 2004; 78: 794-799; discussion 794-799.

519. Wong DR, Agnihotri AK, Hung JW, Vlahakes GJ, Akins CW, Hilgenberg AD, et al. Long-term survival after surgical revascularization for moderate ischemic mitral regurgitation. Ann Thorac Surg 2005; 80: 570-577.

520. Braun J, Bax JJ, Versteegh MI, Voigt PG, Holman ER, Klautz RJ, et al. Preoperative left ventricular dimensions predict reverse remodeling following restrictive mitral annuloplasty in ischemic mitral regurgitation. Eur J Cardiothorac Surg 2005; 27: 847-853.

521. Prifti E, Bonacchi M, Frati G, Giunti IG, Leacche M, Proietti P, et al. Should mild-to-moderate and moderate ischemic mitral regurgitation be corrected in patients with impaired left ventricular function undergoing simultaneous coronary revascularization? J Card Surg 2001; 16: 473-483

522. Trichon BH, Glower DD, Shaw LK, Cabell CH, Anstrom KJ, Felker GM, et al. Survival after coronary revascularization, with and without mitral valve surgery, in patients with ischemic mitral regurgitation. Circulation 2003; 108(Suppl 1): II103-II110.

523. Harris KM, Sundt TM 3rd, Aeppli D, Sharma R, Barzilai B. Can late survival of patients with moderate ischemic mitral regurgitation be impacted by intervention on the valve? Ann Thorac Surg 2002; 74: $1468-1475$.

524. Lam BK, Gillinov AM, Blackstone EH, Rajeswaran J, Yuh B, Bhudia SK, et al. Importance of moderate ischemic mitral regurgitation. Ann Thorac Surg 2005; 79: 462 -470; discussion 462-470.

525. Aklog L, Filsoufi F, Flores KQ, Chen RH, Cohn LH, Nathan NS, et al. Does coronary artery bypass grafting alone correct moderate ischemic mitral regurgitation? Circulation 2001; 104(12 Suppl 1): I68-I75.

526. Rydén T, Bech-Hanssen O, Brandrup-Wognsen G, Nilsson F, Svensson S, Jeppsson A. The importance of grade 2 ischemic mitral regurgitation in coronary artery bypass grafting. Eur J Cardiothorac Surg 2001; 20: 276-281.

527. Mallidi HR, Pelletier MP, Lamb J, Desai N, Sever J, Christakis GT, et al. Late outcomes in patients with uncorrected mild to moderate mitral regurgitation at the time of isolated coronary artery bypass grafting. J Thorac Cardiovasc Surg 2004; 127: 636-644.

528. Grigioni F, Enriquez-Sarano M, Zehr KJ, Bailey KR, Tajik AJ. Ischemic mitral regurgitation: Long-term outcome and prognostic implications with quantitative Doppler assessment. Circulation 2001; 103: $1759-1764$

529. Tolis GA Jr, Korkolis DP, Kopf GS, Elefteriades JA. Revascularization alone (without mitral valve repair) suffices in patients with advanced ischemic cardiomyopathy and mild-to-moderate mitral regurgitation. Ann Thorac Surg 2002; 74: 1476-1480; discussion $1480-1481$.

530. Mantovani V, Mariscalco G, Leva C, Blanzola C, Cattaneo P, Sala A. Long-term results of the surgical treatment of chronic ischemic mitral regurgitation: Comparison of repair and prosthetic replacement. J Heart Valve Dis 2004; 13: 421 -428; discussion 428-429.

531. Di Donato M, Sabatier M, Dor V, Toso A, Maioli M, Fantini F. Akinetic versus dyskinetic postinfarction scar: Relation to surgical outcome in patients undergoing endoventricular circular patch plasty repair. J Am Coll Cardiol 1997; 29: 1569-1575.

532. Dor V, Sabatier M, Di Donato M, Maioli M, Toso A, Montiglio F. Late hemodynamic results after left ventricular patch repair associated with coronary grafting in patients with postinfarction akinetic or dyskinetic aneurysm of the left ventricle. $J$ Thorac Cardiovasc Surg 1995; 110: 1291-1299; discussion 1300-1301.

533. Tavakoli R, Bettex D, Weber A, Brunner H, Genoni M, Pretre R, et al. Repair of postinfarction dyskinetic LV aneurysm with either linear or patch technique. Eur J Cardiothorac Surg 2002; 22: 129134

534. Lange R, Guenther T, Augustin N, Noebauer C, Wottke M, Busch $\mathrm{R}$, et al. Absent long-term benefit of patch versus linear reconstruction in left ventricular aneurysm surgery. Ann Thorac Surg 2005; 80: 537-541; discussion 542 . 
535. Dor V, Sabatier M, Di Donato M, Montiglio F, Toso A, Maioli M. Efficacy of endoventricular patch plasty in large postinfarction akinetic scar and severe left ventricular dysfunction: Comparison with a series of large dyskinetic scars. J Thorac Cardiovasc Surg 1998; 116: $50-59$.

536. de Bakey ME, McCollum CH, Graham JM. Surgical treatment of aneurysm of the descending thoracic aorta: Long-term results in 500 patients. J Cardiovasc Surg (Torino) 1978; 19: 571-576.

537. Crawford ES, Svensson LG, Coselli JS, Safi HJ, Hess KR. Surgical treatment of aneurysm and/or dissection of the ascending aorta, transverse aortic arch, and ascending aorta and transverse aortic arch: Factors influencing survival in 717 patients. J Thorac Cardiovasc Surg 1989; 98: 659-673; discussion 673-674.

538. Ehrlich MP, Ergin MA, McCullough JN, Lansman SL, Galla JD, Bodian CA, et al. Predictors of adverse outcome and transient neurological dysfunction after ascending aorta/hemiarch replacement. Ann Thorac Surg 2000; 69: 1755-1763.

539. Hertzer NR, Beven EG, Young JR, O'Hara PJ, Ruschhaupt WF 3rd, Graor RA, et al. Coronary artery disease in peripheral vascular patients: A classification of 1000 coronary angiograms and results of surgical management. Ann Surg 1984; 199: 223-233.

540. Christeen JT, Schmuziger M, Simonet F. Reoperative coronary artery bypass procedures: Risk factors for early mortality and late survival. Eur J Cardiothorac Surg 1997; 11: 129-133.

541. Dobell AC, Jain AK. Catastrophic hemorrhage during redo sternotomy. Ann Thorac Cardiovasc Surg 1984; 37: 273-278.

542. Kuniyoshi Y, Yamashiro S, Miyagi K, Uezu T, Arakaki K, Koja K. Off-pump redo coronary artery bypass grafting via left thoracotomy. Ann Thorac Cardiovasc Surg 2003; 9: 378-383.

543. Mack MJ. Off-pump surgery and alternatives to standard operation in redo coronary surgery. J Card Surg 2004; 19: 313-319.

544. Lytle BW, Loop FD, Taylor PC, Goormastic M, Stewart RW, Novoa $\mathrm{R}$, et al. The effect of coronary reoperation on the survival of patients with stenoses in saphenous vein bypass grafts to coronary arteries. J Thorac Cardiovasc Surg 1993; 105: 605-612; discussion 612-614.

545. Gersh BJ, Rihal CS, Rooke TW, Ballard DJ. Evaluation and management of patients with both peripheral vascular and coronary artery disease. J Am Coll Cardiol 1991; 18: 203-214.

546. Eagle KA, Rihal CS, Foster ED, Mickel MC, Gersh BJ. Long-term survival in patients with coronary artery disease: Importance of peripheral vascular disease: The Coronary Artery Surgery Study (CASS) Investigators. J Am Coll Cardiol 1994; 23: 1091-1095.

547. O'Rourke DJ, Quinton HB, Piper W, Hernandez F, Morton J, Hettleman B, et al; Northern New England Cardiovascular Disease Study Group. Survival in patients with peripheral vascular disease after percutaneous coronary intervention and coronary artery bypass graft surgery. Ann Thorac Surg 2004; 78: 466-470; discussion 470.

548. Birkmeyer JD, O'Connor GT, Quinton HB, Ricci MA, Morton JR, Leavitt BJ, et al. The effect of peripheral vascular disease on inhospital mortality rates with coronary artery bypass surgery. $J$ Vasc Surg 1995; 21: 445-452.

549. Karthik S, Musleh G, Grayson AD, Keenan DJ, Pullan DM, Dihmis WC, et al. Coronary surgery in patients with peripheral vascular disease: Effect of avoiding cardiopulmonary bypass. Ann Thorac Surg 2004; 77: $1245-1249$.

550. Baker DW, Jones R, Hodges J, Massie BM, Konstam MA, Rose EA. Management of heart failure. III: The role of revascularization in the treatment of patients with moderate or severe left ventricular systolic dysfunction. JAMA 1994; 272: 1528-1534.

551. Passamani E, Davis KB, Gillespie MJ, Killip T. A randomized trial of coronary artery bypass surgery: Survival of patients with a low ejection fraction. N Engl J Med 1985; 312: 1665-1671.

552. Elefteriades JA, Tolis G Jr, Levi E, Mills LK, Zaret BL. Coronary artery bypass grafting in severe left ventricular dysfunction: Excellent survival with improved ejection fraction and functional state. $J$ Am Coll Cardiol 1993; 22: 1411-1417.

553. Afridi I, Grayburn PA, Panza JA, Oh JK, Zoghbi WA, Marwick TH. Myocardial viability during dobutamine echocardiography predicts survival in patients with coronary artery disease and severe left ventricular systolic dysfunction. J Am Coll Cardiol 1998; 32: 921-926.

554. Nelson C, McCrohon J, Khafagi F, Rose S, Leano R, Marwick TH. Impact of scar thickness on the assessment of viability using dobutamine echocardiography and thallium single-photon emission computed tomography: A comparison with contrast-enhanced magnetic resonance imaging. J Am Coll Cardiol 2004; 43: 1248-1256.

555. Schmidt M, Voth E, Schneider CA, Theissen P, Wagner R, Baer FM, et al. F-18-FDG uptake is a reliable predictory of functional recovery of akinetic but viable infarct regions as defined by magnetic resonance imaging before and after revascularization. Magn Reson Imaging 2004; 22: 229-236.

556. Patel ND, Williams JA, Barreiro CJ, Bonde PN, Waldron MM, Chang DC, et al. Surgical ventricular remodeling for multiterritory myocardial infarction: Defining a new patient population. J Thorac Cardiovasc Surg 2005; 130: 1698-1706.

557. Invasive compared with non-invasive treatment in unstable coronary-artery disease: FRISC II prospective randomised multicentre study: FRagmin and Fast Revascularisation during InStability in Coronary artery disease Investigators. Lancet 1999; 354: 708-715.

558. Cannon CP, Weintraub WS, Demopoulos LA, Vicari R, Frey MJ, Lakkis N, et al; TACTICS (Treat Angina with Aggrastat and Determine Cost of Therapy with an Invasive or Conservative Strategy)--Thrombolysis in Myocardial Infarction 18 Investigators. Comparison of early invasive and conservative strategies in patients with unstable coronary syndromes treated with glycoprotein IIb/IIIa inhibitor tirofiban. N Engl J Med 2001; 344: 1879-1887.

559. Fox KA, Poole-Wilson PA, Henderson RA, Clayton TC, Chamberlain DA, Shaw TR, et al; Randomized Intervention Trial of unstable Angina Investigators. Interventional versus conservative treatment for patients with unstable angina or non-ST-elevation myocardial infarction: The British Heart Foundation RITA 3 randomised trial: Randomized Intervention Trial of unstable Angina. Lancet 2002; 360: 743-751.

560. Ottervanger JP, Armstrong P, Barnathan ES, Boersma E, Cooper JS, Ohman EM, et al; GUSTO IV-ACS Investigators. Association of revascularisation with lo mortality in non-ST elevation acute coronary syndrome, a report from GUSTO IV-ACS. Eur Hear $J$ 2004; 25: 1494-1501.

561. Grzybowski M, Clements EA, Parsons L, Welch R, Tintinalli AT, Ross MA, et al. Mortality benefit of immediate revascularization of acute ST-segment elevation myocardial infarction in patients with contraindications to thrombolytic therapy: A propensity analysis. JAMA 2003; 290: 1891-1898.

562. Zijlstra F, Hoorntje JC, de Boer MJ, Reiffers S, Miedema K, Ottervanger JP, et al. Long-term benefit of primary angioplasty as compared with thrombolytic therapy for acute myocardial infarction. N Engl J Med 1999; 341: 1413-1419.

563. Stone GW, Brodie BR, Griffin JJ, Costantini C, Morice MC, St Goar FG, et al. Clinical and angiographic follow-up after primary stenting in acute myocardial infarction: The Primary Angioplasty in Myocardial Infarction (PAMI) stent pilot trial. Circulation 1999; 99: $1548-1554$.

564. Zhang Z, Spertus JA, Mahoney EM, Booth J, Nugara F, Stables RH, et al. The impact of acute coronary syndrome on clinical, economic, and cardiac-specific health status after coronary artery bypass surgery versus stent-assisted percutaneous coronary intervention: 1-year results from the stent or surgery (SoS) trial. Am Heart J 2005; 150: $175-181$

565. Ben-Gal Y, Moses JW, Mehran R, Lansky AJ, Weisz G, Nikolsky $\mathrm{E}$, et al. Surgical versus percutaneous revascularization for multivessel disease in patients with acute coronary syndromes: Analysis from the ACUITY (Acute Catheterization and Urgent Intervention Triage Strategy) trial. JACC Cardiovasc Interv 2010; 3: 10591067.

566. Montalescot G, Brieger D, Eagle KA, Anderson FA Jr, FitzGerald $\mathrm{G}$, Lee MS, et al; GRACE Investigators. Unprotected left main revascularization in patients with acute coronary syndromes. Eur Heart J 2009; 30: 2308-2317.

567. Lee MS, Tseng CH, Barker CM, Menon V, Steckman D, Shemin $\mathrm{R}$, et al. Outcome after surgery and percutaneous intervention for cardiogenic shock and left main disease. Ann Thorac Surg 2008; 86: $29-34$.

568. Mehta RH, Lopes RD, Ballotta A, Frigiola A, Sketch MH Jr, Bossone E, et al. Percutaneous coronary intervention or coronary artery bypass surgery for cardiogenic shock and multivessel coronary artery disease? Am Heart J 2010; 159: 141-147.

569. Parikh SV, de Lemos JA, Jessen ME, Brilakis ES, Ohman EM, Chen AY, et al; CRUSADE and ACTION Registry-GWTG Participants. Timing of in-hospital coronary artery bypass graft surgery for non-ST-segment elevation myocardial infarction patients results from the National Cardiovascular Data Registry ACTION RegistryGWTG (Acute Coronary Treatment and Intervention Outcomes Network Registry-Get With The Guidelines). JACC Cardiovasc Interv 2010; 3: 419-427.

570. Wasvary H, Shannon F, Bassett J, O'Neill W. Timing of coronary artery bypass grafting after acute myocardial infarction. Am Surg 1997; 63: 710-715.

571. Lee DC, Oz MC, Weinberg AD, Lin SX, Ting W. Optimal timing 
of revascularization: Transmural versus nontransmural acute myocardial infarction. Ann Thorac Surg 2001; 71: 1198-1202; discussion 1202-1204.

572. Crossman AW, D'Agostino HJ Jr, Geraci SA. Timing of coronary artery bypass graft surgery following acute myocardial infarction: A critical literature review. Clin Cardiol 2002; 25: 406-410.

573. Locker C, Mohr R, Paz Y, Kramer A, Lev-Ran O, Pevni D, et al Myocardial revascularization for acute myocardial infarction: Benefits and drawbacks of avoiding cardiopulmonary bypass. Ann Thorac Surg 2003; 76: 771-776; discussion 776-777.

574. Jasinski MJ, Wos S, Olszowka P, Bachowski R, Ceglarek W, Widenka K, et al. Primary OPCAB as a strategy for acute coronary syndrome and acute myocardial infarction. Heart Surg Forum 2003; 6: $331-335$.

575. Fattouch K, Guccione F, Dioguardi P, Sampognaro R, Corrado E, Caruso M, et al. Off-pump versus on-pump myocardial revascularization in patients with ST-segment elevation myocardial infarction: A randomized trial. J Thorac Cardiovasc Surg 2009; 137: 650-656; discussion 656-657.

576. Edgerton JR, Herbert MA, Jones KK, Prince SL, Acuff T, Carter $\mathrm{D}$, et al. On-pump beating heart surgery offers an alternative for unstable patients undergoing coronary artery bypass grafting. Heart Surg Forum 2004; 7: 8-15.

577. Rastan AJ, Eckenstein JI, Hentschel B, Funkat AK, Gummert JF, Doll N, et al. Emergency coronary artery bypass graft surgery for acute coronary syndrome: Beating heart versus conventional cardioplegic cariac arrest strategies. Circulation 2006; 114(1 Suppl): I477-I485.

578. Cook JR, Rizo-Patron C, Curtis AB, Gillis AM, Bigger JT Jr, Kutalek SP, et al; AVD Investigators. Effect of surgical revascularization in patients with coronary artery disease and ventricular tachycardia or fibrillation in the Antiarrhythmics Versus Implantable Defibrillators (AVID) Registry. Am Heart J 2002; 143: 821 -826.

579. Dor V, Sabatier M, Montiglio F, Rossi P, Toso A, Di Donato M. Results of nonguided subtotal endocardiectomy associated with left ventricular reconstruction in patients with ischemic ventricular arrhythmias. J Thorac Cardiovasc Surg 1994; 107: 1301-1307; discussion 1307-1308.

580. Di Donato M, Sabatier M, Dor V; RESTORE Group. Surgical ventricular restoration in patients with postinfarction coronary artery disease: Effectiveness on spontaneous and inducible ventricular tachycardia. Semin Thorac Cardiovasc Surg 2001; 13: 480-485.

581. Wellens F, Geelen P, Demirsoy E, Van Praet F, De Geest R, Degrieck I, et al. Surgical treatment of tachyarrhythmias due to postinfarction left ventricular aneurysm with endoaneurysmorrhaphy and cryoablation. Eur J Cardiothorac Surg 2002; 22: 771 -776.

582. Elhendy A, Chapman S, Porter TR, Windle J. Association of myocardial ischemia with mortality and implantable cardioverter-defibrillator therapy in patients with coronary artery disease at risk of arrhythmic death. J Am Coll Cardiol 2005; 46: 1721-1726.

583. DiDonato M, Sabatier M, Dor V, Buckberg G; RESTORE Group. Ventricular arrhythmias after LV remodelling: Surgical ventricular restoration or ICD? Heart Fail Rev 2004; 9: 299-306; discussion 347-351.

584. Parsonnet V, Dean D, Bernstein AD. A method of uniform stratification of risk for evaluating the results of surgery in acquired adult heart disease. Circulation 1989; 79(6 Pt 2): I3-I12.

585. Ferguson TB Jr, Hammill BG, Peterson ED, DeLong ER, Grover FL; STS National Database Committee. A decade of change--risk profiles and outcomes for isolated coronary artery bypass grafting procedures, 1990-1999: A report from the STS National Database Committee and the Duke Clinical Research Institute: Society of Thoracic Surgeons. Ann Thorac Surg 2002; 73: 480-489; discussion 489-490

586. Durand DJ, Perler BA, Roseborough GS, Grega MA, Borowicz LM $\mathrm{Jr}$, Baumgartner WA, et al. Mandatory versus selective preoperative carotid screening: A retrospective analysis. Ann Thorac Surg 2004; 78: 159-166; discussion 159-166.

587. Paiement B, Pelletier C, Dyrda I, Maillé JG, Boulanger M, Taillefer $\mathrm{J}$, et al. A simple classification of the risk in cardiac surgery. Can Anaesth Soc J 1983; 30: 61-68.

588. Charlson ME, Pompei P, Ales KL, MacKenzie CR. A new method of classifying prognostic comorbidity in longitudinal studies: Development and validation. J Chronic Dis 1987; 40: 373-383.

589. Higgins TL, Starr NJ. Risk stratification and outcome assessment of the adult cardiac surgical patient. Semin Thorac Cardiovasc Surg 1991; 3: 88-94.

590. Higgins TL, Estafanous FG, Loop FD, Beck GJ, Blum JM, Paranandi L. Stratification of morbidity and mortality outcome by preoperative risk factors in coronary artery bypass patients: A clinical sever- ity score. JAMA 1992; 267: 2344-2348.

591. O'Connor GT, Plume SK, Olmstead EM, Coffin LH, Morton JR, Maloney CT, et al. Multivariate prediction of in-hospital mortality associated with coronary artery bypass graft surgery: Northern New England Cardiovascular Disease Study Group. Circulation 1992; 85: $2110-2118$.

592. Tremblay NA, Hardy JF, Perrault J, Carrier M. A simple classification of the rsik in cardiac surgery: The first decade. Can J Anaesth 1993; 40: 103-111.

593. Hattler BG, Madia C, Johnson C, Armitage JM, Hardesty RL, Kormos RL, et al. Risk stratification using the Society of Thoracic Surgeons Program. Ann Thorac Surg 1994; 58: 1348-1352.

594. Roques F, Gabrielle F, Michel P, De Vincentiis C, David M, Baudet E. Quality of care in adult heart surgery: Proposal for a self-assessment approach based on a French multicenter study. Eur J Cardiothorac Surg 1995; 9: 433-439; discussion 439-440.

595. Tu JV, Jaglal SB, Naylor D. Multicenter validation of a risk index for mortality, intensive care unit stay, and overall hospital length of stay after cardiac surgery: Steering Committee of the Provincial Adult Cardiac Care Network of Ontario. Circulation 1995; 91: 677-684

596. Hammermeister KE. Risk, predicting outcomes, and improving care. Circulation 1995; 91: 899-900.

597. Weightman WM, Gibbs NM, Sheminant MR, Thackray NM, Newman MA. Risk prediction in coronary artery surgery: A comparison of four risk scores. Med J Aust 1997; 166: 408-411.

598. Soderlind K, Rutberg H, Olin C. Late outcome and quality of life after complicated heart operations. Ann Thoracic Surg 1997; 63: $124-128$

599. Pons JM, Granados A, Espinas JA, Borras JM, Martin I, Moreno V Assessing open heart surgery mortality in Catalonia (Spain) through a predictive risk model. Eur J Cardiothorac Surg 1997; 11: 415423

600. Roques F, Nashef SA, Michel P, Gauducheau E, de Vincentiis C, Baudet E, et al. Risk factors and outcome in European cardiac surgery: Analysis of the EuroSCORE multinational database of 19030 patients. Eur J Cardiothorac Surg 1999; 15: 816-822; discussion 822-823.

601. Nashef SA, Roques F, Michel P, Gauducheau E, Lemeshow S, Salamon R. European system for cardiac operative risk evaluation (EuroSCORE). Eur J Cardiothorac Surg 1999; 16: 9-13.

602. Immer F, Habicht J, Nessensohn K, Bernet F, Stulz P, Kaufmann $\mathrm{M}$, et al. Prospective evaluation of 3 risk stratification scores in cardiac surgery. Thorac Cardiovasc Surg 2000; 48: 134-139.

603. Geissler HJ, Hölzl P, Marohl S, Kuhn-Régnier F, Mehlhorn U, Südkamp M, et al. Risk stratification in heart surgery: Comparison of six score systems. Eur J Cardiothorac Surg 2000; 17: 400-406.

604. Nashef SA, Roques F, Hammill BG, Peterson ED, Michel P, Grover FL, et al; EuroSCORE Project Group. Validation of European System for Cardiac Operative Risk Evaluation (EuroSCORE) in North American cardiac surgery. Eur J Cardiothorac Surg 2002; 22: $101-105$

605. Gatti G, Cardu G, Lusa AM, Pugliese P. Predictors of postoperative complications in high-risk octogenarians undergoing cardiac operation. Ann Thorac Surg 2002; 74: 671-677.

606. Peterson ED, Coombs LP, Ferguson TB, Shroyer AL, DeLong ER, Grover FL, et al. Hospital variability in length of stay after coronary artery bypass surgery: Results from the Society of Thoracic Surgeon's National Cardiac Database. Ann Thorac Surg 2002; 74: $464-473$

607. Karabulut H, Toraman F, Alhan C, Camur G, Evrenkaya S, Dağdelen $\mathrm{S}$, et al. EuroSCORE overestimates the cardiac operative risk. Cardiovasc Surg 2003; 11: 295-298.

608. Hannan EL, Racz MJ, Walford G, Ryan TJ, Isom OW, Bennett E, et al. Predictor of readmission for complication of coronary artery bypass graft surgery. JAMA 2003; 290: 773-780.

609. Michel P, Roques F, Nashef SA; EuroSCORE Project Group. Logistic or additive EuroSCORE for high-risk patients? Eur J Cardiothorac Surg 2003; 23: 684-687; discussion 687.

610. D'Ancona G, Saez de Ibarra JI, Baillot R, Mathieu P, Doyle D, Metras J, et al. Determinants of stroke after coronary artery bypass grafting. Eur J Cardiothorac Surg 2003; 24: 552-556.

611. Shroyer AL, Coombs LP, Peterson ED, Eiken MC, DeLong ER, Chen A, et al; Society of Thoracic Surgeons. The Society of Thoracic Surgeons: 30-day operative mortality and morbidity risk models. Ann Thorac Surg 2003; 75: 1856-1864; discussion 1864-1865.

612. Ho PM, Arciniegas DB, Grigsby J, McCarthy M Jr, McDonald GO, Moritz TE, et al. Predictors of cognitive decline following coronary artery bypass graft surgery. Ann Thorac Surg 2004; 77: 597-603; discussion 603 . 
613. Nilsson J, Algotsson L, Höglund P, Lührs C, Brandt J. Early mortality in coronary bypass surgery: The EuroSCORE versus The Society of Thoracic Surgeons risk algorithm. Ann Thoracic Surg 2004; 77: 1235-1239; discussion 1239-1240.

614. Johnston G, Goss JR, Malmgren JA, Spertus JA. Health status and social risk correlates of extended length of stay following coronary artery bypass surgery. Ann Thoracic Surg 2004; 77: 557-562.

615. Lytle BW. Prolonging patency--choosing coronary bypass grafts. N Engl J Med 2004; 351: 2262-2264.

616. Schachner T, Zimmer A, Nagele G, Laufer G, Bonatti J. Risk factors for late stroke after coronary artery bypass grafting. $J$ Thorac Cardiovasc Surg 2005; 130: 485-490.

617. Sellke FW, DiMaio JM, Caplan LR, Ferguson TB, Gardner TJ, Hiratzka LF, et al; American Heart Association. Comparing onpump and off-pump coronary artery bypass grafting: Numerous studies but few conclusions: A scientific statement from the American Heart Association council on cardiovascular surgery and anesthesia in collaboration with the interdisciplinary working group on quality of care and outcomes research. Circulation 2005; 111: $2858-2864$.

618. Yap CH, Mohajeri M, Ihle BU, Wilson AC, Goyal S, Yii M. Validation of Euroscore model in an Australian patient population. ANZ J Surg 2005; 75: 508-512.

619. Klima U, MacVaugh H 3rd, Bagaev E, Maringka M, Kirschner S, Beilner J, et al. Magnetic Vascular Port in minimally invasive direct coronary artery bypass grafting. Circulation 2004; 110(11 Suppl 1): II55-II60.

620. Filsoufi F, Farivar RS, Aklog L, Anderson CA, Chen RH, Lichtenstein S, et al. Automated distal coronary bypass with a novel magnetic coupler (MVP system). J Thorac Cardiovasc Surg 2004; 127: $185-192$.

621. Vicol C, Eifert S, Oberhoffer M, Boekstegers P, Knez A, Christ F, et al. Early clinical results with a magnetic connector for distal coronary artery anastomoses. Ann Thorac Surg 2005; 79: 1738 1742; discussion 1742-1743.

622. Damiano RJ Jr, Tabaie HA, Mack MJ, Edgerton JR, Mullangi C, Graper WP, et al. Initial prospective multicenter clinical trial of robotically-assisted coronary artery bypass grafting. Ann Thorac Surg 2001; 72: 1263-1268; discussion 1268-1269.

623. Mohr FW, Falk V, Diegeler A, Walther T, Gummert JF, Bucerius J, et al. Computer-enhanced "robotic" cardiac surgery: Experience in 148 patients. J Thorac Cardiovasc Surg 2001; 121: 842-853.

624. Dogan S, Aybek T, Andressen E, Byhahn C, Mierdl S, Westphal K, et al. Totally endoscopic coronary artery bypass grafting on cardiopulmonary bypass with robotically enhanced telemanipulation: Report of forty-five cases. J Thorac Cardiovasc Surg 2002; 123: $1125-1131$.

625. Bonatti J, Schachner T, Bonaros N, Laufer G, Kolbitsch C, Margreiter $\mathrm{J}$, et al. Robotic totally endoscopic coronary artery bypass and catheter based coronary intervention in one operative session. Ann Thorac Surg 2005; 79: 2138-2141.

626. Donias HW, Goodnough SP, Yanulevich J, Karamanoukian HL. Anesthetic and surgical improvements and pitfalls in endoscopic atraumatic coronary artery bypass grafting. J Cardiothorac Vasc Anesth 2003; 17: 524-527.

627. Karagoz HY, Sönmez B, Bakkaloglu B, Kurtoglu M, Erdinç M, Türkeli A, et al. Coronary artery bypass grafting in the conscious patient without endotracheal general anesthesia. Ann Thorac Surg 2000; 70: 91-96.

628. Horvath KA, Cohn LH, Cooley DA, Crew JR, Frazier OH, Griffith $\mathrm{BP}$, et al. Transmyocardial laser revascularization: Results of a multicenter trial with transmyocardial laser revascularization used as sole therapy for end-stage coronary artery disease. J Thorac Cardiovasc Surg 1997; 113: 645-653; discussion 653-654.

629. Schofield PM, Sharples LD, Caine N, Burns S, Tait S, Wistow T, et al. Transmyocardial laser revascularisation in patients with refractory angina: A randomised controlled trial. Lancet 1999; 353: $519-524$.

630. Allen KB, Dowling RD, Fudge TL, Schoettle GP, Selinger SL, Gangahar DM, et al. Comparison of transmyocardial revascularization with medical therapy in patients with refractory angina. $N$ Engl J Med 1999; 341: 1029-1036.

631. Burkhoff D, Schmidt S, Schulman SP, Myers J, Resar J, Becker LC, et al. Transmyocardial laser revascularisation compared with continued medical therapy for treatment of refractory angina pectoris: A prospective randomised trial: ATLANTIC Investigators: Angina Treatments-Lasers and Normal Therapies in Comparison. Lancet 1999; 354: 885-890.

632. Frazier OH, March RJ, Horvath KA. Transmyocardial revascularization with a carbon dioxide laser in patients with end-stage coro- nary artery disease. $N$ Engl J Med 1999; 341: 1021-1028.

633. Horvath KA, Aranki SF, Cohn LH, March RJ, Frazier OH, Kadipasaoglu KA, et al. Sustained angina relief 5 years after transmyocardial laser revascularization with a $\mathrm{CO}(2)$ laser. Circulation 2001; 104(12 Suppl 1): I81-I84.

634. Aaberge L, Rootwelt K, Blomhoff S, Saatvedt K, Abdelnoor M, Forfang K. Continued symptomatic improvement three to five years after transmyocardial revascularization with $\mathrm{CO}(2)$ laser: A late clinical follow-up of the Norwegian Randomized trial with transmyocardial revascularization. J Am Coll Cardiol 2002; 39: 1588 1593.

635. Al-Sheikh T, Allen KB, Straka SP, Heimansohn DA, Fain RL, Hutchins GD, et al. Cardiac sympathetic denervation after transmyocardial laser revascularization. Circulation 1999; 100: 135-140.

\section{Appendix 1. JCS Joint Working Group}

Chair:

- Masami Ochi, Department of Cardiovascular Surgery, Nippon Medical School Graduate School of Medicine

Members:

- Atsushi Amano, Department of Cardiovascular Surgery, Juntendo University Hospital

- Hirokuni Arai, Department of Cardiothoracic Surgery, Tokyo Medical and Dental University Graduate School of Medicine

- Tohru Asai, Division of Cardiovascular Surgery, Department of Surgery, Shiga University of Medical Science

- Hiroyuki Daida, Department of Cardiovascular Medicine, Juntendo University School of Medicine

- Hisayoshi Fujiwara, Hyogo Prefectural Amagasaki Hospital/Hyogo Prefectural Tsukaguchi Hospital

- Taiko Horii, Department of Cardiovascular Surgery, Faculty of Medicine, Kagawa University

- Takaaki Isshiki, Department of Medicine, Teikyo University School of Medicine

- Michio Kawasuji, Department of Cardiovascular Surgery, Graduate School of Medical Sciences, Kumamoto University

- Takeshi Kimura, Department of Cardiovascular Medicine, Kyoto University Graduate School of Medicine

- Junjiro Kobayashi, Department of Cardiovascular Surgery, National Cerebral and Cardiovascular Center

- Izuru Masuda, EBM Center for Preventive Medicine, Takeda Hospital Group

- Hiroshi Niinami, Department of Cardiovascular Surgery, Saitama International Medical Center, Saitama Medical University

- Hiroshi Nishida, Department of Cardiovascular Surgery, The Heart Institute of Japan, Tokyo Women's Medical University

- Kazuhiko Nishigaki, Department of Cardiology, Gifu University Graduate School of Medicine

- Satoshi Ogawa, International University of Health and Welfare, Mita Hospital

- Takayuki Ohno, Department of Cardiovascular Surgery, Mitsui Memorial Hospital

- Hitoshi Okabayashi, Department of Cardiovascular Surgery, Iwate Medical University School of Medicine

- Yoshitaka Okamura, Department of Thoracic and Cardiovascular Surgery, Wakayama Medical University

- Ryuzo Sakata, Department of Cardiovascular Surgery, Kyoto University Graduate School of Medicine

- Teruo Shiba, Division of Diabetes and Metabolism, Toho University Medical Center, Ohashi Hospital

- Hisayoshi Suma, Suma Heart Clinic

- Tetsuya Sumiyoshi, Department of Cardiology, Sakakibara Heart Institute

- Shinichi Takamoto, Mitsui Memorial Hospital

- Tadashi Tashiro, Department of Cardiovascular Surgery, Fukuoka University School of Medicine

- Hitoshi Yaku, Division of Cardiovascular Surgery, Department of Surgery, Kyoto Prefectural University of Medicine

- Fumio Yamamoto, Department of Cardiovascular Surgery, Akita University School of Medicine

- Tsutomu Yamazaki, Clinical Research Support Center, The University of Tokyo Hospital

- Go Watanabe, Department of General and Cardiothoracic Surgery, Kanazawa University School of Medicine

Collaborators:

- Kiyoshi Doi, Division of Cardiovascular Surgery, Department of Surgery, Kyoto Prefectural University of Medicine 
- Masahiro Fujii, Department of Cardiovascular Surgery, Nippon Medical School Graduate School of Medicine

- Michiya Hanyu, Department of Cardiovascular Surgery, Kokura Memorial Hospital

- Soichiro Kitamura, National Cerebral and Cardiovascular Center

- Hiroyuki Nakajima, Department of Cerebrovascular Surgery, Saitama International Medical Center, Saitama Medical University

- Masaru Nishimi, Department of Cardiovascular Surgery, Fukuoka University School of Medicine

- Tomoaki Suzuki, Department of Surgery, Shiga University of Medical Science

- Koichi Tabayashi, Tohoku Kosei Nenkin Hospital

- Osamu Tagusari, IMS Katsushika Heart Center

- Shigeyuki Tomita, Department of General and Cardiothoracic Surgery, Kanazawa University School of Medicine

Independent Assessment Committee:

- Atsushi Hirayama, Division of Cardiovascular Medicine, Department of Medicine, Nihon University School of Medicine

- Kanji Kawachi, Ehime University

- Nobuya Koyama, Division of Cardiovascular Surgery, Department of Surgery, School of Medicine, Faculty of Medicine, Toho University

- Ryozo Nagai, Jichi Medical University

(The affiliations of the members are as of September 2012)

\section{Appendix 2. Coronary Revascularization Council}

Chair:

- Satoshi Ogawa, International University of Health and Welfare, Mita Hospital

Members:

- Hiroyuki Daida, Department of Cardiovascular Medicine, Juntendo
University School of Medicine

- Hisayoshi Fujiwara, Hyogo Prefectural Amagasaki Hospital/Hyogo Prefectural Tsukaguchi Hospital

- Takaaki Isshiki, Department of Medicine, Teikyo University School of Medicine

- Takeshi Kimura, Department of Cardiovascular Medicine, Kyoto University Graduate School of Medicine

- Izuru Masuda, EBM Center for Preventive Medicine, Takeda Hospital Group

- Hiroshi Nishida, Department of Cardiovascular Surgery, The Heart Institute of Japan, Tokyo Women's Medical University

- Masami Ochi, Department of Cardiovascular Surgery, Nippon Medical School Graduate School of Medicine

- Takayuki Ohno, Department of Cardiovascular Surgery, Mitsui Memorial Hospital

- Ryuzo Sakata, Department of Cardiovascular Surgery, Kyoto University Graduate School of Medicine

- Teruo Shiba, Division of Diabetes and Metabolism, Toho University Medical Center, Ohashi Hospital

- Tetsuya Sumiyoshi, Department of Cardiology, Sakakibara Heart Institute

- Shinichi Takamoto, Mitsui Memorial Hospital

- Tsutomu Yamazaki, Clinical Research Support Center, The University of Tokyo Hospital

Observers:

- Kazuhiko Nishigaki, Department of Cardiology, Gifu University Graduate School of Medicine

- Hitoshi Yaku, Division of Cardiovascular Surgery, Department of Surgery, Kyoto Prefectural University of Medicine

(The affiliations of the members are as of September 2012) 